\title{
Methane Decomposition to Carbon Nanotubes and COx -Free H2 over Transition Metal Catalysts
}

I-Wen Wang

Follow this and additional works at: https://researchrepository.wvu.edu/etd

\section{Recommended Citation}

Wang, I-Wen, "Methane Decomposition to Carbon Nanotubes and COx -Free H2 over Transition Metal Catalysts" (2018). Graduate Theses, Dissertations, and Problem Reports. 7272.

https://researchrepository.wvu.edu/etd/7272

This Thesis is protected by copyright and/or related rights. It has been brought to you by the The Research Repository @ WVU with permission from the rights-holder(s). You are free to use this Thesis in any way that is permitted by the copyright and related rights legislation that applies to your use. For other uses you must obtain permission from the rights-holder(s) directly, unless additional rights are indicated by a Creative Commons license in the record and/ or on the work itself. This Thesis has been accepted for inclusion in WVU Graduate Theses, Dissertations, and Problem Reports collection by an authorized administrator of The Research Repository @ WVU. For more information, please contact researchrepository@mail.wvu.edu. 
Methane Decomposition to Carbon Nanotubes and $\mathrm{CO}_{\mathrm{x}}-$ Free $\mathrm{H}_{2}$ over Transition Metal Catalysts

\author{
I-Wen Wang \\ Thesis submitted to the \\ College of Engineering and Mineral Resources \\ at West Virginia University \\ in partial fulfillment of the requirements \\ for the degree of \\ Master of Science \\ in \\ Chemical Engineering \\ John Hu, Ph.D., Committee Chair \\ John W. Zondlo, Ph.D. \\ Hanjing Tian, Ph.D. \\ Department of Chemical and Biomedical Engineering \\ Morgantown, West Virginia
}

2018

Keywords: Methane; Carbon Nanotube; Hydrogen; Transition Metal Catalysts

Copyright 2018 I-Wen Wang 


\section{Abstract \\ Methane Decomposition to Carbon Nanotubes \\ and $\mathrm{CO}_{x}-$ Free $\mathrm{H}_{2}$ over Transition Metal Catalysts}

\section{I-Wen Wang}

Recently, shale gas has become a very important energy source in the United States. The abundance of shale gas resources presents opportunities to develop novel chemical processes that convert its major component, methane, into more valuable fuels and chemicals. Among various methods of hydrogen production, steam reforming of natural gas is the most popular and economical technology, but this process is highly endothermic. Therefore, catalytic methane decomposition (CMD) is an attractive alternative process since supported metal catalysts can be used to catalytically decompose hydrocarbons to produce $\mathrm{CO}_{x}-$ free $\mathrm{H}_{2}$ at more moderate temperatures. This process generates carbon nanotubes (CNTs) or nanofibers along with hydrogen. In this work, the research is focused on the production of CNTs.

Herein, we investigate the mono- and bimetallic $\mathrm{Ni}, \mathrm{Fe}$, and $\mathrm{Co}$ with various mole ratios over $\mathrm{SiO}_{2}$ support by incipient wetness and sol-gel technique. The catalysts were tested under the same reaction conditions and the properties of CNT were characterized by a number of analytical instrumentations such as TEM, XRD, and Raman spectroscopy to correlate with CMD performance. The synthesized bimetallic catalysts were found to have higher activity and stability than monometallic catalysts. Also, we prepared the Fe-based catalysts with different supports $\left(\mathrm{Al}_{2} \mathrm{O}_{3}, \mathrm{ZSM}-5\right.$, and $\left.\mathrm{SiO}_{2}\right)$ and experimental results revealed that metal-support interaction played a key role in the base grown mechanism. Moreover, $\mathrm{Ni} / \mathrm{Al}_{2} \mathrm{O}_{3}$ and $\mathrm{Co} / \mathrm{Al}_{2} \mathrm{O}_{3}$ aerogel catalysts were synthesized using a sol-gel method to enhance CMD performance. It was discovered that the metal-support interaction and tortuosity of the aerogel catalysts determine the activity and capacity. Moreover, the recovery of CNT and catalyst regeneration protocol was developed to explore industrial application potential. 


\section{Acknowledgements}

I am greatly thankful to my advisor, Dr. John $\mathrm{Hu}$, for his patient guidance and support throughout my MS study. I also would like to thank Dr. Deepa Ayillath Kutteri for all her kind teaching and profound knowledge.

I am grateful to Dr. John Zondlo and Dr. Hanjing Tian for serving on my committee and providing invaluable suggestions for my thesis. I sincerely thank Dr. Yan Luo, Mr. Jim Hall, and group members for their help and assistance in the laboratory. I would also like to thank Dr. Marcela Ridegolo and Dr. Qiang Wang in SRF for training and assisting me on the analytical instrumentations.

Finally, I wish to express my sincere gratitude to my parents and sisters for their unconditional love and support on the process of pursuing my master degree and throughout my life. I also thank my close friends for their encouragement and sharing laughter. 


\section{Table of Contents}

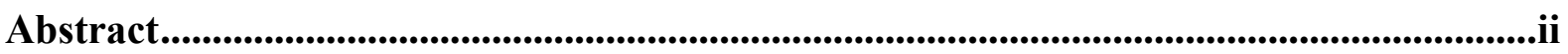

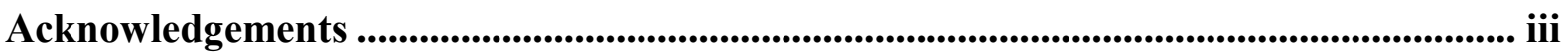

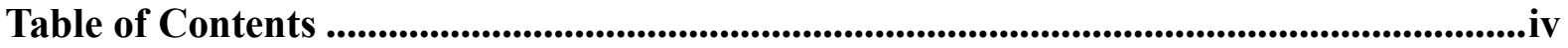

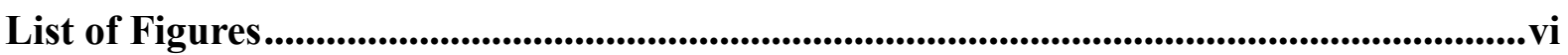

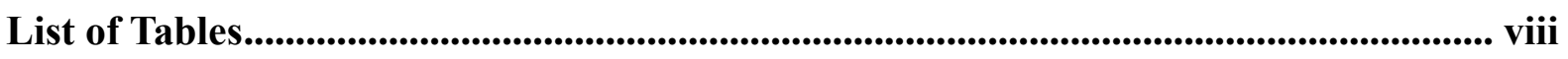

Chapter 1 Introduction..............................................................................................................................1

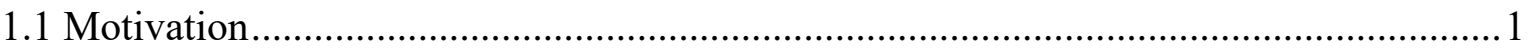

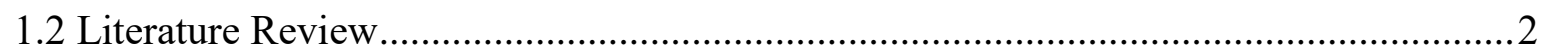

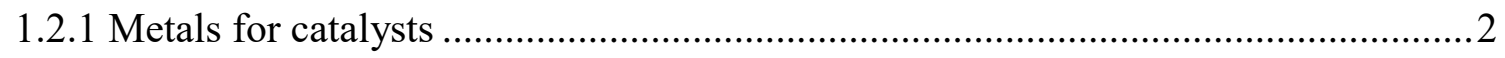

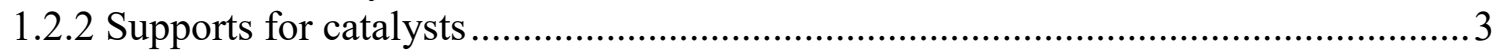

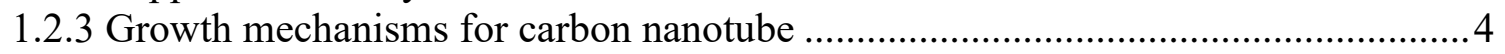

1.2.4 Base grown carbon nanotube.................................................................... 5

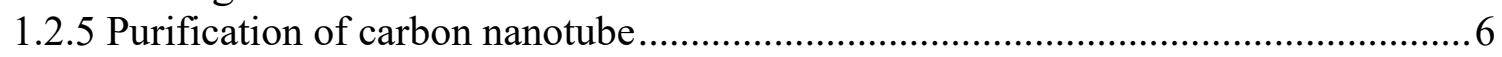

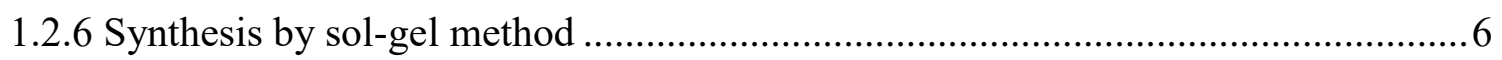

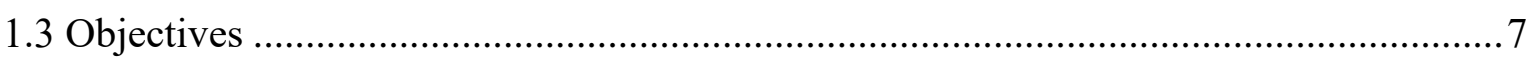

Chapter 2 Experimental Methods and Analysis ...........................................................8

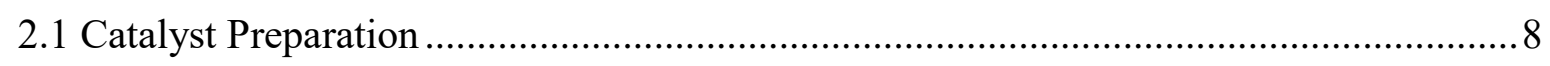

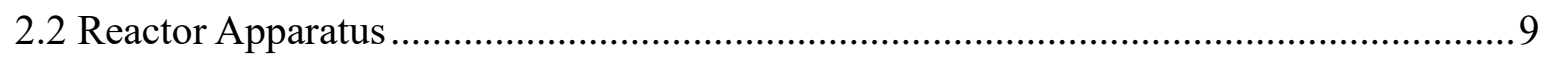

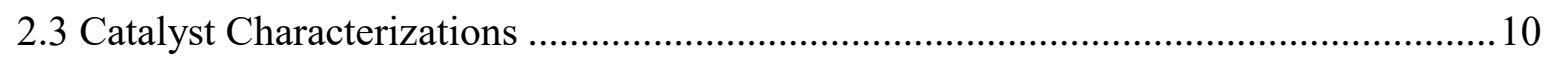

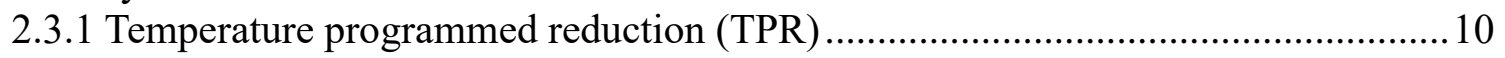

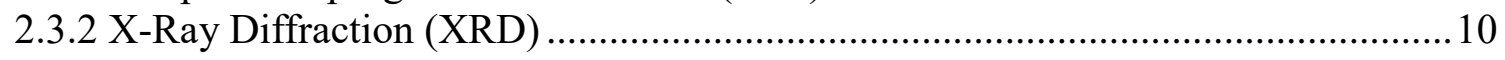

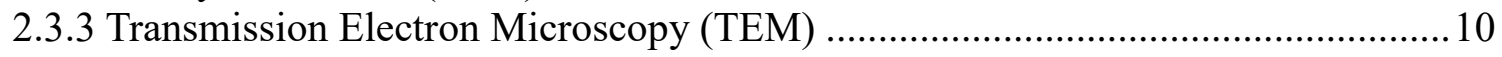

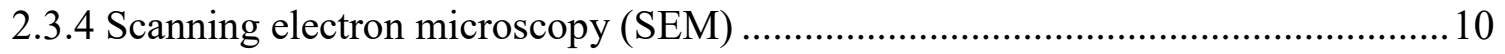

\section{Chapter 3 Mono- and Bimetallic Ni, Co, and Fe Catalysts for Methane}

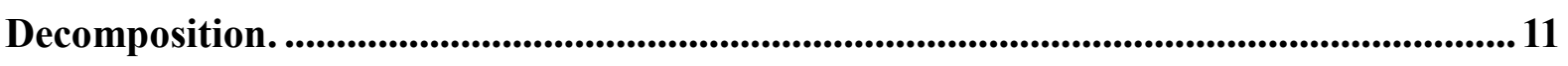

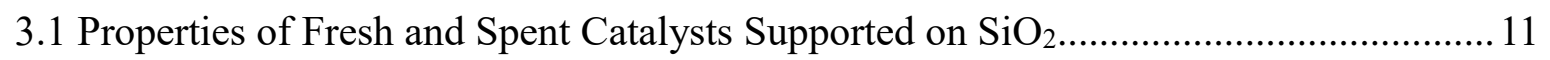

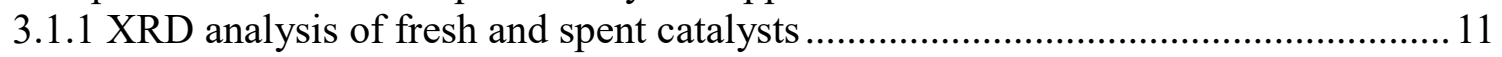

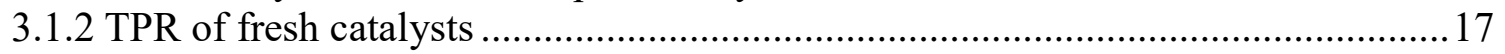

3.2 Effect of Catalyst Composition on $\mathrm{CH}_{4}$ Decomposition and CNT Growth .................20

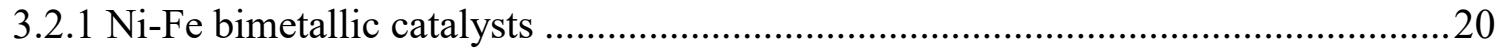

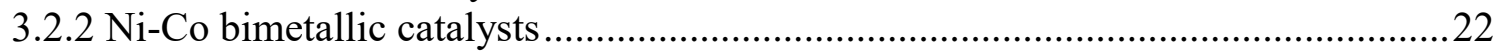

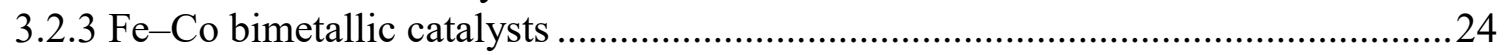

3.3 Comparison of Activities of Reduced and Oxidized Catalysts ....................................26

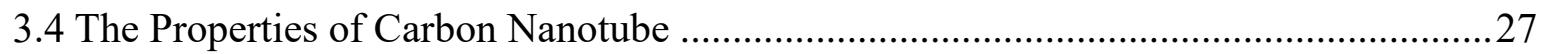

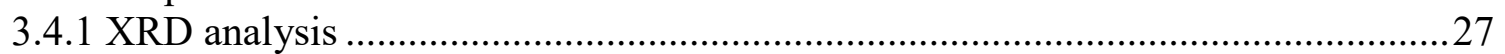

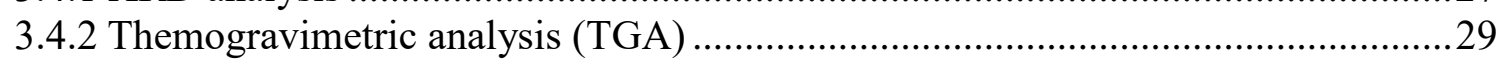




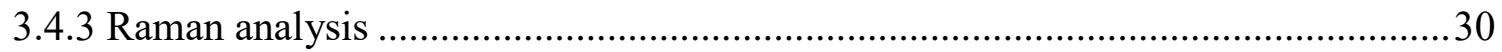

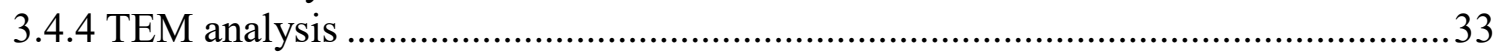

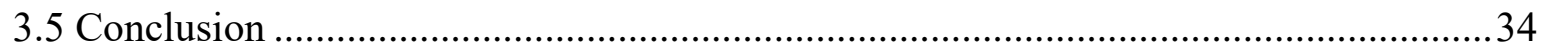

Chapter 4 Fe-Based Catalysts with Different Supports ................................................36

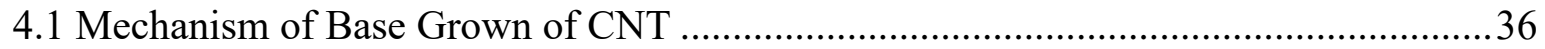

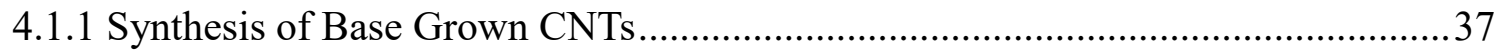

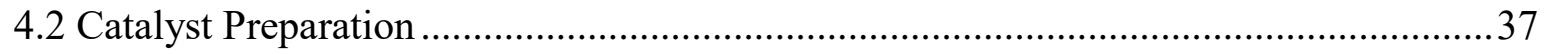

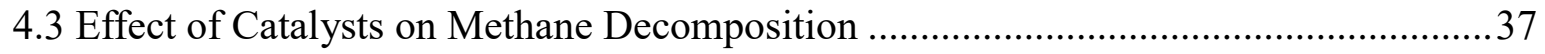

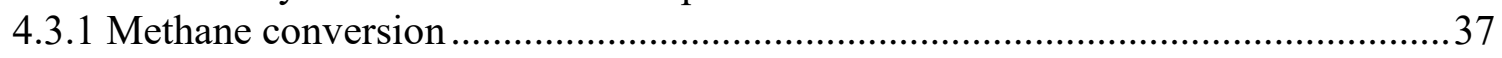

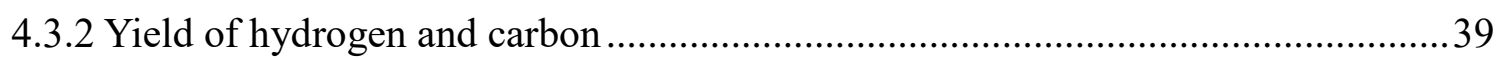

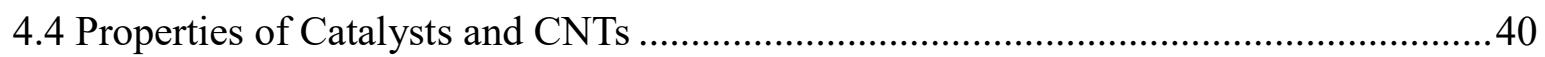

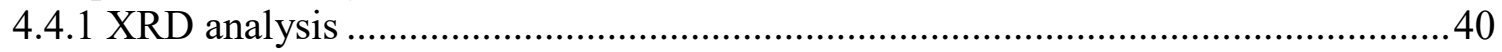

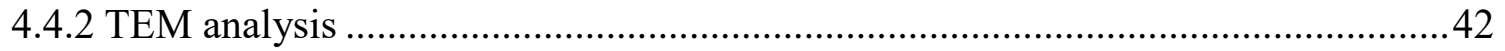

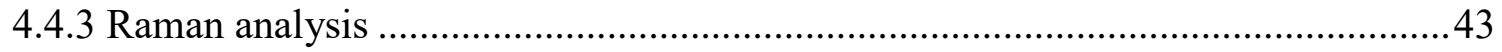

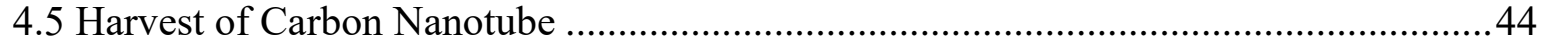

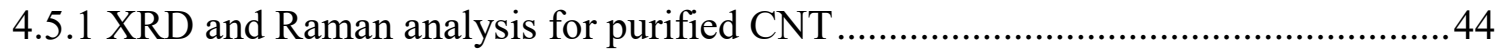

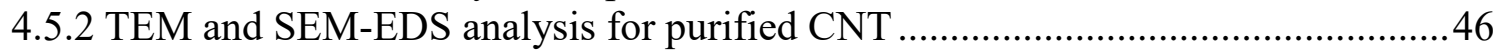

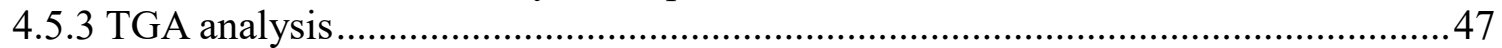

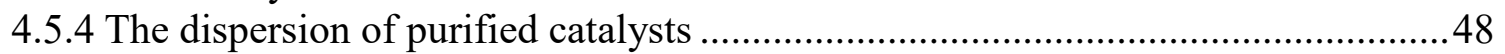

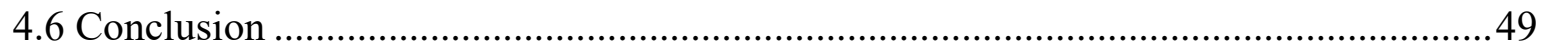

Chapter 5 Synthesis Aerogel Catalyst for Methane Decomposition..................................50

5.1 Catalyst Preparation of $\mathrm{Ni} / \mathrm{Al}_{2} \mathrm{O}_{3}$ and $\mathrm{Co} / \mathrm{Al}_{2} \mathrm{O}_{3}$ Aerogel Catalysts.............................50

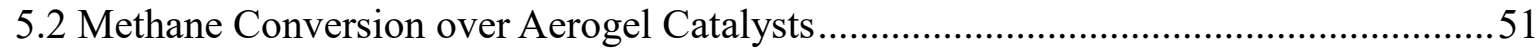

5.3 Characterization of $\mathrm{Ni} / \mathrm{Al}_{2} \mathrm{O}_{3}$ and $\mathrm{Co} / \mathrm{Al}_{2} \mathrm{O}_{3}$ Aerogel Catalysts..................................53

5.4 Growth $\mathrm{CNT}$ over $\mathrm{Ni} / \mathrm{Al}_{2} \mathrm{O}_{3}$ and $\mathrm{Co} / \mathrm{Al}_{2} \mathrm{O}_{3}$ Aerogel Catalysts ....................................58

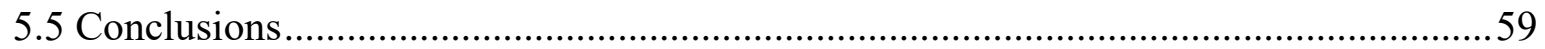

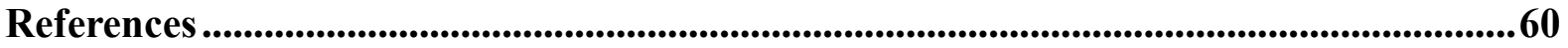




\section{List of Figures}

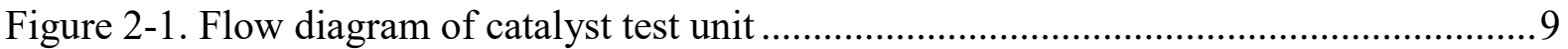

Figure 3-1 (a), (b). XRD of fresh mono and bimetallic Ni-Fe catalysts ................................ 13

Figure 3-2 (a), (b). XRD of fresh mono and bimetallic Ni-Co catalysts ................................. 13

Figure 3-3 (a), (b). XRD of fresh mono and bimetallic Fe-Co catalysts. .............................. 14

Figure 3-4. XRD pattern over spent mono and bimetallic Ni-Fe catalysts .............................. 14

Figure 3-5. XRD pattern of over spent mono and bimetallic Ni-Co catalysts........................ 15

Figure 3-6. XRD pattern over spent mono and bimetallic Fe-Co catalysts ........................... 15

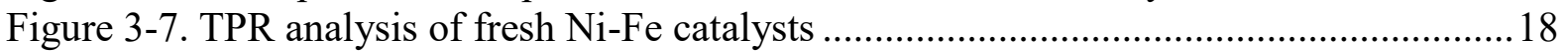

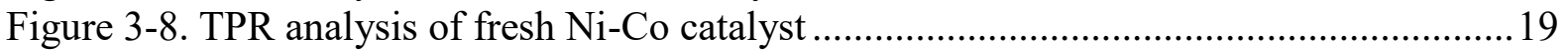

Figure 3-9. TPR analysis of fresh Fe-Co catalysts ............................................................ 19

Figure 3-10. Methane decomposition over $\mathrm{Ni}-\mathrm{Fe} / \mathrm{SiO}_{2}$ catalysts with various mole ratios.....21

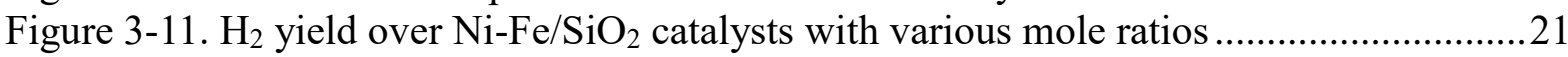

Figure 3-12. Amount of carbon formed over $\mathrm{Ni}-\mathrm{Fe} / \mathrm{SiO}_{2}$ catalysts with various mole ratios .22

Figure 3-13. Methane decomposition over $\mathrm{Ni}-\mathrm{Co} / \mathrm{SiO}_{2}$ catalysts with various mole ratios ....23

Figure 3-14. $\mathrm{H}_{2}$ yield over $\mathrm{Ni}-\mathrm{Co} / \mathrm{SiO}_{2}$ catalysts with various mole ratios ...........................23

Figure 3-15. Amount of carbon formed over $\mathrm{Ni}-\mathrm{Co} / \mathrm{SiO}_{2}$ catalysts with various mole ratios. 24

Figure 3-16. Methane decomposition over $\mathrm{Fe}-\mathrm{Co} / \mathrm{SiO}_{2}$ catalysts with various mole ratios ....24

Figure 3-17. $\mathrm{H}_{2}$ yield over $\mathrm{Fe}-\mathrm{Co} / \mathrm{SiO} 2$ catalysts with various mole ratios.............................25

Figure 3-18. Amount of carbon formed over $\mathrm{Fe}-\mathrm{Co} / \mathrm{SiO}_{2}$ catalysts with various mole ratios. 25

Figure 3-19. Methane decomposition over reduced and oxidised forms of $9 \mathrm{Ni}-1 \mathrm{Fe} / \mathrm{SiO}_{2} \ldots . .27$

Figure 3-20. XRD pattern of CNT over mono and bimetallic (a) Ni-Fe (b) Ni-Co and ..........28

Figure 3-21. Thermal stability of carbon deposited over $9 \mathrm{Ni}-1 \mathrm{Fe} / \mathrm{SiO}_{2}, 9 \mathrm{Ni}-1 \mathrm{Co} / \mathrm{SiO}_{2}$ and

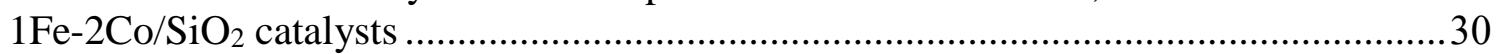

Figure 3-22. Raman spectra of CNT over mono and bimetallic Ni-Fe catalysts....................31

Figure 3-23. Raman spectra of CNT over mono and bimetallic Ni-Co catalysts .................... 32

Figure 3-24. Raman spectra of CNT over mono and bimetallic Fe-Co catalysts .....................32

Figure 3-25. Growth of carbon filaments over (a,b) $9 \mathrm{Ni}-1 \mathrm{Fe} / \mathrm{SiO}_{2}$, (c,d) $9 \mathrm{Ni}-1 \mathrm{Co} / \mathrm{SiO}_{2}$, and

$(\mathrm{e}, \mathrm{f}) 1 \mathrm{Fe}-2 \mathrm{Co} / \mathrm{SiO}_{2}$ catalysts after methane decomposition ......................................... 34

Figure 4-1. Methane decomposition over Fe-based catalysts at $700^{\circ} \mathrm{C}$ (a) different supports

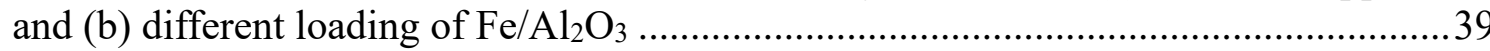

Figure 4-2. Yield of hydrogen and carbon deposited over Fe-based catalysts at $700^{\circ} \mathrm{C}$ (a) and

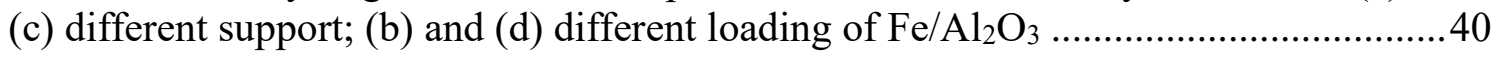

Figure 4-3. XRD patterns of (a) fresh Fe-based catalysts after $\mathrm{H}_{2}$ reduction and (b) spent

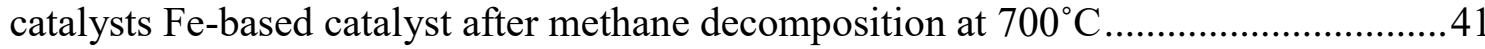

Figure 4-4. Growth of carbon filaments over (a) $\mathrm{Fe} / \mathrm{Al}_{2} \mathrm{O}_{3}$, (b) $\mathrm{Fe} / \mathrm{SiO}_{2}$, (c,d) Fe/ H-ZSM-5

catalysts after methane decomposition ...................................................................... 42

Figure 4-5. Raman spectra of carbon deposited over spent catalysts with different supports . 43

Figure 4-6. (a) XRD patterns of spent catalysts and purified CNT $(24 \mathrm{~h}$ and $48 \mathrm{~h}) ; \ldots \ldots \ldots \ldots . . . .45$

Figure 4-7. TEM images of purified CNT from $9 \mathrm{Ni}-1 \mathrm{Fe} / \mathrm{SiO}_{2}$ catalyst with $\mathrm{HNO}_{3}$ for $48 \mathrm{~h} . .46$

Figure 4-8. SEM-EDX analysis (a) spent $\mathrm{Fe} / \mathrm{Al}_{2} \mathrm{O}_{3}$, (b) purified $\mathrm{CNT}$ from $\mathrm{Fe} / \mathrm{Al}_{2} \mathrm{O}_{3}$, (c)

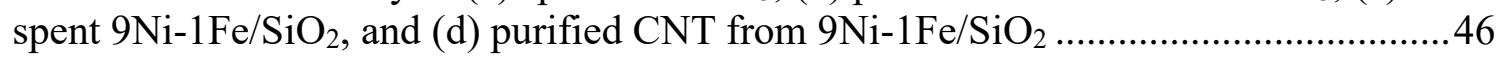

Figure 4-9. TGA profiles of spent catalysts and purified CNT: Weight loss (\%) ................... 48

Figure 4-10. Photographs of the spent catalysts and purified CNT dispersed in isopropanol (a)

just after sonication for 15 mins (b) after dispersion for 60 days .................................49

Figure 5-1. The formation mechanism of (1) Ni/Al $\mathrm{A}_{2} \mathrm{O}_{3}$ and (2) $\mathrm{Co} / \mathrm{Al}_{2} \mathrm{O}_{3}$ aerogel catalysts...51

Figure 5-2. Methane decomposition over aerogel catalysts (a) Methane conversion over

$\mathrm{Ni} / \mathrm{Al}_{2} \mathrm{O}_{3}$ (b) $\mathrm{H}_{2}$ yield over $\mathrm{Ni} / \mathrm{Al}_{2} \mathrm{O}_{3}$ (c) Methane conversion over $\mathrm{Co} / \mathrm{Al}_{2} \mathrm{O}_{3}$ (d) $\mathrm{H}_{2}$ yield 
over $\mathrm{Co} / \mathrm{Al}_{2} \mathrm{O}_{3}$

Figure 5-3. XRD analysis of fresh and spent catalysts (a) $\mathrm{Ni} / \mathrm{Al}_{2} \mathrm{O}_{3}$ and (b) $\mathrm{Co} / \mathrm{Al}_{2} \mathrm{O}_{3} \ldots \ldots \ldots . .54$ Figure 5-4. (a) Raman spectra of spent $\mathrm{Ni} / \mathrm{Al}_{2} \mathrm{O}_{3}$ catalyst and (b) Raman spectra of spent

$\mathrm{Co} / \mathrm{Al}_{2} \mathrm{O}_{3}$ catalyst; (c)TGA analysis of spent $\mathrm{Ni} / \mathrm{Al}_{2} \mathrm{O}_{3}$ and $\mathrm{Co} / \mathrm{Al}_{2} \mathrm{O}_{3}$ catalyst ................55

Figure 5-5. Characterization of the spent $60 \mathrm{wt} \% \mathrm{Ni} / \mathrm{Al}_{2} \mathrm{O}_{3}$ and $\mathrm{Co} / \mathrm{Al}_{2} \mathrm{O}_{3}$ aerogel catalysts

BET analysis of (a) $\mathrm{N}_{2}$ adsorption-desorption isotherms (b) pore sizes distribution (c and

d) SEM images of $60 \mathrm{wt} \% \mathrm{Ni} / \mathrm{Al}_{2} \mathrm{O}_{3}$ aerogel catalyst .57

Figure 5-6. TEM images of the spent $\mathrm{Ni} / \mathrm{Al}_{2} \mathrm{O}_{3}$ catalysts (a-c) $60 \mathrm{wt} \%$ and (d-f) $70 \mathrm{wt} \% \ldots . . .58$

Figure 5-7. TEM images of he spent (a-c) $60 \mathrm{wt} \%$ and (d-f) $70 \mathrm{wt} \% \mathrm{Co} / \mathrm{Al}_{2} \mathrm{O}_{3}$ catalysts ......58 


\section{List of Tables}

Table 3-1. Crystallite size of fresh and spent Ni-Fe bimetallic catalysts calculated from XRD 16

Table 3-2. Crystallite size of fresh and spent Ni-Co bimetallic catalysts calculated from XRD .16

Table 3-3. Crystallite size of fresh and spent Fe-Co bimetallic catalysts calculated from XRD

Table 5-1. Details on $\mathrm{Ni} / \mathrm{Al}_{2} \mathrm{O}_{3}$ and $\mathrm{Co} / \mathrm{Al}_{2} \mathrm{O}_{3}$ aerogel catalysts compositions..............51

Table 5-2. Carbon Productivity (gram carbon/gram catalyst per hour) ..............................52 


\section{Chapter 1 Introduction}

\subsection{Motivation}

Currently, hydrogen appears to be an environmentally benign source of energy since it can be converted into electricity and other energy forms with less pollution and high efficiency. Among various methods of hydrogen production, steam reforming of natural gas is the most popular and economical technology, which contributes to $50 \%$ of the world's hydrogen consumption [1]. However, these processes are highly endothermic $\left(68.7 \mathrm{~kJ} / \mathrm{mol} \mathrm{H}_{2}\right)$ and produce large amounts of $\mathrm{CO}_{\mathrm{x}}$. As a result, steam reforming is accompanied by the water-gas shift reaction and pressure swing adsorption (PSA) other purification steps, thereby significantly increasing the cost of the process. Recently, shale gas has become a very important source of natural gas in the United States. It contributes only 3\% of the United States natural gas production in 2005 , rising to $35 \%$ by 2012 and is predicted to grow to almost $50 \%$ by 2035 [2]. Increase in demand for $\mathrm{CO}_{\mathrm{x}}$-free hydrogen and the abundance of shale gas resources present opportunities to develop novel chemical processes that convert its major component, methane, into more valuable fuels and chemicals. Direct decomposition of methane is an attractive alternative process since it is a less endothermic process $\left(37.4 \mathrm{~kJ} / \mathrm{mol} \mathrm{H}_{2}\right)[3,4]$ compared to steam reforming and also has a high $\mathrm{H} / \mathrm{C}$ ratio compared to other hydrocarbons. This process generates $\mathrm{CO}_{\mathrm{x}}$-free hydrogen, which has a great application in low-temperature fuel cells and also generates valuable carbon nanotubes (CNTs) or nanofibers. In this work, we have concentrated more on the production of CNTs from methane. Methane thermally decomposes to atomic carbon, which eventually forms straight and hollow in chemical equation 1.1.

$$
\mathrm{CH}_{4} \leftrightarrow \mathrm{C}_{(\mathrm{CNT}, \text { fiber })}+2 \mathrm{H}_{2}
$$

Carbon nanotubes (CNTs) or nanofibers are extensively studied due to their unique physical, chemical, mechanical, electrical and optical properties [5-8]. The applications of CNTs depend 
on the number of walls, diameter, length, etc. which provides them with specific properties. They are long graphitic filaments with diameters ranging from 0.4 to $500 \mathrm{~nm}$ and lengths from micrometers to millimeters [8]. They can be single walled or multiwalled. Multiwalled carbon nanotubes (MWCNTs) are predominantly known to have a high surface area and mesoporous structure. These properties increase the application of CNTs as an adsorbent, catalyst support, and electrode material. It has been reported that depending on the process conditions, the carbons formed are different. The difference can be categorized into amorphous (disordered), turbostratic or pyrolytic (less ordered), and carbon filaments (highly ordered, crystalline and graphitic). It is very challenging to produce graphitic carbons (CNTs) by methane decomposition in the absence of a catalyst [9]. Several methods are known for producing high quality carbon nanotubes, such as laser ablation, arc discharge etc. These processes have drawbacks such as operating in high temperature $\left(1200-3000^{\circ} \mathrm{C}\right)$ and vacuum or low pressure. Non-catalytic decomposition of methane was studied at temperatures of $1000-1100^{\circ} \mathrm{C}$ which produced various forms of amorphous carbon [9]. For CNT synthesis, catalysts with nanometer-sized metal particles are essential, which will also help to reduce the temperature for methane decomposition.

\subsection{Literature Review}

\subsubsection{Metals for catalysts}

Transition metals are the typical catalyst metal material for methane decomposition since their partially filled $3 \mathrm{~d}$ orbitals facilitate the decomposition due to the partial acceptance of the $\mathrm{C}-\mathrm{H}$ bond of methane [10]. Among the metal catalysts used, most researchers have focused on Ni-based catalyst due to their high catalytic activity and capability of producing CNT [12, 13]. Although Ni catalysts showed superior performance, they deactivated immediately at temperatures above $600{ }^{\circ} \mathrm{C}[14,15]$. To improve the durability and reduce the deactivation of 
the catalyst at the reaction temperatures, different metals, and metal oxides have been introduced to the Ni-based catalysts [16-21]. Iron-based catalysts have also been studied but showed a shorter lifetime and lower activity than Ni catalysts [21]. When Fe-based catalysts were used, a higher temperature range was required to achieve reasonable productivity. Cobalt catalysts have received less attention than $\mathrm{Ni}$ - and Fe-containing catalysts, but there are few studies which show their activity for methane decomposition [23-25]. Based on previous studies it can be summarized that the catalytic activity of iron group metals is in the order of $\mathrm{Ni}>\mathrm{Co}>\mathrm{Fe}[23]$. Unfortunately, the activity of the catalyst is gradually declined during the course of the reaction due to the coverage of active sites by the carbon. Recently, it was discovered from molecular simulation and experimental results that bimetallic catalysts have a significant influence on the growth properties of CNTs [26-28].

Bimetallic or alloy catalysts of $\mathrm{Ni}$, Fe or Co have better stability than monometallic ones due to structural and electronic rearrangements that occur during alloy formation. This property can help reduce the activation energy, thereby lowering the CNT growth temperature. Also, these types of catalysts can form stable complexes or solid solutions of small nanoparticles that can prevent metal agglomeration, which causes the loss in catalytic activity. The growth of CNTs and metal particle size are very much related because metal particle size controls the CNT diameter. Hence it is very important to prepare a catalyst with controlled particle size in order to grow CNTs with a controlled diameter. A combination of monometallic catalysts with other active metals can lead to some promising catalysts [21, 23, 29, 30].

\subsubsection{Supports for catalysts}

It is accepted that metal nanoparticles dispersed over oxide supports can enhance the catalytic performance as the strong metal-support interaction (SMSI) changes the particle size or the electronic state of metal species [31,32]. Takenaka et al. compared the performance of 
$\mathrm{Ni}$ on various supports, i.e. $\mathrm{SiO}_{2}, \mathrm{TiO}_{2}$, graphite, $\mathrm{Al}_{2} \mathrm{O}_{3}, \mathrm{MgO}$, and $\mathrm{SiO}_{2} \cdot \mathrm{MgO}$, which had different activity and stability on methane decomposition [32]. Ermakova conducted a study of Fe-based catalyst on $\mathrm{SiO}_{2}, \mathrm{Al}_{2} \mathrm{O}_{3}, \mathrm{ZrO}_{2}, \mathrm{TiO}_{2}$ and bare iron. Among these supports, $\mathrm{SiO}_{2}$ had the maxima yield of carbon on the decomposition of methane [33]. Fe-Mo particles on alumina $\left(\mathrm{Al}_{2} \mathrm{O}_{3}\right)$ produced a much higher amount of SWNTs than those grown on silica $\left(\mathrm{SiO}_{2}\right)$ [34]. This was ascribed to the stronger metal support interaction for $\mathrm{Al}_{2} \mathrm{O}_{3}$ support as compared with $\mathrm{SiO}_{2} . \mathrm{MgO}$ is an attractive support material from the view of large-scale synthesis of SWNTs and DWNTs because the supported catalysts give high-quality nanotubes and $\mathrm{MgO}$ can be removed by relatively mild acidic treatment [35]. The metal-support interaction has been studied by using flat substrates such as $\mathrm{Si}, \mathrm{SiO}_{2}$, and crystals of sapphire $\left(\mathrm{Al}_{2} \mathrm{O}_{3}\right)$ and $\mathrm{MgO}$ as a model system [36-38]. These studies have also shown that the support material significantly influences the catalytic activity of metal catalysts, suggesting the importance of the metalsupport, in this case, metal-substrate, interaction. Recently a thorough study was published on the role of the metal-support interaction in the formation of CNT. Three metals, $\mathrm{Cu}, \mathrm{Fe}$, and $\mathrm{Ni}$, of low, moderate, and high catalytic activity was chosen for this comparison on substrates including $\mathrm{CaO}, \mathrm{Al}_{2} \mathrm{O}_{3}, \mathrm{SiO}_{2}$, and $\mathrm{TiO}_{2}$. Nickel provided the highest nanofiber yield among the 12 catalyst systems tested when supported on $\mathrm{TiO}_{2}$. Ni supported on $\mathrm{SiO}_{2}$ and $\mathrm{Al}_{2} \mathrm{O}_{3}$ was far less active and was virtually unreactive when supported on $\mathrm{CaO}$. $\mathrm{Cu}$ was most active on $\mathrm{CaO}$ and $\mathrm{SiO}_{2}$ and less so when supported on $\mathrm{TiO}_{2}$ or $\mathrm{Al}_{2} \mathrm{O}_{3}[39]$.

\subsubsection{Growth mechanisms for carbon nanotube}

There are several models that can be utilized to explain the tip growth mechanism. It was assumed that carbon formed on the surface of the metal nanoparticle diffuses to the back side of the nanoparticle. Still, it is not known about the driving force which is responsible for the carbon diffusion. Some researchers suggested that carbon diffusion 
was caused by the temperature gradient created in the particle due to the exothermic decomposition of methane on the surface and also the endothermic deposition of carbon on the rear surface $[5,69]$. It was also explained that due to lower surface energy of basal planes of graphite compared to prismatic planes carbon filaments precipitate with the basal planes into a tubular structure [41]. Metal support interactions also have played an important role in the growth mechanisms in the carbon nanotubes. If the metal support interaction is weak (acute contact angle with the support), methane decomposes on the top surface of the metal and carbon diffuses towards the downside of the metal. The metal particle is squeezed out because of pressure build-up due to the formation of layers of graphite at the interior of the graphitic cap. When the metal is exposed to methane, growth continues until the surface of the metal is covered with excess carbon.

\subsubsection{Base grown carbon nanotube}

A majority of above-mentioned literature have shown that catalytic methane decomposition forms CNTs via "tip growth" mechanism. One of the main disadvantages of tip grown CNTs is that during the process of harvesting CNT from the catalyst using acid or base treatment the metal nanoparticles are dissolved and the catalyst is sacrificed. Also, for tip grown CNT, catalyst nanoparticle which is attached to its tip is considered as an impurity. Hence extraction of CNT with a complete recovery of the catalyst is most recommended. To overcome this problem, catalysts and reaction processes were designed in such a way to produce "base grown" CNT. Base grown CNT can be easily harvested, and the catalyst can be regenerated without getting consumed during the extraction process. In addition, the literature search has shown that very few research was done in the area of base growth CNTs, especially their advantages over tip growth CNTs. Hence a portion of our research is focused on the synthesis of base-growth CNT's. There are only few reports which show the base growth study of CNTs. 
The base-growth mechanism was reported for MWCNTs $[35,36]$ and also for SWCNTs $[37$, 38]. One of them employed chemical vapor deposition (CVD) method using ethylene as the carbon source and iron oxide on porous $\mathrm{Si}$ as catalyst [46]. Iron oxide nanoparticles remain attached to the support during CNT growth. however, it remains unclear how to scale up these processes because of the lack of strategies in scaling up nanotube growth. Another report disclosed a growth process of carbon nanotubes from iron carbide $\left(\mathrm{Fe}_{3} \mathrm{C}\right)$ nanoparticles in chemical vapor deposition using ethylene as the feedstock [44]. Based on the previous literature we have to incorporate the metal support interaction concept for the production of base growth CNT over Fe-based catalysts.

\subsubsection{Purification of carbon nanotube}

In the CDM process, the as-synthesized carbon nanotubes contained both metal particles and support. Further purification was required to remove metal and support impurities which could otherwise obstacle CNT utilization in several areas $[40,41]$. Chemical oxidation was one commonly used method for CNT purification to open up the tip, end or the defect on sidewalls where functional groups can be added for other catalytic or chemical synthesis applications. Currently, mineral acids, such as sulfuric acid, nitric acid, or hydrochloric acid, were widely used for purification or functionalization [42-44]. Although some experimental works have been reported on either methane decomposition or purification of CNT separately, there are few papers investigating the integration of these two steps. Therefore, our research investigates the formation mechanism of CNT, purification of CNT, and characterization of CNT to correlate the surface property with the catalytic performance.

\subsubsection{Synthesis by sol-gel method}

Aerogels are highly porous materials, which are typically synthesized by the sol-gel method [45-49] and used in catalysts, thermal insulation, and energy storage [50-52]. $\mathrm{Ni}^{2+}$ - 
doped $\mathrm{Al}_{2} \mathrm{O}_{3}$ aerogel has been widely used as a catalyst for many chemical reactions [53-56]. In this study, $\mathrm{Ni} / \mathrm{Al}_{2} \mathrm{O}_{3}$ and $\mathrm{Co} / \mathrm{Al}_{2} \mathrm{O}_{3}$ aerogel catalysts were synthesized using a sol-gel method to demonstrate enhanced performance over those made from conventional incipient wetness approaches.

\subsection{Objectives}

The objectives of this work are:

(1) To compare the activity of mono- and bimetallic metal (Ni, Fe, and $\mathrm{Co}$ ) on $\mathrm{SiO}_{2}$ with various mole ratio in methane decomposition reaction and their effects on carbon nanotubes formation.

(2) To study the effect of the Fe-based catalyst with different supports $\left(\mathrm{Al}_{2} \mathrm{O}_{3}, \mathrm{ZSM}-5\right.$, and $\mathrm{SiO}_{2}$ ) on bases growth CNT. In addition, the separation and purification of the carbon nanotube are investigated.

(3) To prepare Ni and $\mathrm{Co}$ aerogel catalysts supported on $\mathrm{Al}_{2} \mathrm{O}_{3}$ by sol-gel method and compare its activity with those prepared by incipient wetness technique. 


\section{Chapter 2 Experimental Methods and Analysis}

\subsection{Catalyst Preparation}

Mono- and bimetallic $\mathrm{Ni}, \mathrm{Fe}$, and $\mathrm{Co}$ catalysts were synthesized by a dry impregnation or incipient wetness impregnation methods. $\mathrm{Ni}\left(\mathrm{NO}_{3}\right)_{2} \cdot 6 \mathrm{H}_{2} \mathrm{O}$ (Acros Organics), $\mathrm{Fe}\left(\mathrm{NO}_{3}\right)_{2} .9 \mathrm{H}_{2} \mathrm{O}$ (Alfa-Aesar) and $\mathrm{Co}\left(\mathrm{NO}_{3}\right)_{2} .6 \mathrm{H}_{2} \mathrm{O}$ (Acros Organics) were used as precursors. Fumed $\mathrm{SiO}_{2}\left(\mathrm{CAB}-\mathrm{O}-\mathrm{SIL}-\mathrm{EH}-5\right.$ untreated $\left.\mathrm{SiO}_{2}, \mathrm{CABOT}\right)$ was used as support material. An aqueous solution of metal precursor (corresponding to $60 \mathrm{wt} \%$ metal loading) was impregnated onto the support. The sample was dried in an oven at $130{ }^{\circ} \mathrm{C}$ for overnight (16h). This as-synthesized catalyst was subjected to calcination in a muffle furnace and then reduced in $10 \% \mathrm{H}_{2}$ in Ar flow $(70 \mathrm{ml} / \mathrm{min})$. Monometallic $\mathrm{Ni} / \mathrm{SiO}_{2}$ was calcined at $500{ }^{\circ} \mathrm{C}$, at ramping rate of $5{ }^{\circ} \mathrm{C} / \mathrm{min}$ for $10 \mathrm{~h}$ and reduced at 450 ${ }^{\circ} \mathrm{C}, 10{ }^{\circ} \mathrm{C} / \mathrm{min}$ for $4 \mathrm{~h} ; \mathrm{Fe} / \mathrm{SiO}_{2}$ was calcined at $500{ }^{\circ} \mathrm{C}, 5{ }^{\circ} \mathrm{C} / \mathrm{min}$ for $10 \mathrm{~h}$ and reduced at $700{ }^{\circ} \mathrm{C}, 10{ }^{\circ} \mathrm{C} / \mathrm{min}$ for $4 \mathrm{~h} ; \mathrm{Co} / \mathrm{SiO}_{2}$ was calcined at $450{ }^{\circ} \mathrm{C}, 5^{\circ} \mathrm{C} / \mathrm{min}$ for $3 \mathrm{~h}$ and reduced at $580{ }^{\circ} \mathrm{C}, 10{ }^{\circ} \mathrm{C} / \mathrm{min}$ for $4 \mathrm{~h}$. Bimetallic $\mathrm{Ni}-\mathrm{Fe} / \mathrm{SiO}_{2}$ was calcined at $500{ }^{\circ} \mathrm{C}, 5{ }^{\circ} \mathrm{C} / \mathrm{min}$ for $10 \mathrm{~h}$ and reduced at $700{ }^{\circ} \mathrm{C}, 10{ }^{\circ} \mathrm{C} / \mathrm{min}$ for $4 \mathrm{~h} ; \mathrm{Ni}-\mathrm{Co} / \mathrm{SiO}_{2}$ was calcined at $750{ }^{\circ} \mathrm{C}, 5$ ${ }^{\circ} \mathrm{C} / \mathrm{min}$ for $5 \mathrm{~h}$ and reduced at $700{ }^{\circ} \mathrm{C}, 10{ }^{\circ} \mathrm{C} / \mathrm{min}$ for $2 \mathrm{~h} ; \mathrm{Fe}-\mathrm{Co} / \mathrm{SiO}_{2}$ was calcined at 450 ${ }^{\circ} \mathrm{C}, 5{ }^{\circ} \mathrm{C} / \mathrm{min}$ for $3 \mathrm{~h}$, and reduced at $580{ }^{\circ} \mathrm{C}, 10{ }^{\circ} \mathrm{C} / \mathrm{min}$ for $4 \mathrm{~h}$. The present work concerns monometallic $\mathrm{Ni}, \mathrm{Fe}, \mathrm{Co}$ and bimetallic Ni-Fe, Ni-Co and $\mathrm{Fe}-\mathrm{Co}$ catalysts. Bimetallic catalysts were prepared by a co-impregnation method with different mole ratios such as $1: 1,1: 2,2: 1,9: 1,4: 1,1: 9$. These catalysts are designated as $\mathrm{xM}-\mathrm{yN}$ where $\mathrm{M}, \mathrm{N}$, and $\mathrm{x}$, y stands for metal and mole number respectively. 


\subsection{Reactor Apparatus}

A quartz-tube fixed-bed reactor with the length of $44.5 \mathrm{~cm}$ and diameter of $10 \mathrm{~mm}$ was used for catalytic performance tests. The schematic flow diagram of the reactor system is shown in Figure 2-1. In a typical test, $0.1 \mathrm{~g}$ catalyst was placed in the reactor and the reaction temperature was measured with a K- type thermocouple fixed at the catalyst bed. Prior to activity tests, the catalyst was subjected to a reduction at their respective temperatures and was later purged with $\mathrm{N}_{2}$ for $30 \mathrm{~min}$. Then the temperature was increased to $650{ }^{\circ} \mathrm{C}\left(10^{\circ} \mathrm{C} / \mathrm{min}\right)$ or $700^{\circ} \mathrm{C}$ in $\mathrm{N}_{2}(70 \mathrm{ml} / \mathrm{min})$ and feed was switched to reactant gas $\left(30 \% \mathrm{CH}_{4} / \mathrm{N}_{2}, 70 \mathrm{ml} / \mathrm{min}\right)$ and a space velocity of $42000 \mathrm{~h}^{-1}$ was achieved. The composition of the outlet gas was measured by online gas chromatography (Perkin ElmerARNEL, Clarus 500) equipped with a thermal conductivity detector. GC was calibrated with standard gases before analysis.

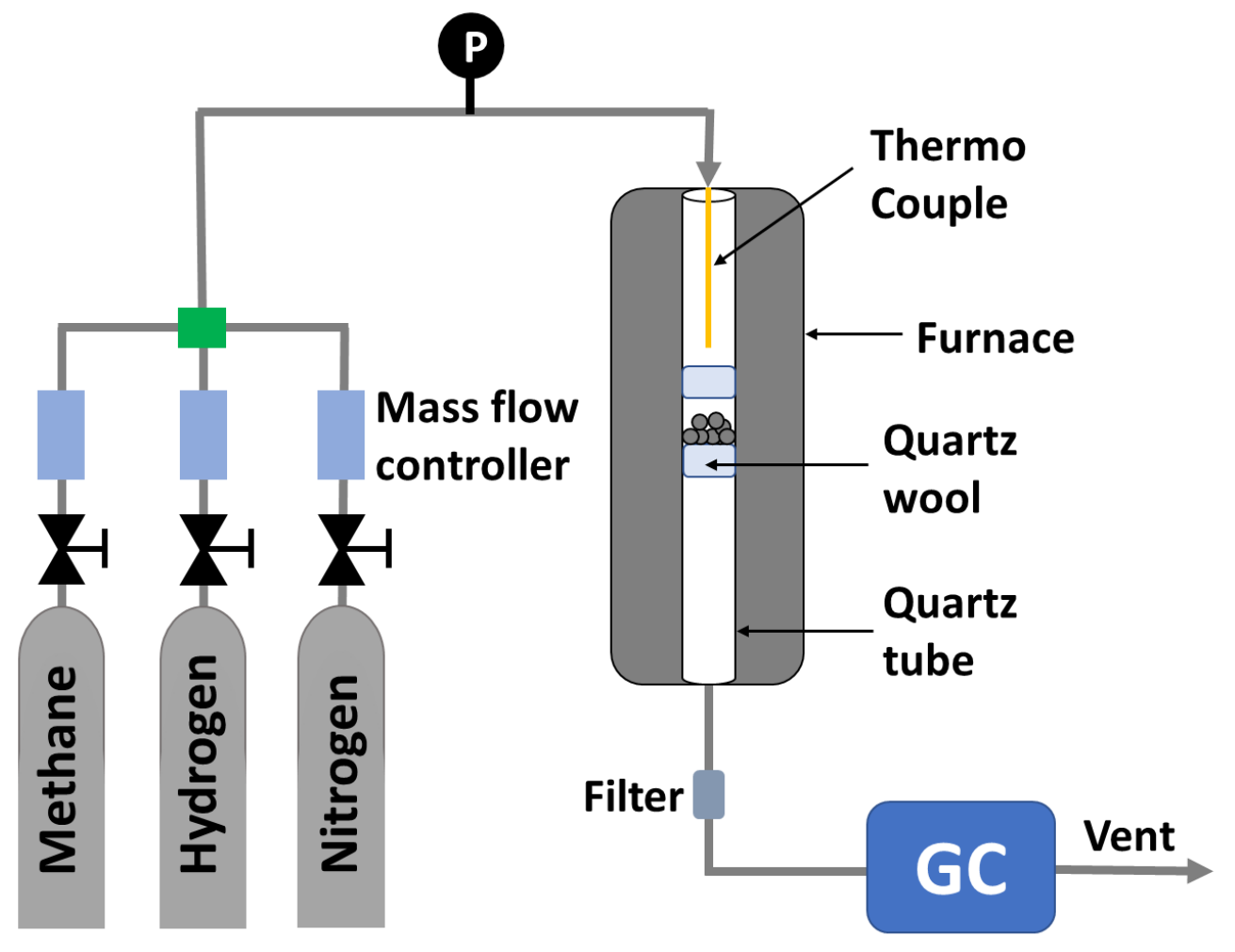

Figure 2-1. Schematic flow diagram of catalyst test unit 


\subsection{Catalyst Characterizations}

\subsubsection{Temperature programmed reduction (TPR)}

Temperature-programmed-reduction (TPR) was performed for the catalysts using Micromeritics AutoChem HP chemisorption analyser equipped with a TCD detector. The catalysts were degassed in $200^{\circ} \mathrm{C}$ for $1 \mathrm{~h}$. After cooling to $\mathrm{RT}$, the temperature was ramped to $850{ }^{\circ} \mathrm{C}$ in 10 vol\% $\mathrm{H}_{2} / \mathrm{Ar}(50 \mathrm{ml} / \mathrm{min})$ with a linear heating rate of $10{ }^{\circ} \mathrm{C} / \mathrm{min}$. and the TCD signal was recorded.

\subsubsection{X-Ray Diffraction (XRD)}

The catalysts with carbon deposition obtained after reaction at 650 and $700{ }^{\circ} \mathrm{C}$ were characterized by XRD. The XRD measurements were performed on PANalytical X'pert Pro using $\mathrm{Cu} \mathrm{K} \alpha$ radiation. The step scans were taken over the range of $10-90^{\circ}$ and the scan rate was $5^{\circ} / \mathrm{min}$.

\subsubsection{Transmission Electron Microscopy (TEM)}

The morphologies and microstructures of the carbon materials were characterized by Jeol TEM-2100 and the operating voltage was $200 \mathrm{kV}$. The samples were prepared by sonication of the spent catalyst in isopropanol and the suspension was dropped onto a $\mathrm{Cu}$ grid for analysis.

\subsubsection{Scanning electron microscopy (SEM)}

Scanning electron microscopy (SEM) images were obtained through the measurement on a JEOL JSM-7600F SEM equipped with an Oxford INCA EDS. Raman experiments were carried out in Renishaw Invia Raman spectrometer at ambient atmosphere and room temperature. The Raman spectra were recorded using a green excitation line 532 nm. Thermogravimetric analysis was performed using the TA_SDT-650_Discovery model instrument in $5 \% \mathrm{O}_{2} / \mathrm{He}$ atmosphere, from $150-900{ }^{\circ} \mathrm{C}$, at a constant heating rate of 2 and $5{ }^{\circ} \mathrm{C} / \mathrm{min}$. 


\section{Chapter 3 Mono- and Bimetallic Ni, Co, and Fe Catalysts \\ for Methane Decomposition}

\subsection{Properties of Fresh and Spent Catalysts Supported on $\mathrm{SiO}_{2}$}

\subsubsection{XRD analysis of fresh and spent catalysts}

The characteristic peaks for all the metals ( $\mathrm{Ni}, \mathrm{Fe}$, and $\mathrm{Co}$ ) were identified using the XRD analysis. The amorphous peak of $\mathrm{SiO}_{2}$ support was not visible in the diffraction pattern due to the high intensity of peaks for the metal loaded ( $60 \%$ metal on $40 \% \mathrm{SiO}_{2}$ support). The sharp peaks for metals confirmed the crystalline phase of the active element $(\mathrm{Ni} / \mathrm{Fe} / \mathrm{Co})$ and the corresponding $2 \theta$ values represented their metallic state. The Ni characteristic peaks were observed at $2 \theta^{\circ}=44.6^{\circ}, 52.0^{\circ}, 76.6^{\circ}(\mathrm{JCPDS}$ No. $04-850)$; Fe characteristic peaks were at $2 \theta^{\circ}$ $=45.1^{\circ}, 65.5^{\circ}, 82.8^{\circ}(\mathrm{JCPDS}$ No. $65-4899)$ and for Co the peaks were at $2 \theta^{\circ}=44.4^{\circ}, 51.6^{\circ}$, $76^{\circ}$ (JCPDS No. 15-0806). For bimetallic Ni-Fe catalysts with different ratios, we observed a peak shifting which signified alloy formation (Figure 3-1 (b)). The transformation from the fcc to the bcc phase as a function of Fe content was observed in Ni-Fe bulk alloys [57, 58]. For the monometallic Ni catalyst, the (111) plane represents the fcc phase and for the monometallic Fe catalyst, the (110) plane represents the bcc phase. In the bimetallic catalyst, when $\mathrm{Fe}$ is introduced to a Ni-rich system $(9 \mathrm{Ni}-1 \mathrm{Fe})$ a single set of diffraction patterns corresponding to the fcc phase of Ni-Fe alloy was observed. This peak was also found to be shifted towards a lower $2 \theta$ value, converging to the diffraction pattern of the $\mathrm{Ni}$ fcc phase. Similarly, for the NiCo bimetallic catalyst, alloy formation was confirmed using XRD analysis (Figure 3-2). The fcc phase (111) of monometallic Co was observed at $2 \theta=44.4^{\circ}$, which was slightly shifted towards a higher $2 \theta$ value (Ni phase), representing the $\mathrm{Ni}-\mathrm{Co}$ alloy formation. Also, for the Fe-Co bimetallic system, alloy formation was observed where the bcc phase for Fe was shifted towards the lower $2 \theta$ values, representing the fcc phase of $\mathrm{Co}$ and the $\mathrm{Fe}-\mathrm{Co}$ alloy formation (Figure 3-3). Hence from XRD analysis, we could confirm the formation of alloy in the 
bimetallic $\mathrm{Ni} / \mathrm{Fe} / \mathrm{Co}$ catalysts prepared, which thereby would help to increase the stability of the catalyst under the reaction conditions. After the reaction, the used catalysts were once again characterized by XRD analysis (Figure 3-4,5, and 6). The majority of the catalysts were stable in their metallic form but the monometallic Fe catalyst (Figure 3-4) transferred into iron carbide. But for the bimetallic catalysts, it was observed that the alloy formation has helped to prevent the oxidation of the metals and thereby increasing its lifetime or stability. From the XRD data, the mean crystallite size of metal nanoparticles before and after the reaction was calculated, using the Scherrer equation (Tables 3-1,2, and 3). The mean crystallite size of fresh Ni catalyst was found to be $25 \mathrm{~nm}$, while for fresh Fe catalyst it was $29 \mathrm{~nm}$. When Ni-Fe bimetallic catalysts were prepared, we could observe a significant decrease in the crystallite size, which even reduced up to $9 \mathrm{~nm}$ for $2 \mathrm{Ni}-1 \mathrm{Fe}$ catalyst. In the case of fresh Co catalyst, the crystallite size was found to be $21 \mathrm{~nm}$. For fresh Ni-Co bimetallic catalysts, the crystallite size was found to be in between that of $\mathrm{Ni}$ and Co catalysts, $22-25 \mathrm{~nm}$. Also, for Fe-Co catalyst, we can observe the crystallite size of $17-28 \mathrm{~nm}$, which is in the range of Fe and Co monometallic ones. Even after the methane decomposition, there was a very little increase in the crystallite size of spent $\mathrm{Ni}$ $\mathrm{Fe} / \mathrm{Ni}-\mathrm{Co}$ and Fe-Co catalysts. Hence there is not much agglomeration of the nanoparticles, which signifies the stable nature of the catalyst. 

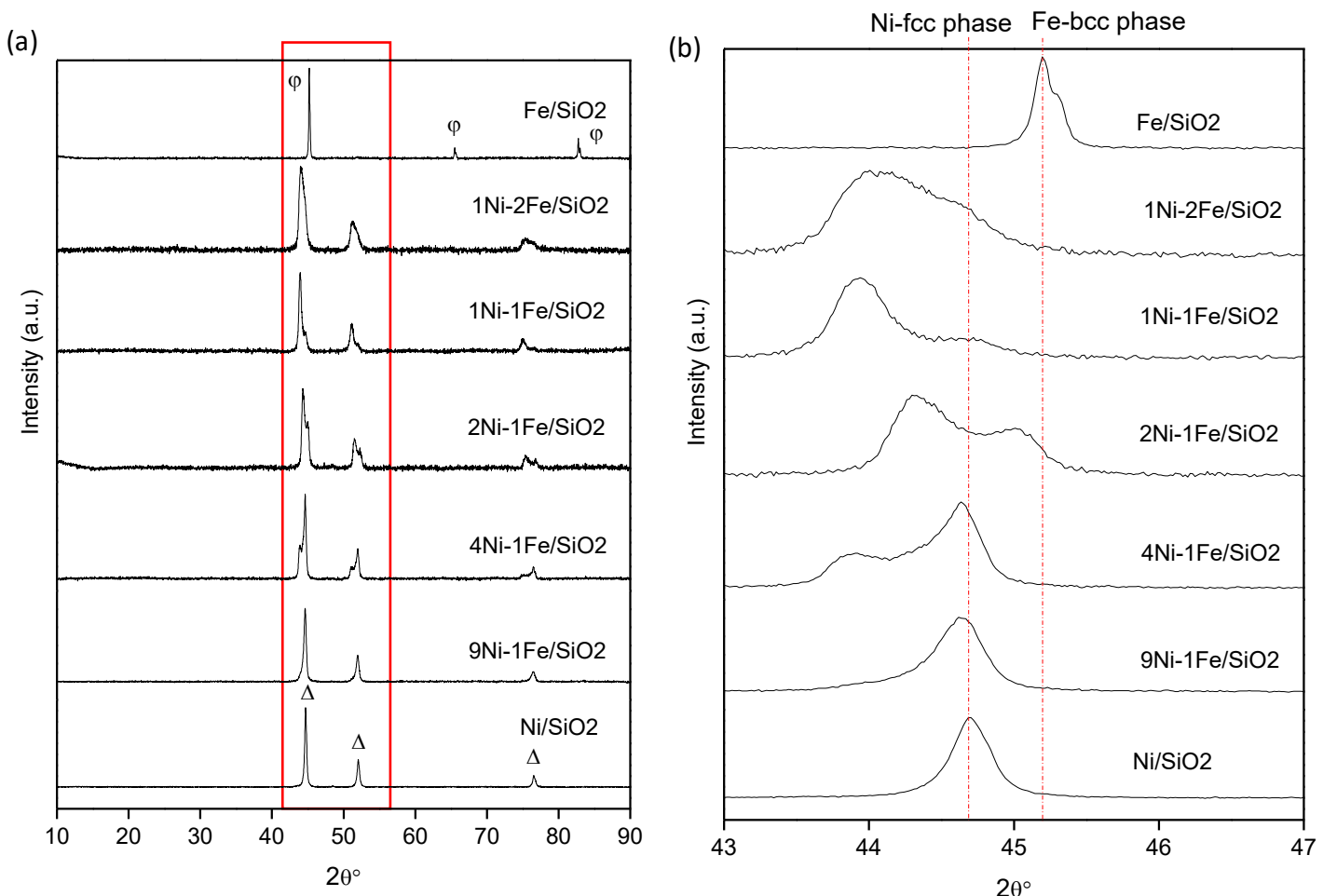

Figure 3-1 (a), (b). XRD of fresh mono and bimetallic Ni-Fe catalysts
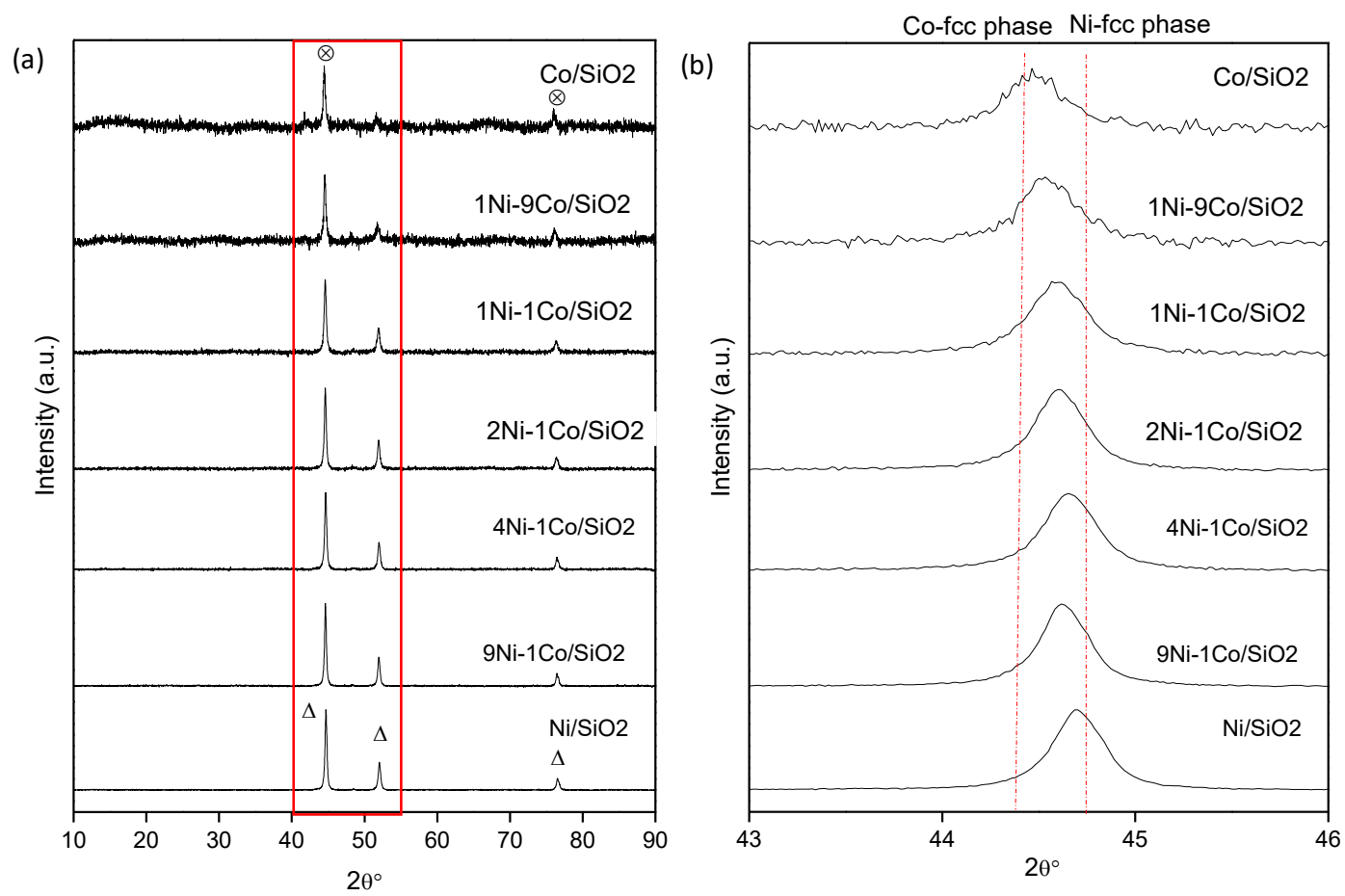

Figure 3-2 (a), (b). XRD of fresh mono and bimetallic Ni-Co catalysts 

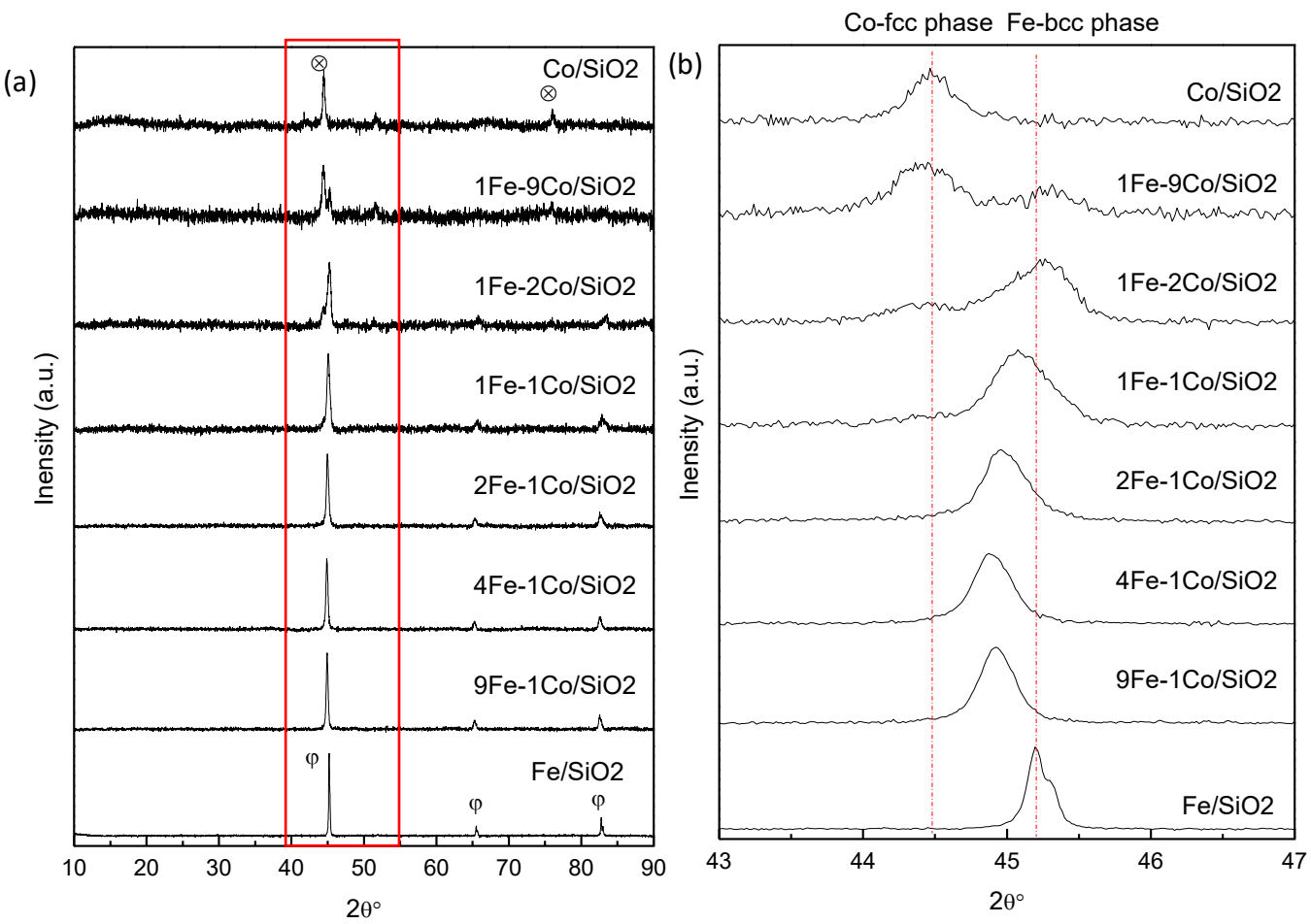

Figure 3-3 (a), (b). XRD of fresh mono and bimetallic Fe-Co catalysts.

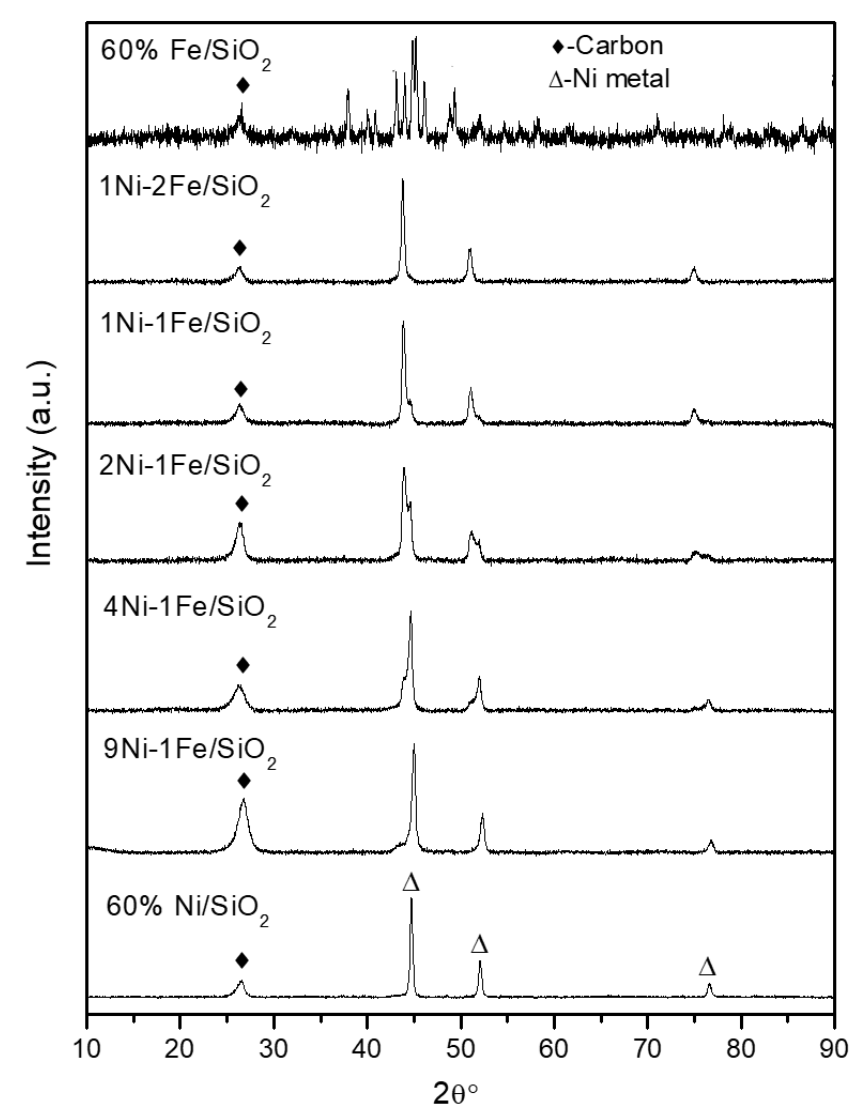

Figure 3-4. XRD pattern over spent mono and bimetallic Ni-Fe catalysts 


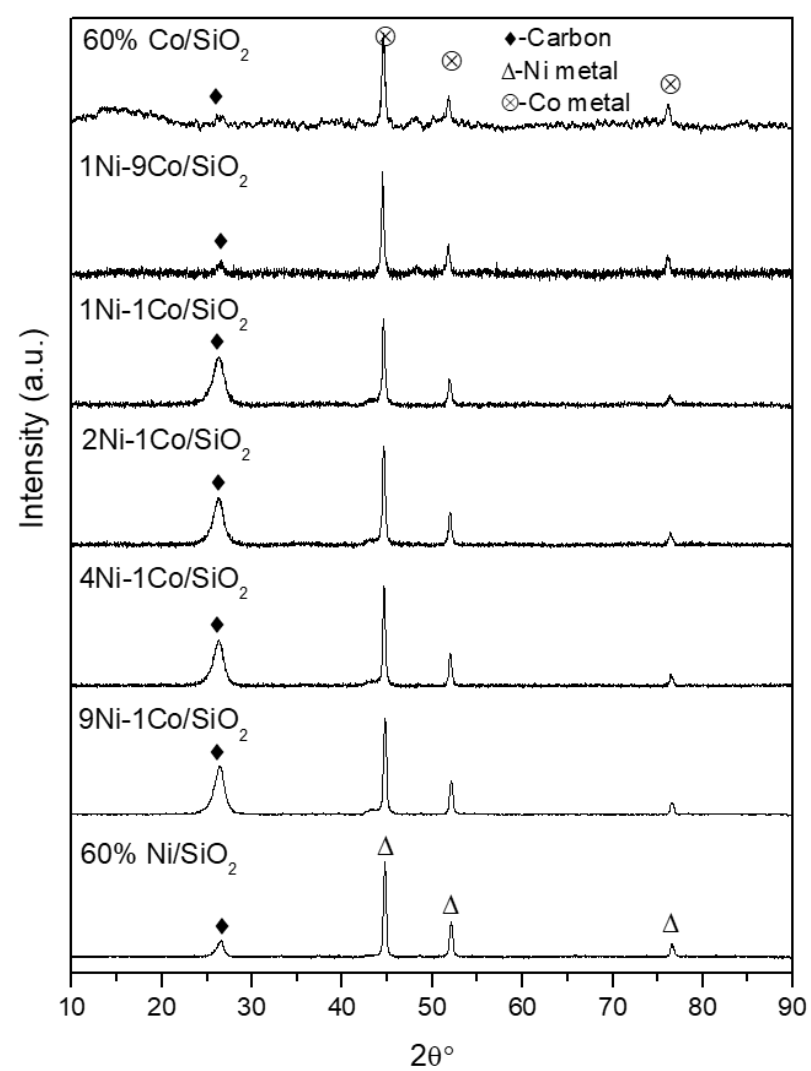

Figure 3-5. XRD pattern of over spent mono and bimetallic Ni-Co catalysts

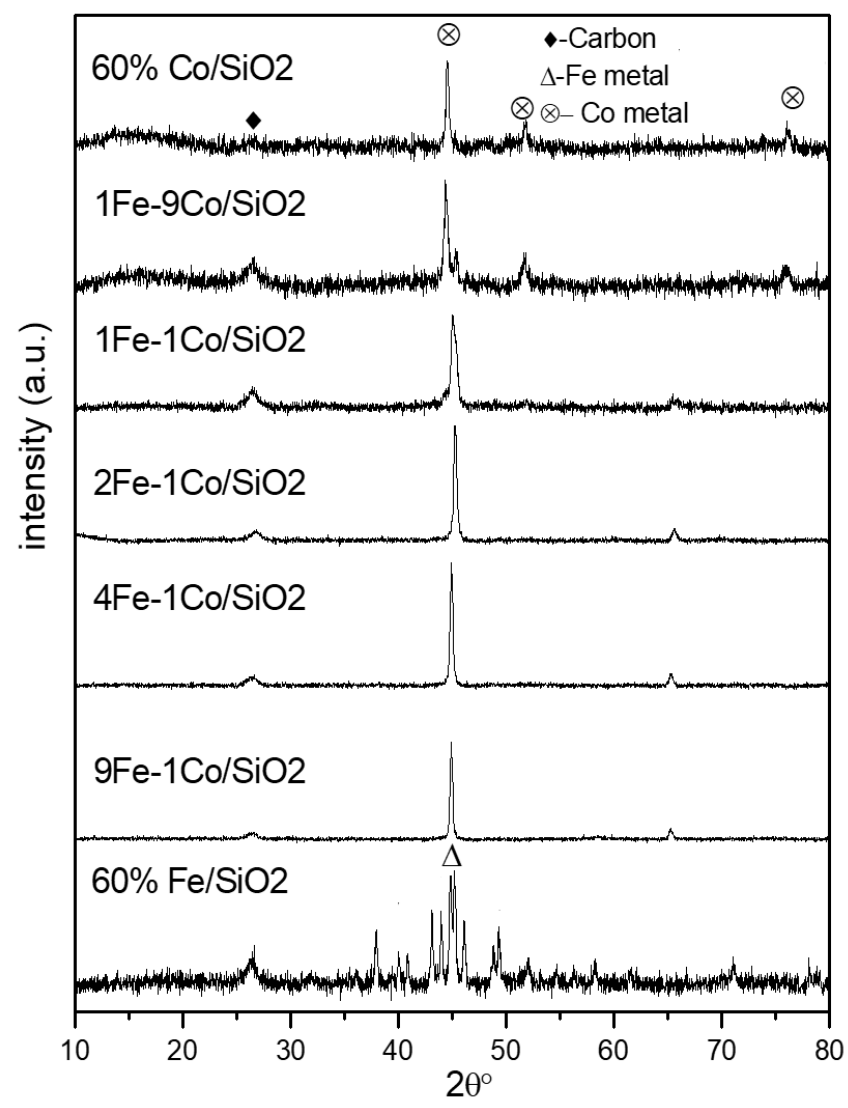

Figure 3-6. XRD pattern over spent mono and bimetallic Fe-Co catalysts 
Table 3-1. Crystallite size of fresh and spent Ni-Fe bimetallic catalysts calculated from XRD

\begin{tabular}{lll}
\hline & \multicolumn{2}{c}{ Crystallite size (nm) } \\
\cline { 2 - 3 } Catalyst & Fresh & Spent \\
\hline $\mathrm{Fe} / \mathrm{SiO}_{2}$ & 29 & 13 \\
$1 \mathrm{Ni}-2 \mathrm{Fe} / \mathrm{SiO}_{2}$ & 19 & 22 \\
$1 \mathrm{Ni}-1 \mathrm{Fe} / \mathrm{SiO}_{2}$ & 17 & 20 \\
$2 \mathrm{Ni}-1 \mathrm{Fe} / \mathrm{SiO}_{2}$ & 9 & 9 \\
$4 \mathrm{Ni}-1 \mathrm{Fe} / \mathrm{SiO}_{2}$ & 10 & 12 \\
$9 \mathrm{Ni}-1 \mathrm{Fe} / \mathrm{SiO}_{2}$ & 20 & 20 \\
$\mathrm{Ni} / \mathrm{SiO}$ & 25 & 25 \\
\hline
\end{tabular}

Table 3-2. Crystallite size of fresh and spent Ni-Co bimetallic catalysts calculated from XRD

\begin{tabular}{lll}
\hline & \multicolumn{2}{c}{ Crystallite size (nm) } \\
\cline { 2 - 3 } Catalyst & Fresh & Spent \\
\hline $\mathrm{Co} / \mathrm{SiO}_{2}$ & 21 & 24 \\
$1 \mathrm{Ni}-9 \mathrm{Co} / \mathrm{SiO}_{2}$ & 22 & 26 \\
$1 \mathrm{Ni}-1 \mathrm{Co} / \mathrm{SiO}_{2}$ & 23 & 24 \\
$2 \mathrm{Ni}-1 \mathrm{Co} / \mathrm{SiO}_{2}$ & 25 & 25 \\
$4 \mathrm{Ni}-1 \mathrm{Co} / \mathrm{SiO}_{2}$ & 24 & 26 \\
$9 \mathrm{Ni}-1 \mathrm{Co} / \mathrm{SiO}_{2}$ & 25 & 25 \\
$\mathrm{Ni} / \mathrm{SiO}$ & 25 & 25 \\
\hline
\end{tabular}


Table 3-3. Crystallite size of fresh and spent Fe-Co bimetallic catalysts calculated from XRD

\begin{tabular}{lll}
\hline & \multicolumn{2}{c}{ Crystallite size (nm) } \\
\cline { 2 - 3 } Catalyst & Fresh & Spent \\
\hline $\mathrm{Fe} / \mathrm{SiO}_{2}$ & 29 & 13 \\
$9 \mathrm{Fe}-1 \mathrm{Co} / \mathrm{SiO}_{2}$ & 28 & 31 \\
$4 \mathrm{Fe}-1 \mathrm{Co} / \mathrm{SiO}_{2}$ & 26 & 28 \\
$2 \mathrm{Fe}-1 \mathrm{Co} / \mathrm{SiO}_{2}$ & 23 & 25 \\
$1 \mathrm{Fe}-1 \mathrm{Co} / \mathrm{SiO}_{2}$ & 17 & 18 \\
$1 \mathrm{Fe}-9 \mathrm{Co} / \mathrm{SiO}_{2}$ & 17 & 18 \\
$\mathrm{Co} / \mathrm{SiO}$ & 21 & 24 \\
\hline
\end{tabular}

\subsubsection{TPR of fresh catalysts}

$\mathrm{H}_{2}$-TPR is a sensitive technique for the reducibility of the synthesized catalysts. The TPR results also supported XRD data for the alloy formation in the bimetallic catalysts. In the monometallic Ni catalyst, two reduction peaks were observed, one at around $367{ }^{\circ} \mathrm{C}$ and the other at $470{ }^{\circ} \mathrm{C}$ (Figure 3-7). First peak corresponds to the reduction of bulk NiO, which was weakly interacted with the $\mathrm{SiO}_{2}$ support and the second weak reduction peak was associated with the reduction of $\mathrm{NiO}$ species, which had a very strong interaction with the $\mathrm{SiO}_{2}$ support [66]. For monometallic Fe catalyst, a typical TPR profile has three peaks at around 470, 576 and $727^{\circ} \mathrm{C}$, respectively (Figure 3-7). These correspond to the three consecutive reduction steps, $\alpha-\mathrm{Fe}_{2} \mathrm{O}_{3} \rightarrow \mathrm{Fe}_{3} \mathrm{O}_{4} \rightarrow \mathrm{FeO} \rightarrow \mathrm{Fe}[60,61]$. In the monometallic Co catalyst, the low temperature reduction peak centered at $306{ }^{\circ} \mathrm{C}$ and the second peak at $360{ }^{\circ} \mathrm{C}$ was assigned to the two-step reduction of spinel, i.e., $\mathrm{Co}_{3} \mathrm{O}_{4} \rightarrow \mathrm{CoO} \rightarrow \mathrm{Co}$ (Figure 3-8). An additional shoulder peak was also observed at around $433{ }^{\circ} \mathrm{C}$ [69]. However, the absence of high reduction temperature peaks shows that the interaction of cobalt with the $\mathrm{SiO}_{2}$ support was not strong. TPR studies of bimetallic Ni-Fe catalysts showed that with the increase in Ni content the high 
temperature reduction peaks of Fe were shifted towards the reduction temperature of Ni species (Figure 3-7). For Fe-Co catalysts, the increase in Co content lowered the reduction temperature of the catalyst or Co facilitated the reduction of Fe (Figure 3-9). When Fe was present in high concentrations, the catalyst exhibited the properties of Fe. Hence an increase in the Co reduction temperature was observed $[62,63]$. The TPR profiles of Ni-Co catalysts (Figure 38) indicated that $\mathrm{Co}_{3} \mathrm{O}_{4}$ was easier to reduce than $\mathrm{NiO}$, whereas an increase in $\mathrm{Ni}$ content retards the reduction of $\mathrm{Co}_{3} \mathrm{O}_{4}$. Hence the incorporation of $\mathrm{Co}$ should improve the reducibility of $\mathrm{NiO}$.

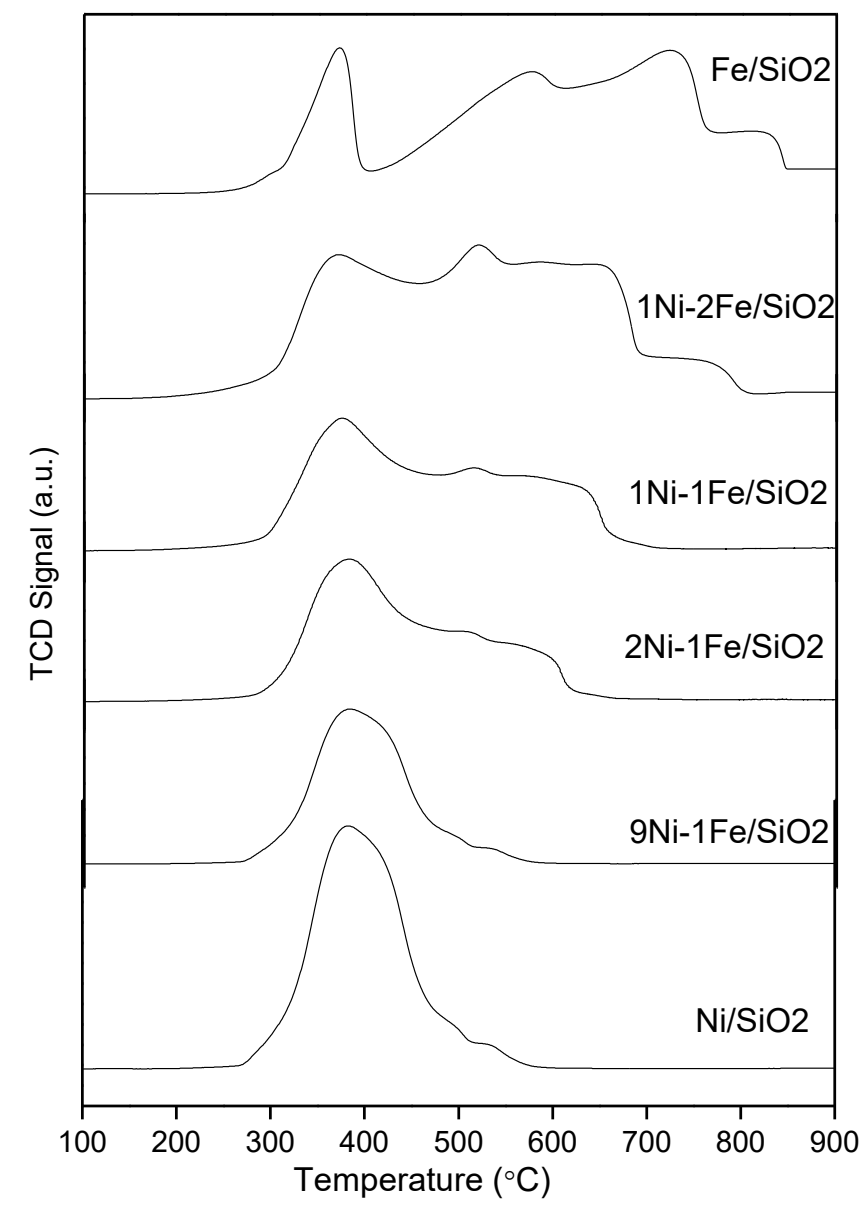

Figure 3-7. TPR analysis of fresh Ni-Fe catalysts 


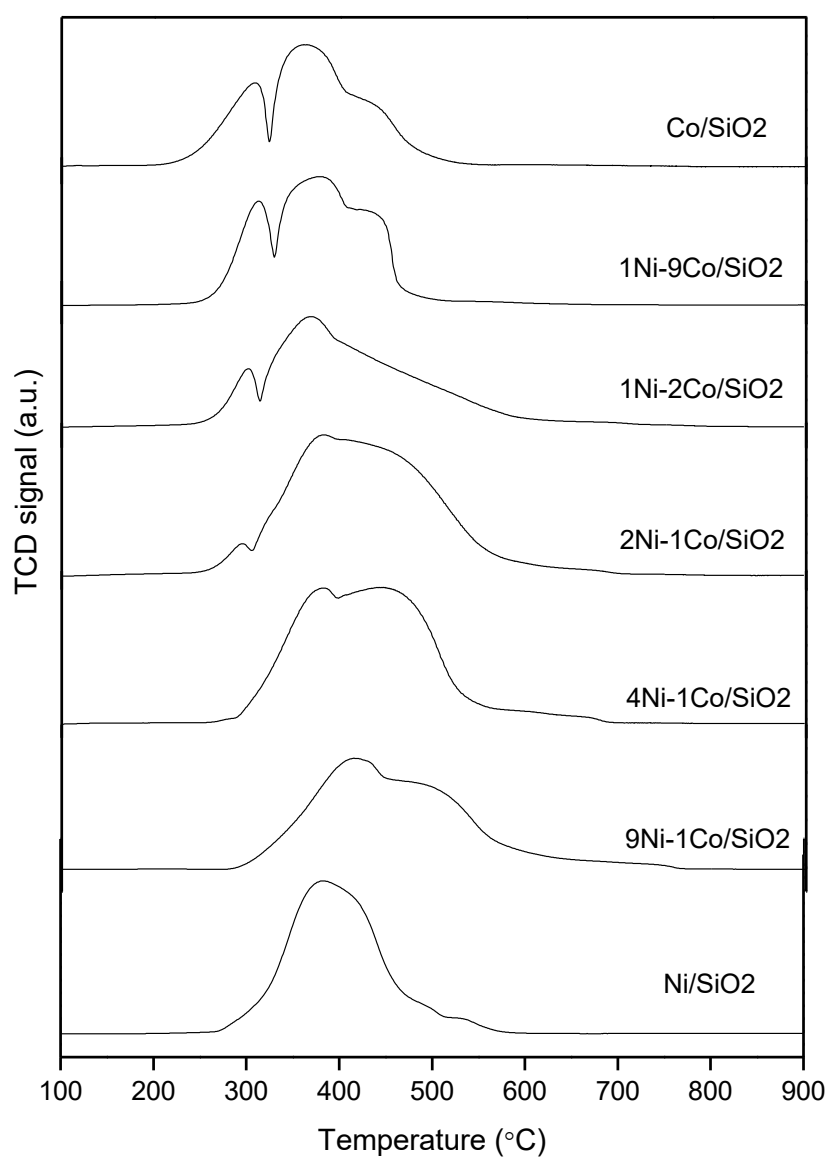

Figure 3-8. TPR analysis of fresh Ni-Co catalyst

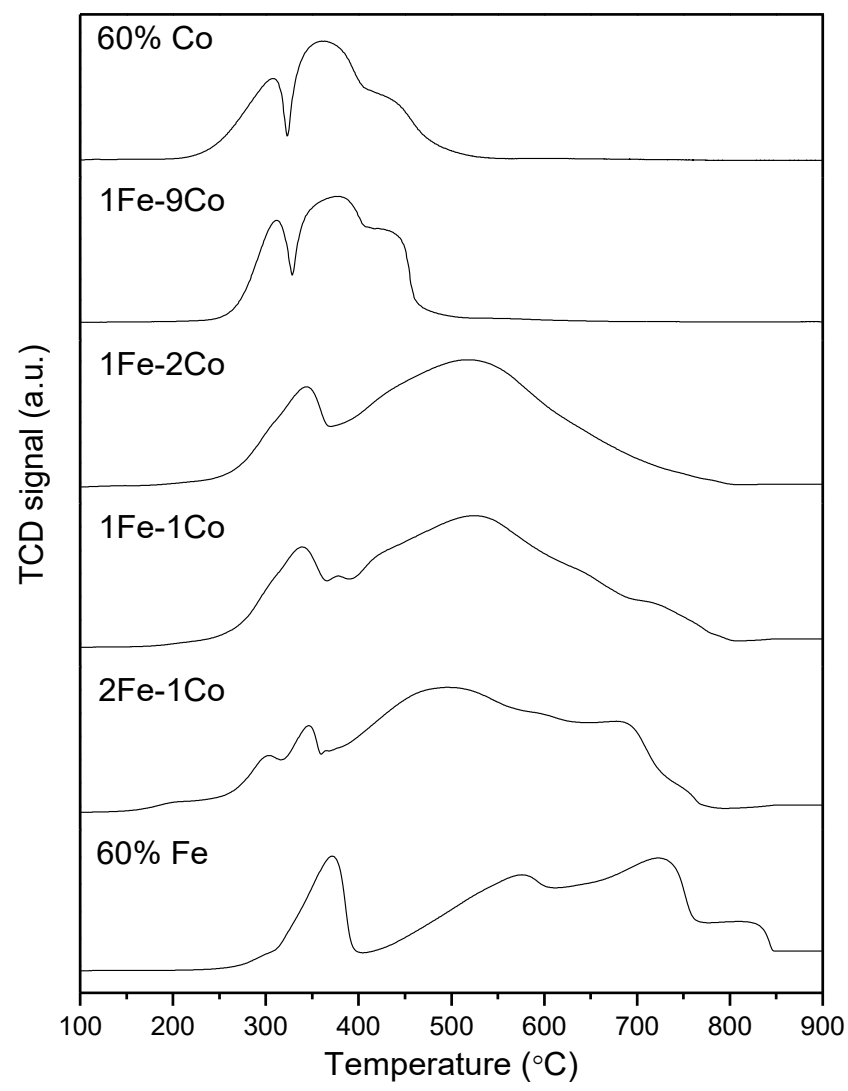

Figure 3-9. TPR analysis of fresh Fe-Co catalysts 


\subsection{Effect of Catalyst Composition on $\mathrm{CH}_{4}$ Decomposition and CNT Growth}

\subsubsection{Ni-Fe bimetallic catalysts}

Initial studies were performed using monometallic $\mathrm{Ni} / \mathrm{SiO}_{2}$ catalyst. It was observed that even though $\mathrm{Ni} / \mathrm{SiO}_{2}$ showed a high $\mathrm{CH}_{4}$ conversion of $50 \%$, it started deactivating and reached a conversion of $40 \%$ in 60 min of reaction (Figure 3-10). Similarly, monometallic $\mathrm{Fe} / \mathrm{SiO}_{2}$ was tested, which showed a very low initial activity of $11 \%$ and gradually deactivated to $4 \% \mathrm{CH}_{4}$ conversion. Mono- metallic $\mathrm{Ni} / \mathrm{SiO}_{2}$ was a very active catalyst; unfortunately, it deactivated very fast. Hence the effect of Fe promoter addition on the activity of the $\mathrm{Ni} / \mathrm{SiO} 2$ catalyst for methane decomposition reaction has been shown. Several Ni-Fe mole ratios $(9: 1,4: 1,2: 1$, $1: 1,1: 2)$ were studied. $4 \mathrm{Ni}-1 \mathrm{Fe} / \mathrm{SiO}_{2}$ and $2 \mathrm{Ni}-1 \mathrm{Fe} / \mathrm{SiO}_{2}$ exhibited a similar activity to monometallic $\mathrm{Ni} / \mathrm{SiO}_{2}$ catalyst at $\mathrm{TOS}=30 \mathrm{~min}$, but afterwards it was observed that $4 \mathrm{Ni}-$ $1 \mathrm{Fe} / \mathrm{SiO}_{2}$ catalyst retained its activity even after $\mathrm{TOS}=60 \mathrm{~min}$, whereas $2 \mathrm{Ni}-1 \mathrm{Fe} / \mathrm{SiO}{ }_{2}$ deactivated like the $\mathrm{Ni} / \mathrm{SiO}_{2}$ catalyst. Reactions were also performed with $1 \mathrm{Ni}-1 \mathrm{Fe} / \mathrm{SiO}$ and $1 \mathrm{Ni}-2 \mathrm{Fe} / \mathrm{SiO}_{2}$, which showed a very low $\mathrm{CH}_{4}$ conversion (16-20\%) compared to the above catalysts, but they had maintained the activity throughout the reaction time. Thus, it was concluded that high $\mathrm{Ni}$ content in the $\mathrm{Ni}-\mathrm{Fe}$ bimetallic catalyst exhibits higher conversion, which helps to increase the stability or the lifetime of the catalyst. Hence $9 \mathrm{Ni}-1 \mathrm{Fe} / \mathrm{SiO}_{2}$ was prepared, which showed an excellent conversion rate of $60 \%$, the highest among all the Ni and Fe catalysts studied here, and its activity was very stable even at $60 \mathrm{~min}$ of reaction.

The $\mathrm{H}_{2}$ yield was found to be in the range of $30-40 \%$ for catalysts with higher Ni content such as $9 \mathrm{Ni}-1 \mathrm{Fe} / \mathrm{SiO}_{2}, 4 \mathrm{Ni}-1 \mathrm{Fe} / \mathrm{SiO}_{2}$, and $2 \mathrm{Ni}-1 \mathrm{Fe} / \mathrm{SiO}_{2}$, while the rest of the catalysts showed only 5-12\% $\mathrm{H}_{2}$ yield (Figure 3-11). The amount of carbon formed per gram of catalyst was calculated, which was found to be approximately $2.3-2.5$ g over $9 \mathrm{Ni}-1 \mathrm{Fe} / \mathrm{SiO}_{2}, 4 \mathrm{Ni}-1 \mathrm{Fe} / \mathrm{SiO}_{2}$, and $2 \mathrm{Ni}-1 \mathrm{Fe} / \mathrm{SiO}_{2}$ and was less than $0.4 \mathrm{~g}$ for the rest of the catalysts (Figure 3-12). 


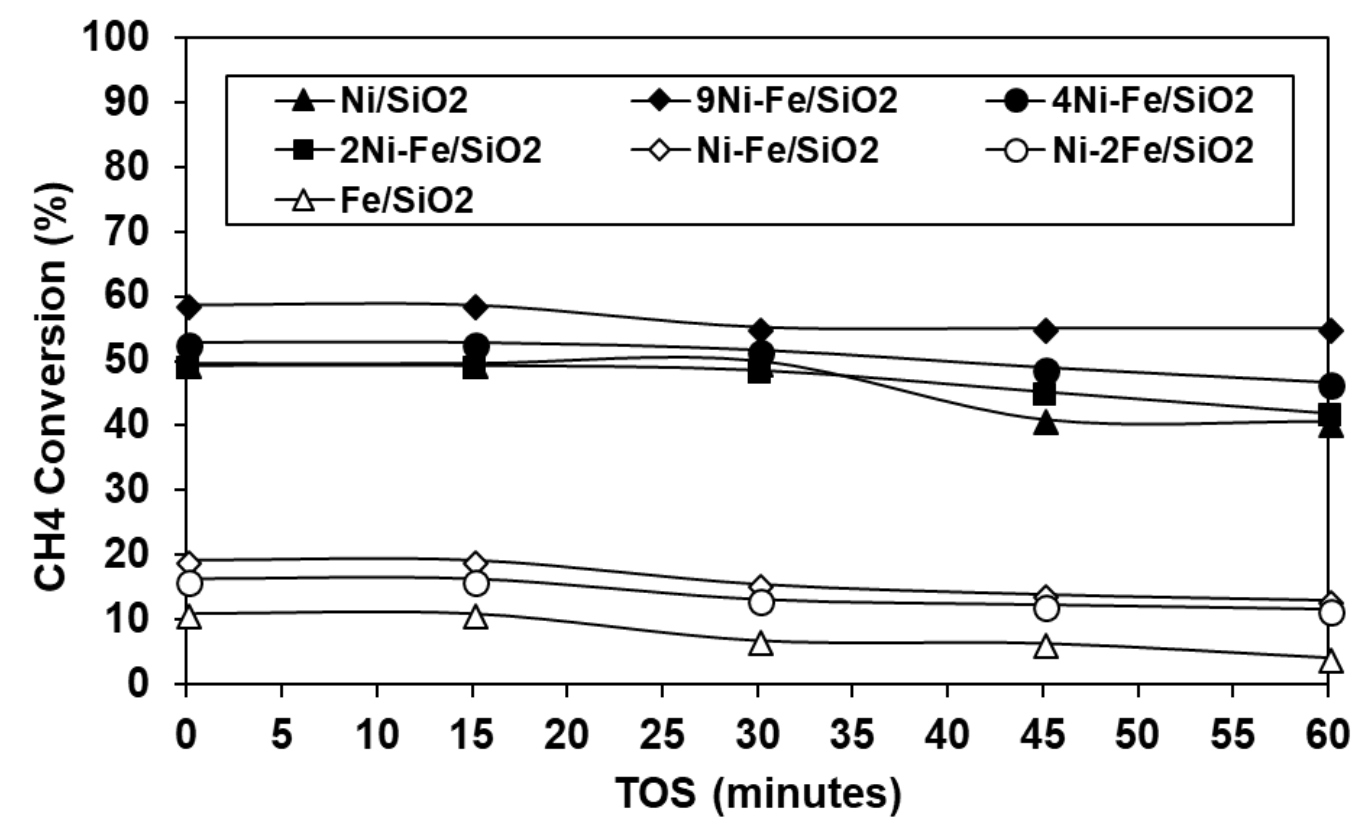

Figure 3-10. Methane decomposition over $\mathrm{Ni}-\mathrm{Fe} / \mathrm{SiO}_{2}$ catalysts with various mole ratios

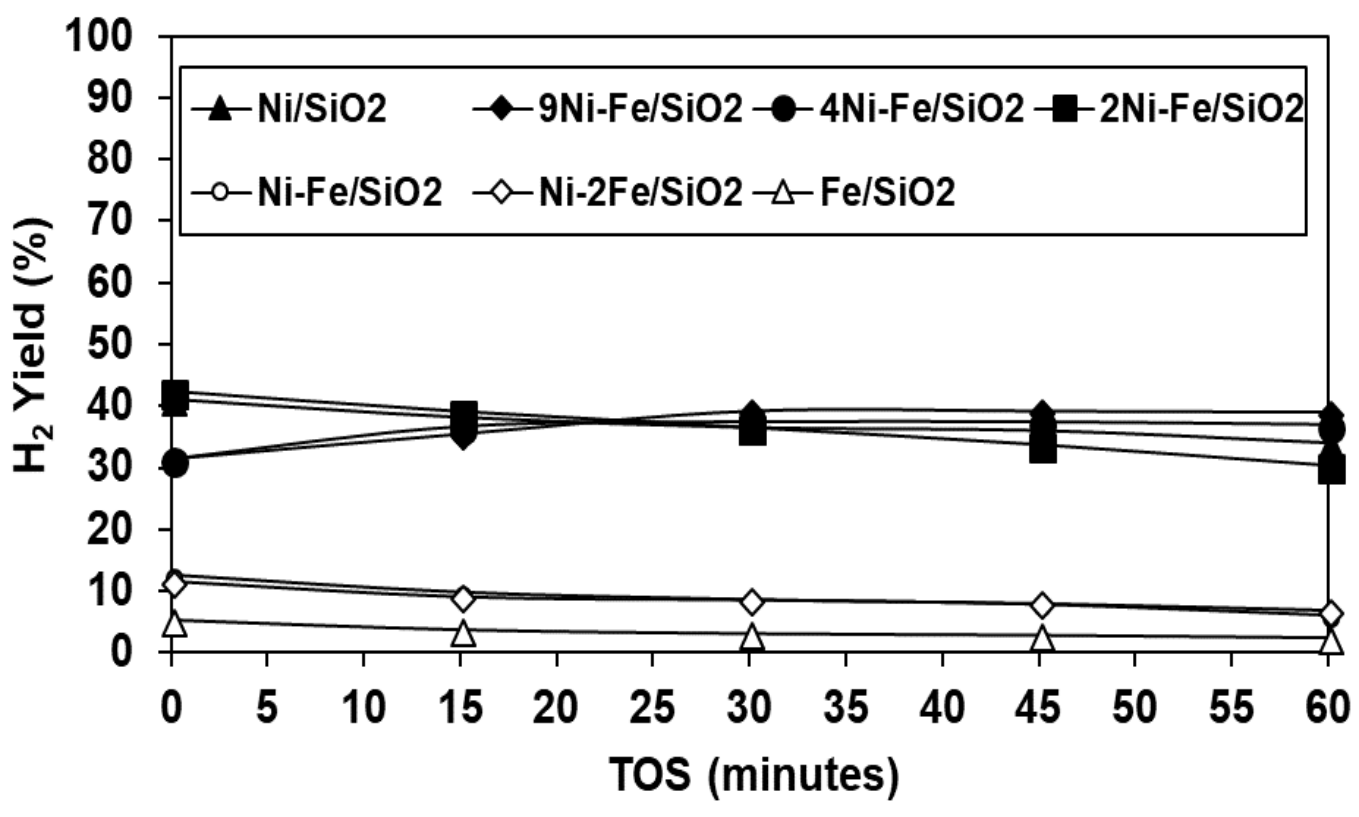

Figure 3-11. $\mathrm{H}_{2}$ yield over $\mathrm{Ni}-\mathrm{Fe} / \mathrm{SiO}_{2}$ catalysts with various mole ratios 


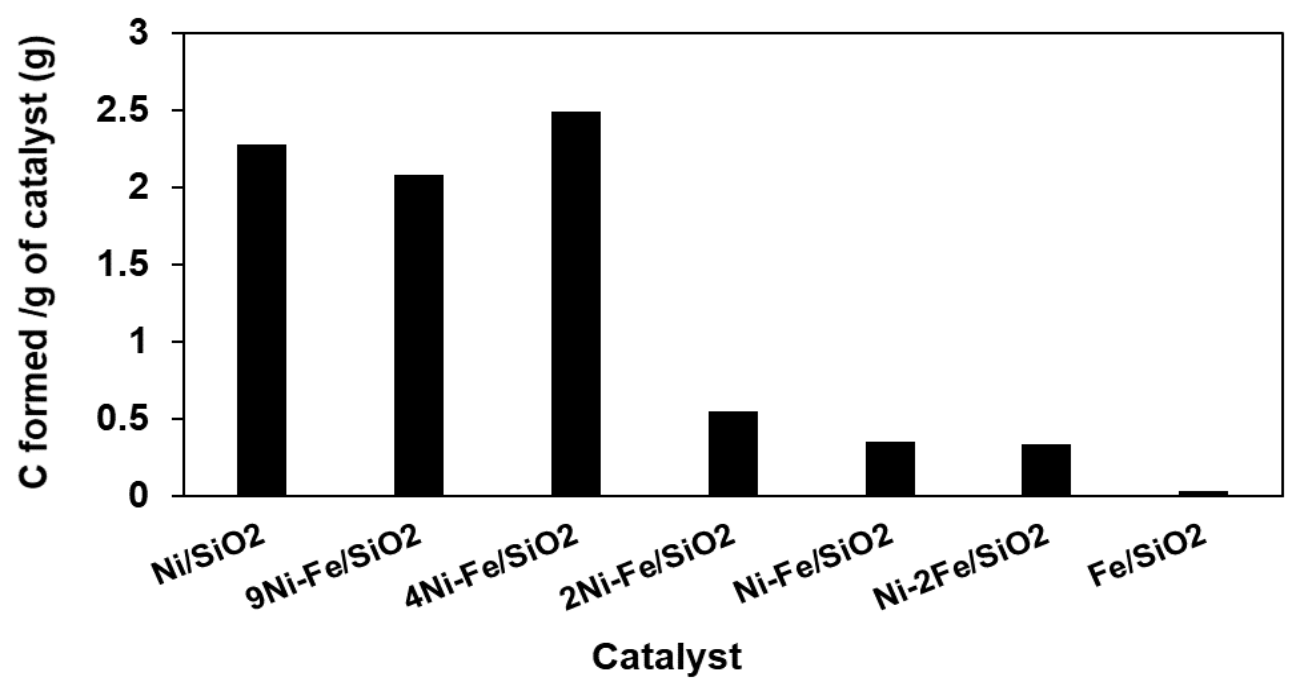

Figure 3-12. Amount of carbon formed over $\mathrm{Ni}-\mathrm{Fe} / \mathrm{SiO}_{2}$ catalysts with various mole ratios

\subsubsection{Ni-Co bimetallic catalysts}

Methane conversion over mono- and bimetallic Ni and Co catalysts are studied in this section. Under the reaction conditions, $\mathrm{Co} / \mathrm{SiO}_{2}$ showed a $\mathrm{CH}_{4}$ conversion of $37 \%$ but deactivated to $9 \%$ within 5 min of reaction (Figure 3-13). Ni/SiO 2 already showed good initial activity but had a gradual deactivation during the course of the reaction. Hence, to improve the activity of $\mathrm{Co} / \mathrm{SiO}_{2}$ and to increase the stability of $\mathrm{Ni} / \mathrm{SiO}_{2}$ catalysts, we have prepared a bimetallic combination of $\mathrm{Ni}-\mathrm{Co}$ catalysts with various $\mathrm{Ni}$ : Co mole ratios, such as $9 \mathrm{Ni}-1 \mathrm{Co}$, $4 \mathrm{Ni}-1 \mathrm{Co}, 2 \mathrm{Ni}-1 \mathrm{Co}, 1 \mathrm{Ni}-1 \mathrm{Co}, 2 \mathrm{Ni}-1 \mathrm{Co}$, and $1 \mathrm{Ni}-9 \mathrm{Co}$, on a $\mathrm{SiO}_{2}$ support. Similar to $\mathrm{Ni}-\mathrm{Fe}$ catalysts, the Ni-Co combination also showed a maximum conversion of $55 \%$. Ni-Co catalysts such as $9 \mathrm{Ni}-1 \mathrm{Co}, 4 \mathrm{Ni}-1 \mathrm{Co}, 2 \mathrm{Ni}-1 \mathrm{Co}$, and $1 \mathrm{Ni}-1 \mathrm{Co}$ showed a similar initial conversion of $50-55 \%$ and retained their activity throughout the reaction. A catalyst with higher Co content was also tested, $1 \mathrm{Ni}-9 \mathrm{Co}$, which showed an initial conversion of $53 \%$, but within 15 minutes of reaction. It was observed that the high $\mathrm{Ni}$ content in the $\mathrm{Ni}-\mathrm{Co}$ bimetallic catalyst exhibited higher conversion and the presence of $\mathrm{Co}$ as a promoter contributed to increasing the catalyst lifetime. 
$\mathrm{H}_{2}$ yield was found to be in the range of $38-40 \%$ for catalysts with higher Ni content such as $9 \mathrm{Ni}-1 \mathrm{Co} / \mathrm{SiO} 2,4 \mathrm{Ni}-1 \mathrm{Co} / \mathrm{SiO}$, and $2 \mathrm{Ni}-1 \mathrm{Co} / \mathrm{SiO}$, whereas $\mathrm{Co} / \mathrm{SiO}_{2}$ and $1 \mathrm{Ni}-9 \mathrm{Co} / \mathrm{SiO}_{2}$ showed only an initial $\mathrm{H}_{2}$ yield of $28-33 \%$ which reduced to $6 \%$ within 5 min of reaction (Figure 3-14). The amount of carbon formed per gram of catalyst was calculated, which was found to be approximately $2.3-2.5 \mathrm{~g}$ over $9 \mathrm{Ni}-1 \mathrm{Co} / \mathrm{SiO}{ }_{2}, 4 \mathrm{Ni}-1 \mathrm{Co} / \mathrm{SiO}_{2}$, and $2 \mathrm{Ni}-1 \mathrm{Fe} / \mathrm{SiO}{ }_{2}$ and was $0.15-0.27 \mathrm{~g}$ for $\mathrm{Co} / \mathrm{SiO}_{2}$ and $1 \mathrm{Ni}-9 \mathrm{Co} / \mathrm{SiO}_{2}$ catalysts (Figure 3-15).

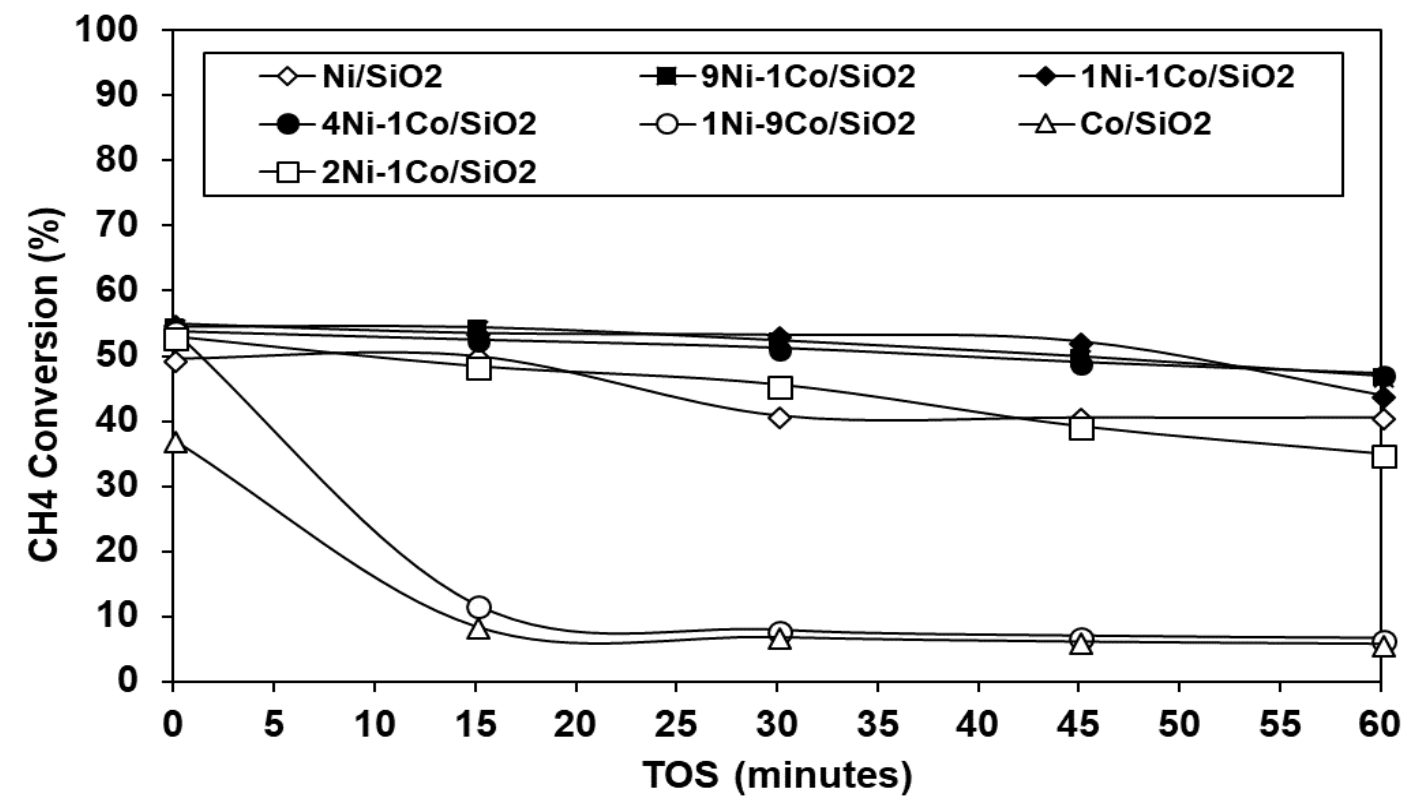

Figure 3-13. Methane decomposition over $\mathrm{Ni}-\mathrm{Co} / \mathrm{SiO}_{2}$ catalysts with various mole ratios

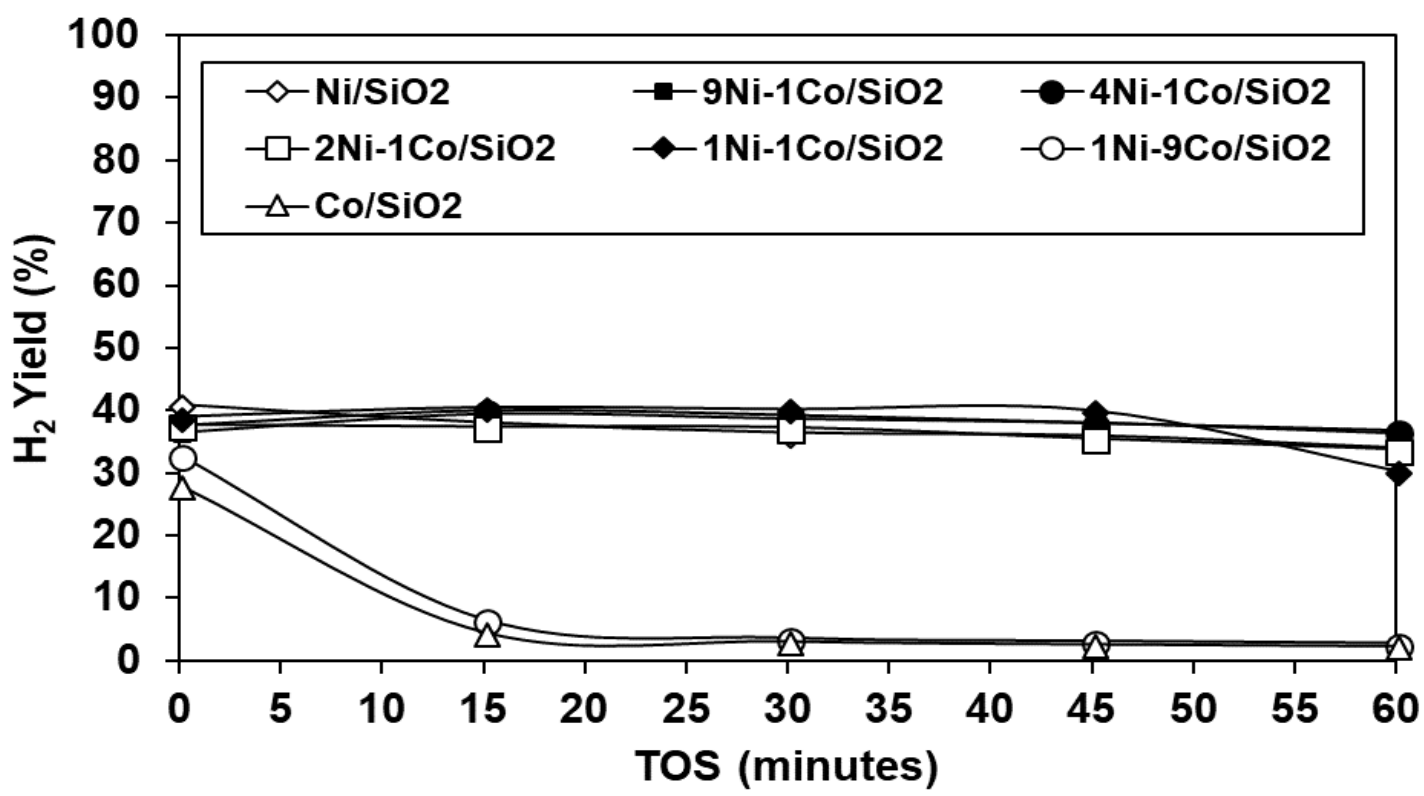

Figure 3-14. $\mathrm{H}_{2}$ yield over $\mathrm{Ni}-\mathrm{Co} / \mathrm{SiO}_{2}$ catalysts with various mole ratios 


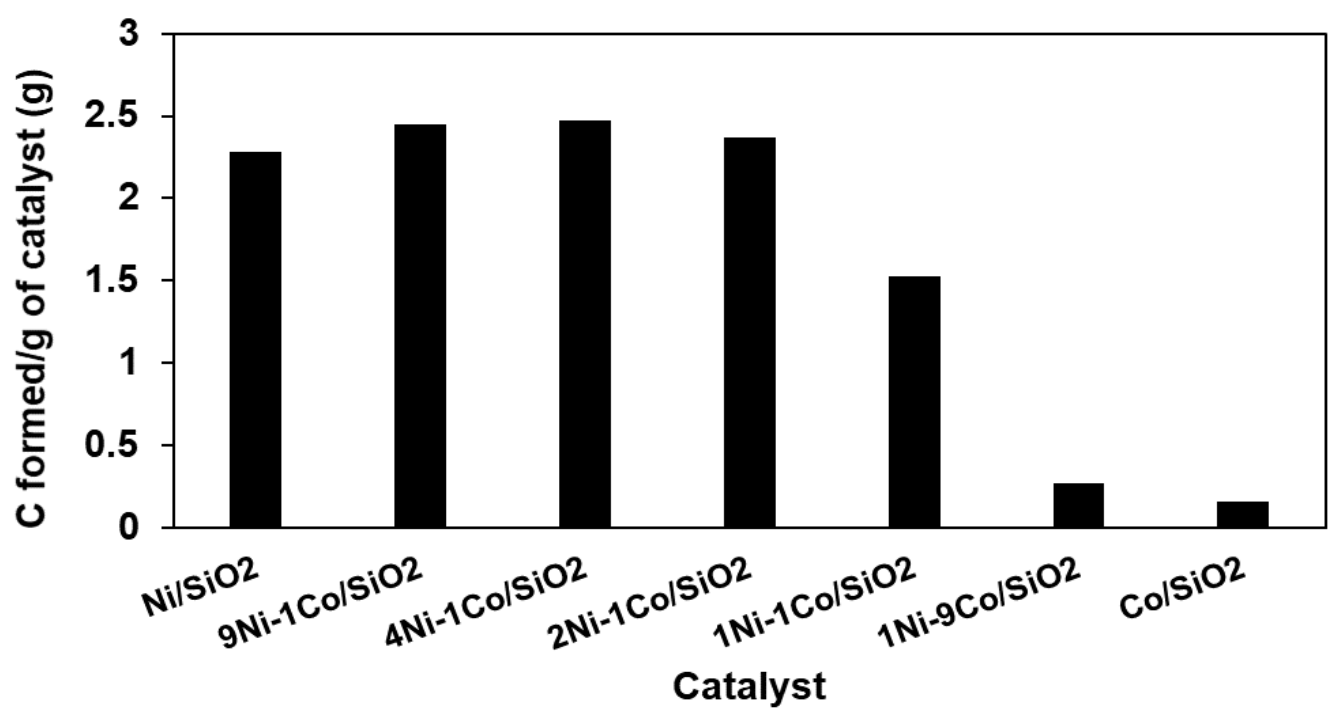

Figure 3-15. Amount of carbon formed over $\mathrm{Ni}-\mathrm{Co} / \mathrm{SiO}_{2}$ catalysts with various mole ratios

\subsubsection{Fe-Co bimetallic catalysts}

Methane decomposition reactions over mono- and bimetallic Fe-Co catalysts are explained in this section (Figure 3-16). Bimetallic $\mathrm{Fe}-\mathrm{Co} / \mathrm{SiO}_{2}$ catalysts were prepared with various $\mathrm{Fe}$ : Co mole ratios, such as $9 \mathrm{Fe}-1 \mathrm{Co}, 2 \mathrm{Fe}-1 \mathrm{Co}, 1 \mathrm{Fe}-1 \mathrm{Co}, 1 \mathrm{Fe}-2 \mathrm{Co}$, and $1 \mathrm{Fe}-9 \mathrm{Co}$, over a $\mathrm{SiO}_{2}$ support. It was observed that $1 \mathrm{Fe}-2 \mathrm{Co} / \mathrm{SiO}_{2}$ showed the highest $\mathrm{CH}_{4}$ conversion of $51 \%$ but has undergone drastic deactivation and showed a conversion of only $15 \%$ at $60 \mathrm{~min}$

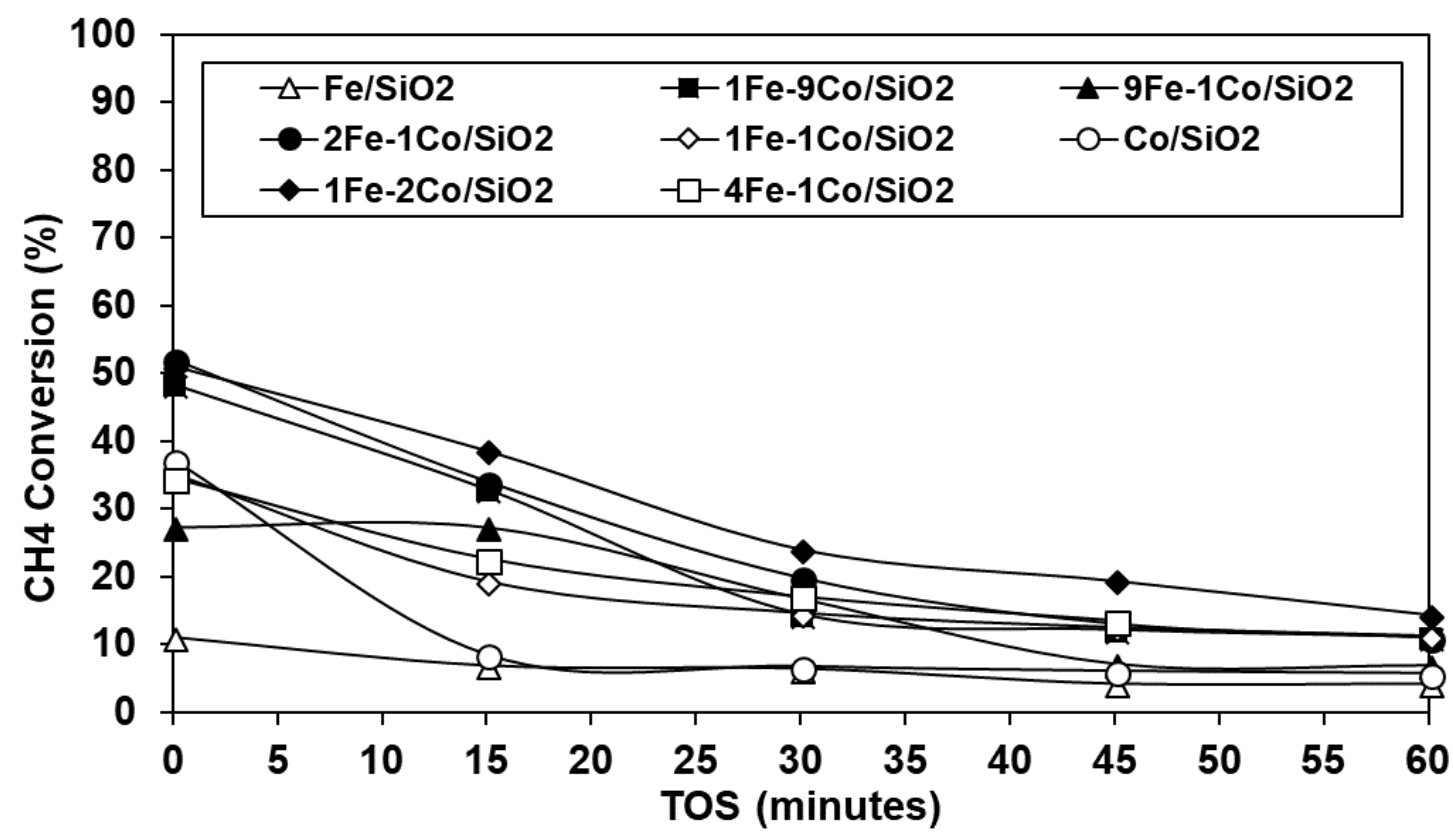

Figure 3-16. Methane decomposition over $\mathrm{Fe}-\mathrm{Co} / \mathrm{SiO}_{2}$ catalysts with various mole ratios 
of reaction. Among the catalysts studied here, even though the activity is not excellent, the stability was better over $9 \mathrm{Fe}-1 \mathrm{Co} / \mathrm{SiO}_{2}$ and $4 \mathrm{Fe}-1 \mathrm{Co} / \mathrm{SiO}_{2}$. The maximum $\mathrm{H}_{2}$ yield of $29 \%$ (Figure 3-17) and carbon yield of $0.8 \mathrm{~g}$ was observed with $1 \mathrm{Fe}-2 \mathrm{Co} / \mathrm{SiO}_{2}$ (Figure 3-18).

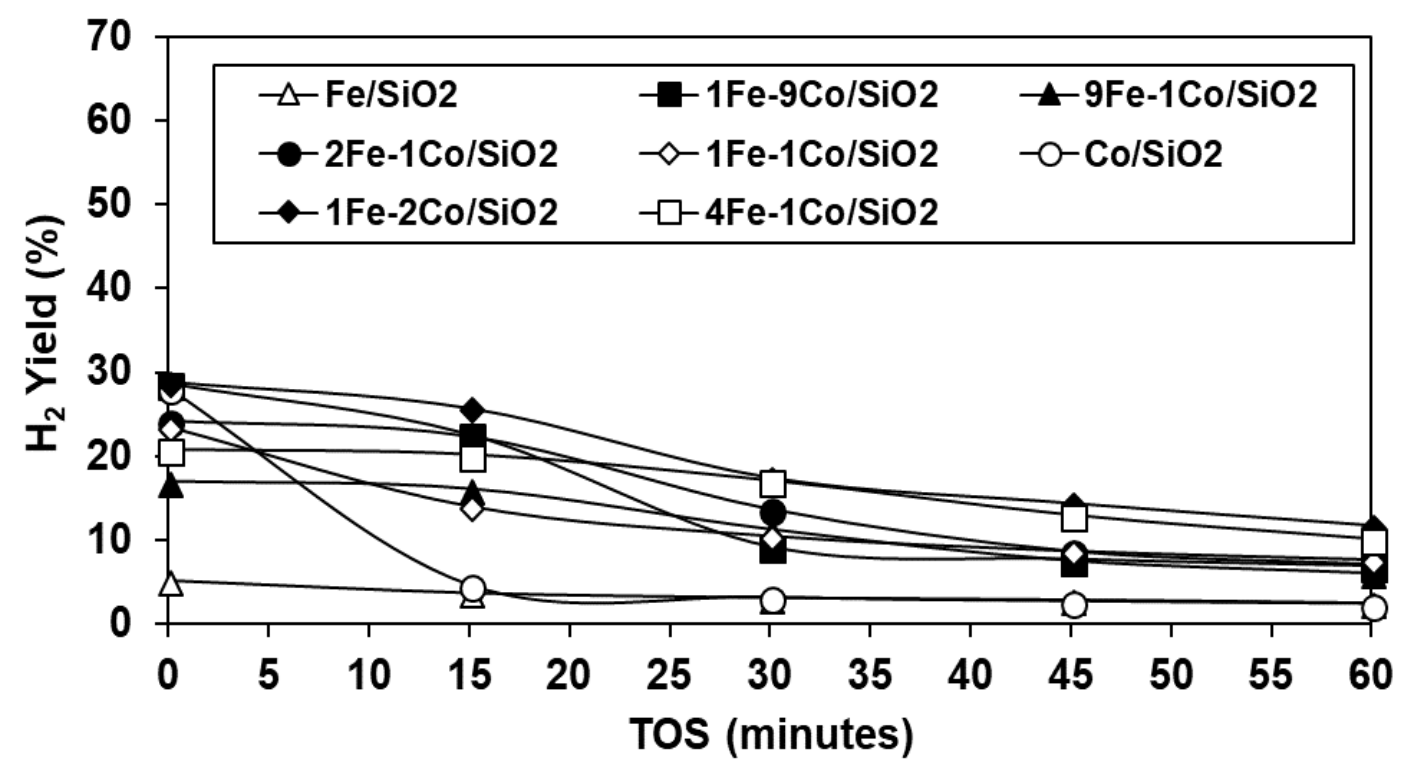

Figure 3-17. $\mathrm{H}_{2}$ yield over $\mathrm{Fe}-\mathrm{Co} / \mathrm{SiO} 2$ catalysts with various mole ratios

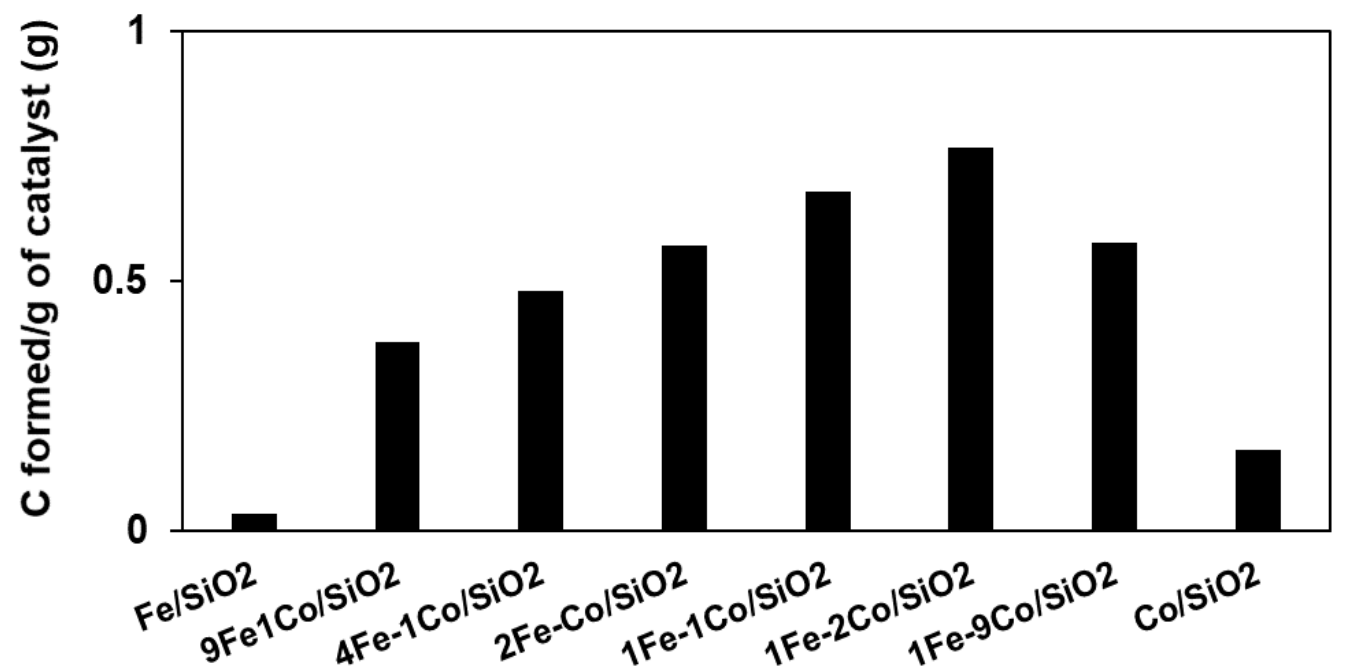

Catalyst

Figure 3-18. Amount of carbon formed over $\mathrm{Fe}-\mathrm{Co} / \mathrm{SiO}_{2}$ catalysts with various mole ratios 


\subsection{Comparison of Activities of Reduced and Oxidized Catalysts}

Generally, transition metal catalysts $(\mathrm{Ni} / \mathrm{Fe} / \mathrm{Co})$ were used in their reduced forms $\left(\mathrm{Ni}^{0} / \mathrm{Fe}^{0} / \mathrm{Co}^{0}\right)$ for the $\mathrm{CNT}$ synthesis by methane decomposition. However, some literature reports have shown that it may not be necessary to pre-reduce the catalysts for the reaction [71]. For our experiments we have used oxidized and reduced forms of $9 \mathrm{Ni}-1 \mathrm{Fe} / \mathrm{SiO}_{2}$ catalyst since it has shown a very good activity for methane decomposition reactions (Figure 3-19). Both the catalysts showed a similar activity at the initial point of the reaction (ca. 60\%). The activity shown by the oxidized catalyst can be due to the in-situ reduction of the lattice oxygen which supplied energy for methane decomposition, which is an endothermic process. In addition, there can be an in-situ consumption of $\mathrm{H}_{2}$ formed, which assisted the shifting of the equilibrium towards the methane decomposition step or carbon formation [71]. As we have shown before (Figure $3-10$ ), the reduced $9 \mathrm{Ni}-1 \mathrm{Fe} / \mathrm{SiO}_{2}$ catalyst showed a constant activity till the end of the reaction but the oxidized form of the catalyst was gradually deactivated from $60 \%$ to $41 \%$ conversion rate in $60 \mathrm{~min}$ of reaction time. The amount of carbon formed per gram of catalyst was also in the range of $2.2-2.5 \mathrm{~g}$ for both catalysts. In summary, in our case even though the oxidized form of the catalyst catalyzed the methane decomposition to carbon and $\mathrm{H}_{2}$, the stability of the catalysts was lesser compared to that of their reduced forms. This may be because reduced forms are stabilized due to their alloy phases, which helps to increase their lifetime and stability. 


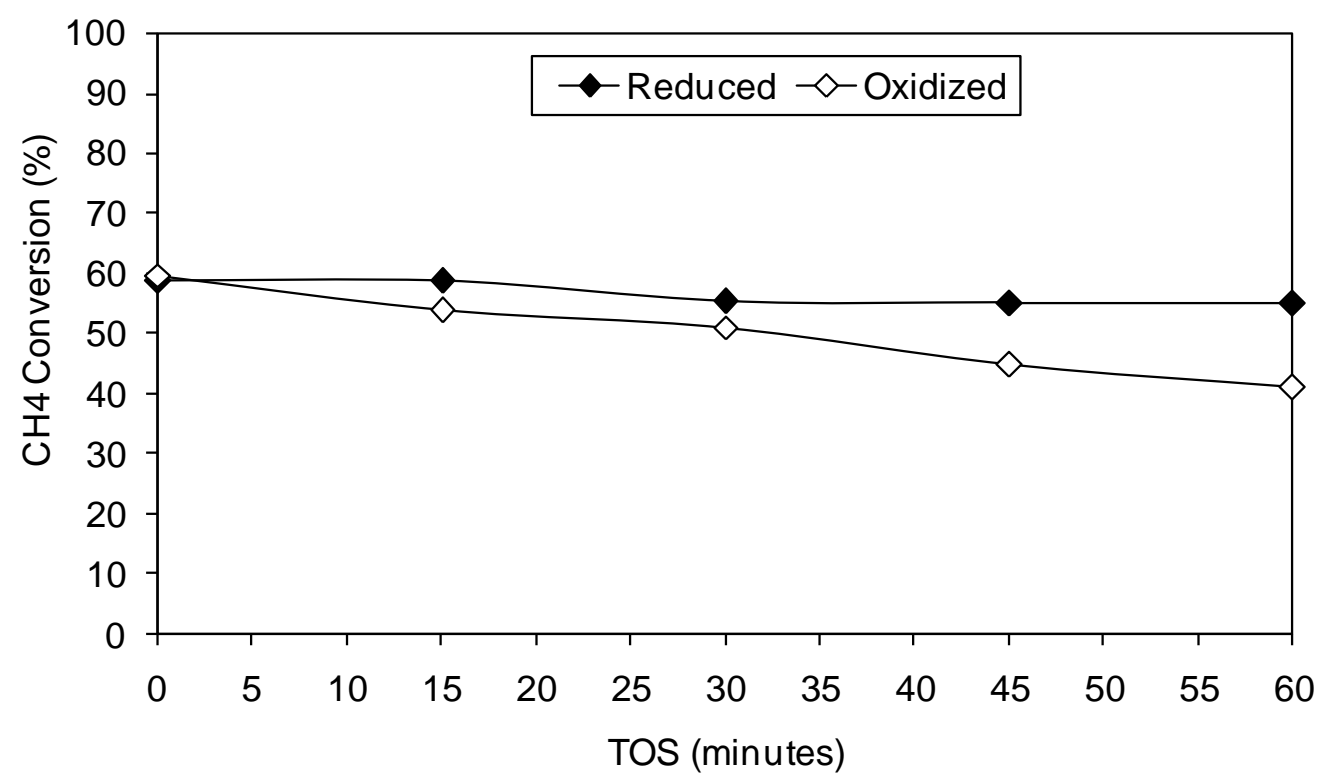

Figure 3-19. Methane decomposition over reduced and oxidized forms of $9 \mathrm{Ni}-1 \mathrm{Fe} / \mathrm{SiO}_{2}$

\subsection{The Properties of Carbon Nanotube}

\subsubsection{XRD analysis}

All the XRD patterns of the used catalysts showed the presence of graphitic carbon by a very intense peak (002) at $2 \theta=26.2^{\circ}$ (Figures 3-4,5, and 6). All characteristic metal and alloy peaks were also identified and the d-spacing of CNTs were calculated using Bragg's equation $(\mathrm{d}=\lambda / 2 \operatorname{Sin} \theta)$ for the graphitic peak, which was found to be $0.34 \mathrm{~nm}$ and it correlates well with distance of two graphite layers $(0.3354 \mathrm{~nm})$ implying the high crystallinity of the carbon grown over all the catalysts. The intensity of the (002) diffraction peak is related to the degree of graphitization (Figure 3-20). So lower intensity represents the less graphitized material [72]. In the case of $\mathrm{Ni}-\mathrm{Fe}$ bimetallic catalysts, we can observe that $9 \mathrm{Ni}-1 \mathrm{Fe} / \mathrm{SiO}_{2}$ or the bimetallic catalyst with highest Ni content produced CNT with the highest degree of graphitization and its degree decreases with increase in the amount of $\mathrm{Fe}$ in the catalyst. The degree of graphitization for $\mathrm{Ni}-\mathrm{Fe}$ catalyst was in the order $9 \mathrm{Ni}-1 \mathrm{Fe}>\mathrm{Ni}>4 \mathrm{Ni}-1 \mathrm{Fe}>2 \mathrm{Ni}-1 \mathrm{Fe}>1 \mathrm{Ni}-2 \mathrm{Fe}>\mathrm{Fe}$. For Ni-Co bimetallic catalyst, $4 \mathrm{Ni}-1 \mathrm{Co} / \mathrm{SiO}_{2}$ produced $\mathrm{CNT}$ with highest graphitization degree and was in the order $4 \mathrm{Ni}-1 \mathrm{Co}>2 \mathrm{Ni}-1 \mathrm{Co}>\mathrm{Ni}>1 \mathrm{Ni}-1 \mathrm{Co}=9 \mathrm{Ni}-1 \mathrm{Co}>1 \mathrm{Ni}-9 \mathrm{Co}>\mathrm{Co}$. For $\mathrm{Fe}-\mathrm{Co}$ 
catalysts the overall intensity of the CNT peak was very less compared to Ni-based catalysts and the whole set of Fe-Co catalysts produced less graphitized CNT. Hence in general Ni content in the bimetallic catalyst is influencing the degrees of graphitization of the carbon formed during the methane decomposition reaction.
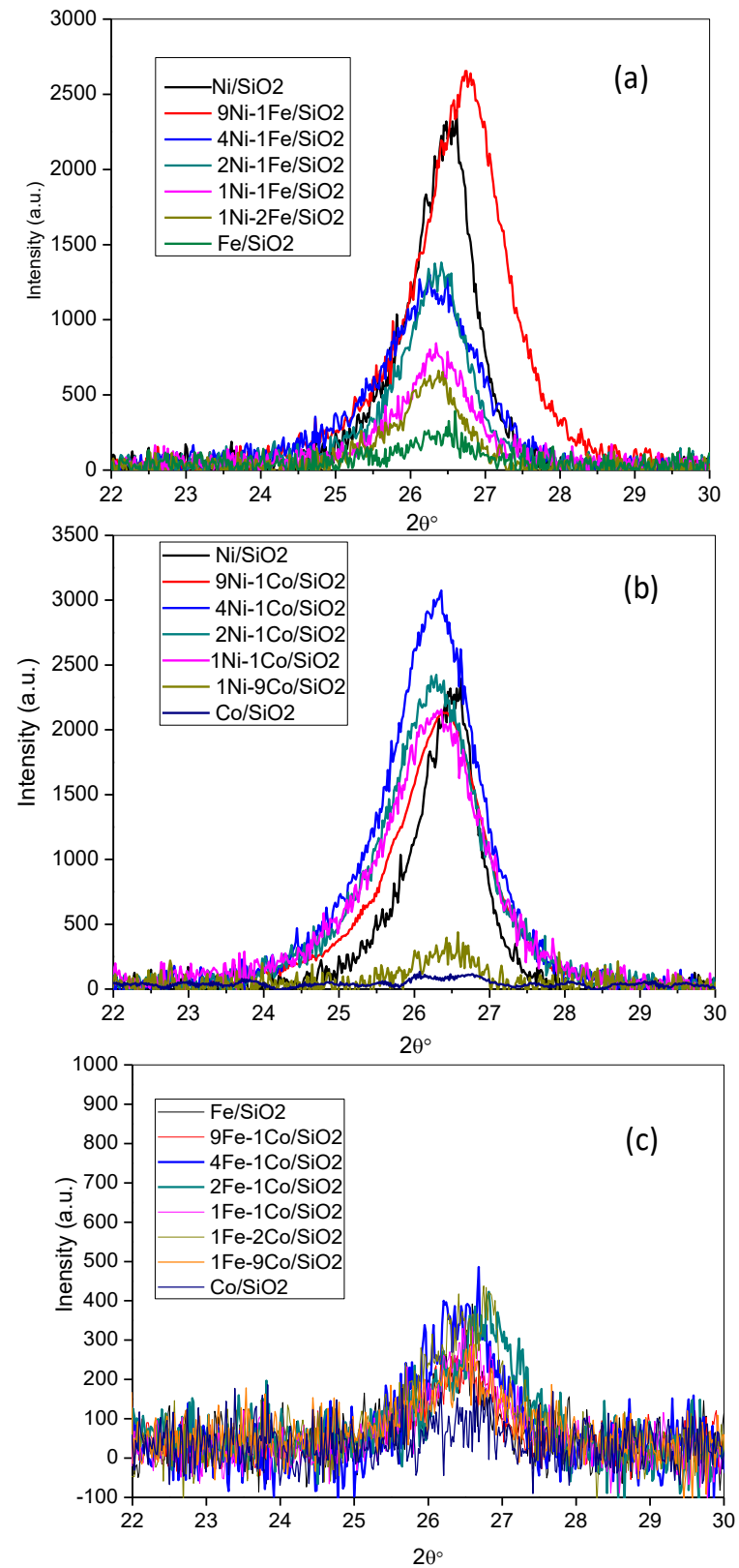

Figure 3-20. XRD pattern of CNT over mono and bimetallic (a) Ni-Fe (b) Ni-Co and (c) Fe-Co catalysts 


\subsubsection{Thermogravimetric analysis (TGA)}

Thermal stability of CNT was studied using thermogravimetric analysis. Spent catalysts such as $9 \mathrm{Ni}-1 \mathrm{Fe} / \mathrm{SiO}_{2}, 9 \mathrm{Ni}-1 \mathrm{Co} / \mathrm{SiO}_{2}$, and $1 \mathrm{Fe}-2 \mathrm{Co} / \mathrm{SiO}_{2}$ were studied since these catalysts showed better activity than the rest of the catalysts (Figure 3-21). These catalysts were analyzed in $2 \% \mathrm{O}_{2} / \mathrm{He}$ atmosphere. The carbon deposited on the catalyst, amorphous or CNT decomposes into $\mathrm{CO}$ or $\mathrm{CO}_{2}$ in $\mathrm{O}_{2}$ atmosphere. In certain cases, there is a possibility that the catalyst species also get oxidized under these conditions. It was observed that there was no thermal degradation in the temperature range of $200-350^{\circ} \mathrm{C}$, which corresponds to the amorphous carbon. Hence, we could confirm that the carbon deposited on these catalysts is not amorphous in nature. The weight loss observed in all catalysts corresponds to the CNT deposited on the catalyst. From TGA analysis of CNTs it is understood that higher the degradation temperature of carbon, the higher its stability. For $9 \mathrm{Ni}-1 \mathrm{Fe} / \mathrm{SiO}_{2}$, the thermal degradation started at around $500{ }^{\circ} \mathrm{C}$ and there was a weight loss of $75 \%$. For $9 \mathrm{Ni}-1 \mathrm{Co} / \mathrm{SiO}_{2}$ degradation started from $450{ }^{\circ} \mathrm{C}$ with a weight loss of $70 \%$. For $1 \mathrm{Fe}-2 \mathrm{Co} / \mathrm{SiO}_{2}$ catalyst, there was a slight increase in weight, $2 \%$ at a temperature of around $350{ }^{\circ} \mathrm{C}$, which can be due to the oxidation of Fe present in the catalyst. At around $410{ }^{\circ} \mathrm{C}$, a weight loss of $45-50 \%$ was observed, which was lower than $9 \mathrm{Ni}-1 \mathrm{Fe} / \mathrm{SiO}_{2}$ and $9 \mathrm{Ni}-\mathrm{Co} / \mathrm{SiO}_{2}$ catalysts. The onset temperatures for $9 \mathrm{Ni}-1 \mathrm{Fe} / \mathrm{SiO}_{2}, 9 \mathrm{Ni}-\mathrm{Co} / \mathrm{SiO}_{2}$, and $1 \mathrm{Fe}-$ $2 \mathrm{Co} / \mathrm{SiO}_{2}$ are $500-660{ }^{\circ} \mathrm{C}, 450-650{ }^{\circ} \mathrm{C}$ and $410-640{ }^{\circ} \mathrm{C}$ respectively., which indicates that the CNT formed over $9 \mathrm{Ni}-1 \mathrm{Fe} / \mathrm{SiO}_{2}$ catalyst has a higher degree of graphitization, as well as lesser defects on the CNT's [73]. Hence it can be concluded that a smaller difference in the onset and end temperature indicates the formation of highly graphitized CNT's. It is also understood that there is no amorphous carbon formation during methane decomposition over these catalysts and the amount of carbon formed over $1 \mathrm{Fe}-2 \mathrm{Co} / \mathrm{SiO}_{2}$ is the minimum in comparison to $9 \mathrm{Ni}$ $1 \mathrm{Fe} / \mathrm{SiO}_{2}$ and $9 \mathrm{Ni}-\mathrm{Co} / \mathrm{SiO}_{2}$ catalysts. 


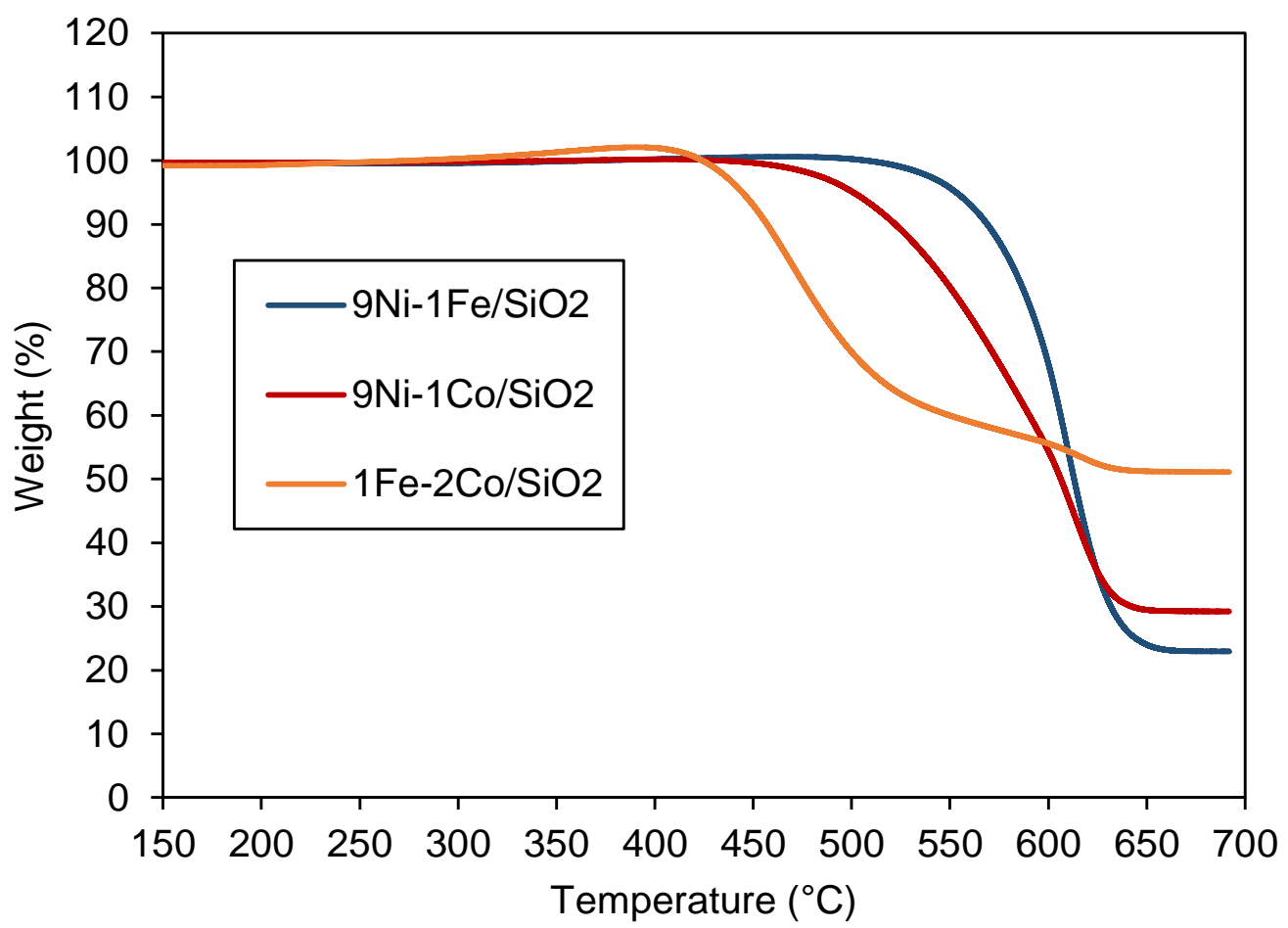

Figure 3-21. Thermal stability of carbon deposited over $9 \mathrm{Ni}-1 \mathrm{Fe} / \mathrm{SiO}_{2}, 9 \mathrm{Ni}-1 \mathrm{Co} / \mathrm{SiO}_{2}$ and $1 \mathrm{Fe}-2 \mathrm{Co} / \mathrm{SiO}_{2}$ catalysts

\subsubsection{Raman analysis}

Raman spectroscopic study was performed to measure the quality and crystallinity of carbon (Figures 3-22,23,24). Two distinct bands were observed for all the catalysts, the D-band at $1336 \mathrm{~cm}^{-1}$ and G-band at $1570 \mathrm{~cm}^{-1}$. D-band represents either disordered or amorphous carbon and G-band represents the crystalline carbon [4]. From TGA analysis it was confirmed that there is no amorphous carbon deposited on the catalyst (Figure 3-21). Hence the intensity ratio, $\mathrm{I}_{\mathrm{D}} / \mathrm{I}_{\mathrm{G}}$ explains the graphitization degree and the crystallinity of the CNTs [74]. The catalyst having lowest $\mathrm{I}_{\mathrm{D}} / \mathrm{I}_{\mathrm{G}}$ carbon with the highest crystallinity. For Ni-Fe catalysts (Figure 3-22) we could observe that $\mathrm{I}_{\mathrm{D}} / \mathrm{I}_{\mathrm{G}}$ value was lowest for $9 \mathrm{Ni}-\mathrm{Fe}, 4 \mathrm{Ni}-1 \mathrm{Fe}, \mathrm{Ni}, 1 \mathrm{Ni}-2 \mathrm{Fe}$ showed similar $\mathrm{I}_{\mathrm{D}} / \mathrm{I}_{\mathrm{G}}$ value $(0.829-0.874)$, better crystallinity than $2 \mathrm{Ni}-\mathrm{Fe}, 1 \mathrm{Ni}-1 \mathrm{Fe}$ and $\mathrm{Fe}$ catalysts with higher $\mathrm{I}_{\mathrm{D}} / \mathrm{I}_{\mathrm{G}}$ value (0.944-1.26). Raman spectra for Ni-Co catalysts (Figure 3-23) shows that 9Ni-1Co gave most crystalline CNT with lowest $\mathrm{I}_{\mathrm{D}} / \mathrm{I}_{\mathrm{G}}(0.765)$, while $\mathrm{Ni}, 4 \mathrm{Ni}-\mathrm{Co}$, 1Ni-1Co showed similar $\mathrm{I}_{\mathrm{D}} / \mathrm{I}_{\mathrm{G}}(0.868-0.883)$. We didn’t observe any distant bands for Co and 
1Ni-9Co catalysts since the amount of CNT formed for these catalysts were lesser than the detection limits. For $4 \mathrm{Fe}-1 \mathrm{Co}$ crystallinity calculated was the highest, $\left(\mathrm{I}_{\mathrm{D}} / \mathrm{I}_{\mathrm{G}}=0.896\right)$, while $\mathrm{Fe}$, 9Fe-1Co, $2 \mathrm{Fe}-1 \mathrm{Co}$ showed similar $\mathrm{I}_{\mathrm{D}} / \mathrm{I}_{\mathrm{G}}(0.983-0.99)$. Remaining catalyst ratios such as $1 \mathrm{Fe}-$ $1 \mathrm{Co}, \mathrm{Fe}-2 \mathrm{Co} \mathrm{Fe}-\mathrm{Co}$ catalysts $4 \mathrm{Fe}-1 \mathrm{Co}$ formed $\mathrm{CNT}$ with highest $\mathrm{I}_{\mathrm{D}} / \mathrm{I}_{\mathrm{G}}(1.019-1042)$ due to the low crystallinity of the CNT formed (Figure 3-24).

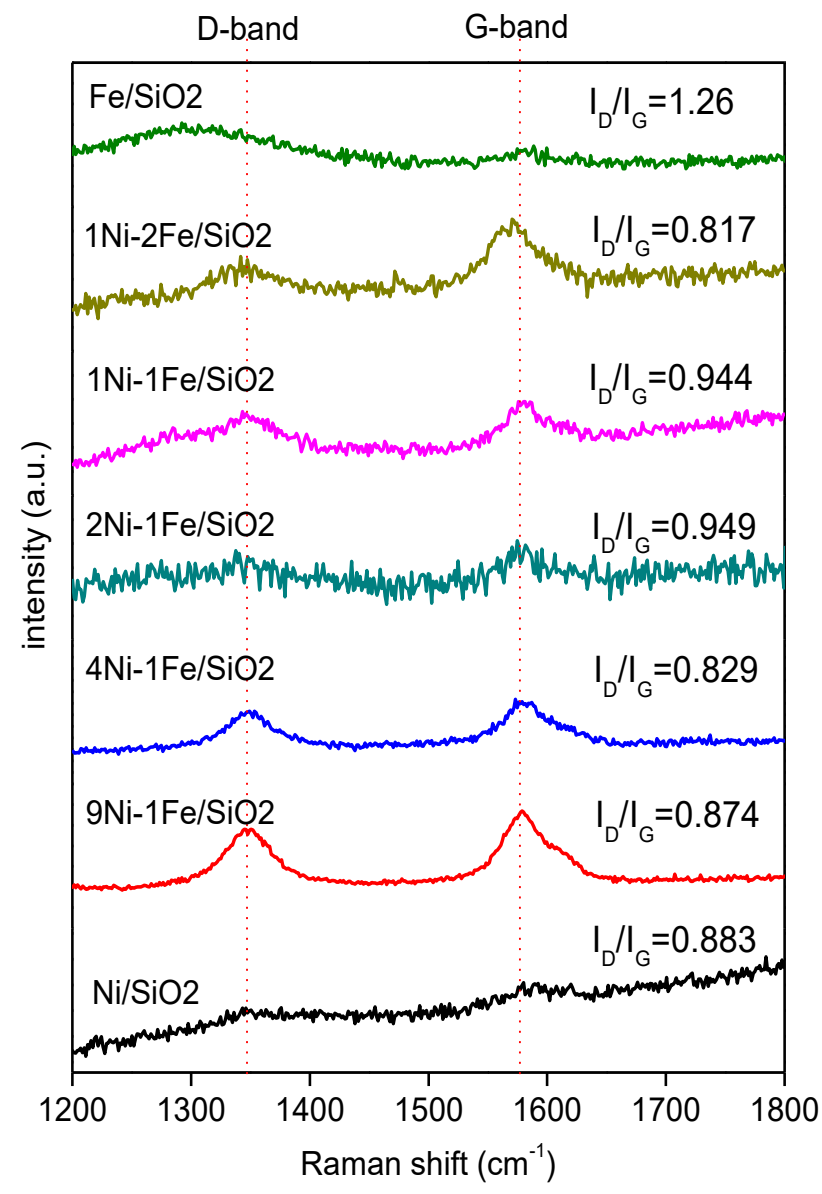

Figure 3-22. Raman spectra of CNT over mono and bimetallic Ni-Fe catalysts 


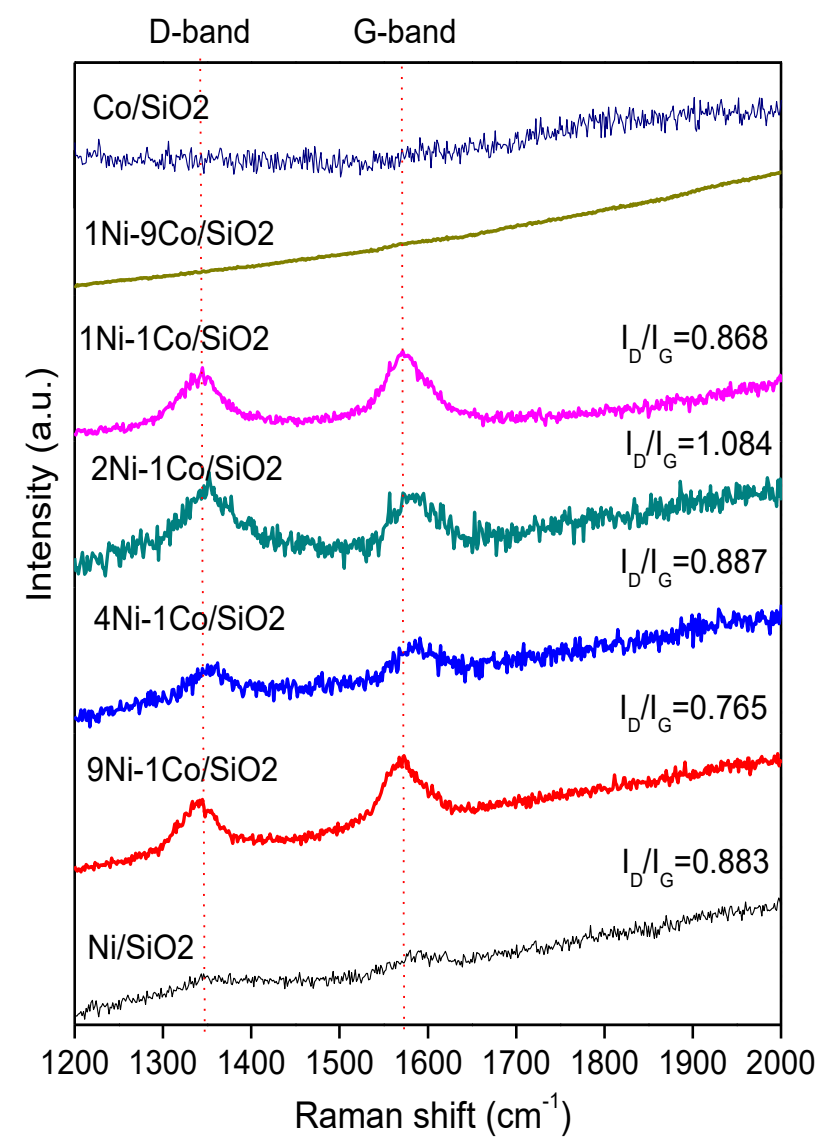

Figure 3-23. Raman spectra of CNT over mono and bimetallic Ni-Co catalysts

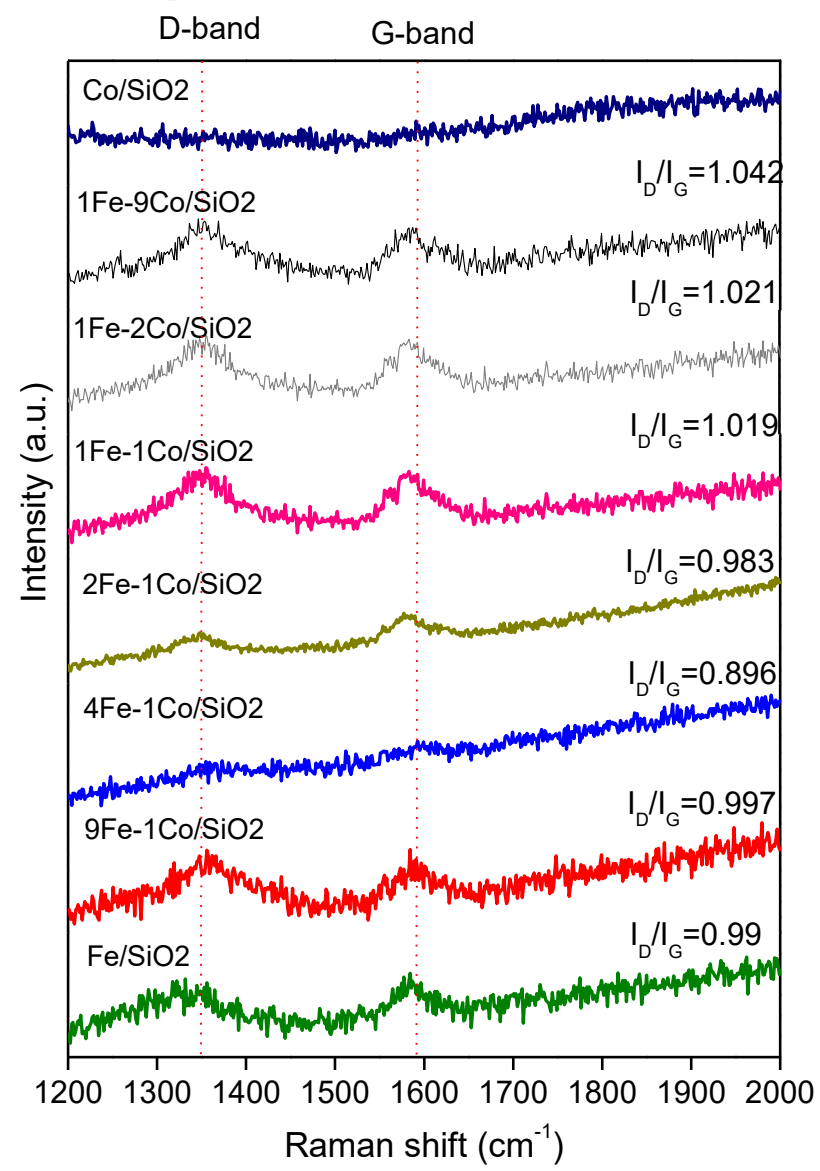

Figure 3-24. Raman spectra of CNT over mono and bimetallic Fe-Co catalysts 


\subsubsection{TEM analysis}

Structural morphology, particle size, diameter and growth of CNT was studied using TEM technique. This analysis was limited to the certain catalysts from each set of bimetallic catalysts (Ni-Fe/Ni-Co and Fe-Co) which showed the best performance and stable nature in the methane decomposition reactions (Figure 3-25). Hence TEM analysis was performed over the used 9Ni$1 \mathrm{Fe} / \mathrm{SiO}_{2}, 9 \mathrm{Ni}-1 \mathrm{Co} / \mathrm{SiO}_{2}$, and $1 \mathrm{Fe}-2 \mathrm{Co} / \mathrm{SiO}_{2}$ catalysts. It was observed that the $\mathrm{CNT}$ formed in our experiments are found to be MWCNT due to large crystallite size of active site metal nanoparticles, confirmed by XRD techniques. The CNTs formed over all these catalysts showed a very crowded dense population with entangled fibers. CNT's were growing in random directions due to space competition of growth [73]. The length of the CNT depends on the duration of the process, hence to obtain longer filaments, the duration of the reaction has to be extended.

For $9 \mathrm{Ni}-1 \mathrm{Fe} / \mathrm{SiO}_{2}$ catalyst it was observed that most of the CNT formed where of 100 $120 \mathrm{~nm}$. The wall of the tube was very thick with graphite layer stacked very closely. Another interesting feature was that when Ni-Fe catalyst was used we could observe a "tip growth" of CNT whereas the CNT grows it takes the metal nanoparticle along with it and is situated at the tip of the CNT. The shape of the metal nanoparticle was "cone or pear-shaped" tapered towards the end and forms an angle with the tubular axis. From HR-TEM it was observed that the wall of CNT formed were of "fishbone or herringbone" structure in which the graphene layers are stacked obliquely with respect to the fiber axis. In these type of CNT, the graphite planes are formed at an angle to the axis of the nanotube and hence there is a higher possibility for the edge plane sites/defects in these CNTs [75]. For 9Ni-1Co catalyst, MWCNT's with 50-60 nm diameters were formed, also with a metal nanoparticle at the tip. But from HR-TEM it was observed that the wall of these CNT's had a parallel morphology (graphite planes arranged parallel to the tubular axis). But certain fibers formed in these catalysts didn't have metal 
nanoparticles at the tip and gave a mixture of tip and base grown CNT's. HR-TEM has confirmed the parallel morphology of the CNT wall for these catalysts.
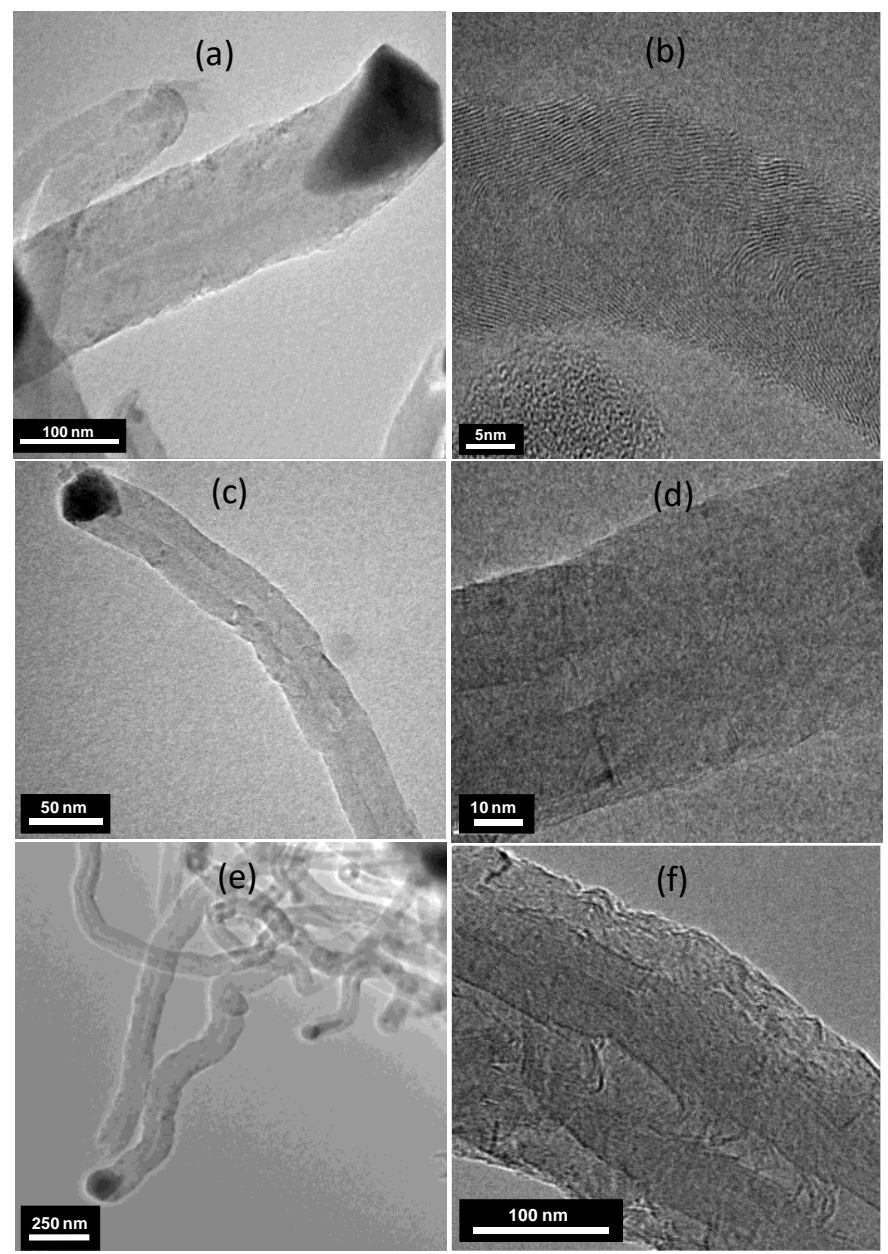

Figure 3-25. Growth of carbon filaments over $(\mathrm{a}, \mathrm{b}) 9 \mathrm{Ni}-1 \mathrm{Fe} / \mathrm{SiO} 2$, (c,d) $9 \mathrm{Ni}-1 \mathrm{Co} / \mathrm{SiO}_{2}$, $(\mathrm{e}, \mathrm{f}) 1 \mathrm{Fe}-2 \mathrm{Co} / \mathrm{SiO}_{2}$ catalysts after methane decomposition

\subsection{Conclusion}

The catalytic activity, selectivity and stability of mono and bimetallic Ni/Fe/Co based catalysts was demonstrated for the methane decomposition study. The novelty in our work is that we investigated the performance of transition metal catalysts $(\mathrm{Ni} / \mathrm{Fe} / \mathrm{Co})$ for the synthesis of both tip and base grown CNT's by methane decomposition. We have synthesized mono and bimetallic $\mathrm{Ni} / \mathrm{Fe} / \mathrm{Co}$ catalysts by dry impregnation over $\mathrm{SiO}_{2}$ support. The XRD and $\mathrm{H}_{2}$-TPR analysis confirmed the formation of the alloy in the 
bimetallic catalysts. The effect of catalyst composition on methane decomposition and CNT growth was studied over various mole ratios of $\mathrm{Ni}, \mathrm{Fe}$ and Co-based catalysts. High Ni content in the Ni-Fe bimetallic catalyst exhibited higher methane conversion and also contributed to an increase in the stability of the catalyst. In the case of Ni-Co bimetallic catalyst also higher $\mathrm{Ni}$ content exhibited higher conversion and Co present in the catalyst contributed to increase the catalyst lifetime. Among Fe-Co catalysts, the activity towards methane conversion was comparatively lower than $\mathrm{Ni}-\mathrm{Fe}$ and $\mathrm{Ni}-\mathrm{Co}$ catalysts. The quality of the CNT's formed over these catalysts was analysed using XRD, TGA, Raman and TEM techniques. From XRD analysis it was understood that Ni content in the bimetallic catalyst controls the degrees of graphitization of the carbon formed. From TGA analysis it was concluded that there was no amorphous carbon formation during methane decomposition over these catalysts. The quality of the carbon, that is the degree of crystallinity was calculated using Raman analysis. TEM analysis helped to understand the different morphologies of the CNT, diameter, wall type (parallel or fish bone type) and also the growth mechanism such as tip and base growth on different catalysts. It was understood that Ni-Fe catalyst selectively produced tip grown CNT's with fishbone wall pattern, while Ni-Co and Fe-Co catalysts formed a mixture of tip and base grown CNT's with parallel wall pattern. 


\section{Chapter 4 Fe-Based Catalysts with Different Supports}

There are only very few studies that have correlated the catalyst properties (Fe loaded on $\mathrm{SiO}_{2}, \mathrm{Al}_{2} \mathrm{O}_{3}$, or $\mathrm{H}-\mathrm{ZSM}-5$ ) which would help us to produce $\mathrm{CO}_{\mathrm{x}}$-free $\mathrm{H}_{2}$ and synthesize base grown CNT's by methane decomposition. Base grown CNT's can be easily harvested and help in better regeneration of the catalyst. Hence in the present work, we prepared Fe-based catalysts on various supports and also investigated the strong metal interaction responsible for base grown CNT's. In addition to this, we have attempted to separate and purify the CNT's from the catalyst surface and also analyzed its purity.

\subsection{Mechanism of Base Grown of CNT}

Stronger interaction of metal nanoparticles with support (obtuse angle of metal with the support) facilitates "base growth" of carbon nanotubes [5]. Decomposition of methane and carbon diffusion in the initial stage is similar to that of the tip growth model but the carbon precipitated is unable to push away the metal upwards. Hence the precipitated carbon is compelled to emerge out from the upper side of the metal (away from the support surface). It is also known from the literature that the high surface energy of the metal nanoparticles is reduced by the deposition of the graphene planes, which are strongly chemisorbed on to the metal surface. A graphitic cap is formed on the metal nanoparticle which is lifted upwards, during the further deposition of carbon fragments. Hence, we observe a hollow carbon nanotube growing away from the metal nanoparticle, which is still attached to the support or a base growth of carbon nanotubes [76]. 


\subsubsection{Synthesis of base grown CNT's}

Based on previous literature we found out that Fe based catalysts generated base grown CNT's. Also, from our catalyst screening studies using mono and bimetallic $\mathrm{Ni} / \mathrm{Fe} / \mathrm{Co}$ catalysts we have discovered that $60 \% \mathrm{Fe} / \mathrm{SiO}_{2}$ was selectively forming base grown CNT's during methane decomposition. Hence, we chose $\mathrm{Fe} / \mathrm{SiO}_{2}$ catalysts for our preliminary work. From our experimental results we found that $\mathrm{Fe} / \mathrm{SiO}_{2}$ had a very low methane conversion, $11 \%$ and eventually got reduced to $4 \%$ at $\mathrm{T}=650{ }^{\circ} \mathrm{C}$, $\mathrm{TOS}$ $=60$ minutes, GHSV $=42000 \mathrm{~h}^{-1}$. As a result, the reaction conditions have to be optimized to obtain better conversion and yields of $\mathrm{H}_{2}$ and CNT.

\subsection{Catalyst Preparation}

Fe-based catalysts were prepared by incipient wetness technique. $\mathrm{Fe}\left(\mathrm{NO}_{3}\right)_{2} .9 \mathrm{H}_{2} \mathrm{O}$ (Alfa Aesar) was selected as a metal precursor and $\mathrm{Al}_{2} \mathrm{O}_{3}$ (Alfa Aesar), fumed $\mathrm{SiO}_{2}$ (CAB-O-SILEH-5 untreated $\left.\mathrm{SiO}_{2}, \mathrm{CABOT}\right)$, and ZSM-5 (CBV-5524G, $\mathrm{SiO}_{2} / \mathrm{Al}_{2} \mathrm{O}_{3}$ mole ratio = 50, Zeolyst International company) were utilized as catalyst supports. The $40 \mathrm{wt} \%$ supports were impregnated with an aqueous solution of iron nitrate corresponding to $60 \mathrm{wt} \%$. The samples were dried in air at $130^{\circ} \mathrm{C}$ overnight, and then calcined at $500^{\circ} \mathrm{C}$ for $10 \mathrm{~h}$. The obtained catalysts were designed as $\mathrm{Fe} / \mathrm{Al}_{2} \mathrm{O}_{3}, \mathrm{Fe} / \mathrm{SiO}_{2}$, and $\mathrm{Fe} / \mathrm{H}-\mathrm{ZSM}-5$. Besides the $60 \mathrm{wt} \% \mathrm{Fe} / \mathrm{Al}_{2} \mathrm{O}_{3}$, we also prepared the 10 and $30 \mathrm{wt} \% \mathrm{Fe} / \mathrm{Al}_{2} \mathrm{O}_{3}$ for loading comparison. These catalysts were designated as $\mathrm{X} \mathrm{Fe} /$ support ( $\mathrm{X}$ means weight \% loading of Fe).

\subsection{Effect of Catalysts on Methane Decomposition}

\subsubsection{Methane conversion}

The catalytic activity of Fe-catalysts on various supports $\left(\mathrm{Fe} / \mathrm{Al}_{2} \mathrm{O}_{3}, \mathrm{Fe} / \mathrm{H}-\mathrm{ZSM}-5\right.$, and $\mathrm{Fe} / \mathrm{SiO}_{2}$ ) for methane decomposition at $700^{\circ} \mathrm{C}$ were studied. The main products from methane 
decomposition are hydrogen gas and carbon or CNT. Quantification of $\mathrm{H}_{2}$ was performed using GC analysis while carbon deposited on the catalyst was calculated based on the weight gain of the catalyst after the reaction and was characterized using different techniques. Growth rates of CNT on two supports suggest that the catalyst morphology can greatly affect the activity of the catalysts because in CCVD the rate determining step is the adsorption and decomposition of hydrocarbons by catalyst particles. From our experiments, we observed that the conversion of $\mathrm{CH}_{4}$ depends on the types of support, such as $\mathrm{Al}_{2} \mathrm{O}_{3}, \mathrm{SiO}_{2}$, and H-ZSM-5. For Fe/H-ZSM-5 and $\mathrm{Fe} / \mathrm{SiO}_{2}$ catalysts, the initial conversions were $50 \%$ and $36 \%$ respectively (Figure $4-1$ (a)). Even though $\mathrm{Fe} / \mathrm{Al}_{2} \mathrm{O}_{3}$ had a higher initial conversion (58\%) the activity reduced (20\%) within 1h of reaction. On Fe/H-ZSM-5 catalyst the initial conversion was also high (50\%) but there was a drastic decrease in its activity to $15 \%$ in $15 \mathrm{~min}$. but it maintained this conversion rate throughout the reaction time. Similarly, $\mathrm{Fe} / \mathrm{SiO}_{2}$ with an initial conversion of $36 \%$ got reduced to $9 \%$. Above results indicated that supports had a significant impact on the catalysts. The support enhanced the performance of the catalyst activity, as the effect on electronic properties or structure was related to the interaction between metals and supports [77-79].

The support of H-ZSM-5 consisted of $\mathrm{Al}_{2} \mathrm{O}_{3}$ and $\mathrm{SiO}_{2}$, and it showed the lower conversion than pure $\mathrm{Al}_{2} \mathrm{O}_{3}$ support. Acidic $\mathrm{Al}_{2} \mathrm{O}_{3}$ support had higher activity than with $\mathrm{SiO}_{2}$. Also, the structure of the zeolite was a three-dimensional cage and channel, which was more complex and constrained. The cage structure of ZSM-5 might inhibit the distribution of Fe oxide particles. Hence, carbon may deposit on both the external surfaces of the catalyst and the internal channel, which induce the CNT deposition in the internal channel, and evenly block pores structure and the catalytic deactivation.

Catalytic activity for methane conversions of $\mathrm{Fe} / \mathrm{Al}_{2} \mathrm{O}_{3}$ was with time on stream over various Fe loading. The Fe loading were $10 \mathrm{wt} \%, 30 \mathrm{wt} \%$, and $60 \mathrm{wt} \%$ which initial conversion were $18 \%, 40 \%$, and $58 \%$, respectively. The conversion increased as the loading of Fe 
increased but after $15 \mathrm{~min}$, all catalysts began to deactivate gradually. The conversion of $30 \%$ $\mathrm{Fe} / \mathrm{Al}_{2} \mathrm{O}_{3}$ catalyst dropped from $40 \%$ to $18 \%$ and $10 \% \mathrm{Fe} / \mathrm{Al}_{2} \mathrm{O}_{3}$ decreased to $10 \%$. In addition, $60 \% \mathrm{Fe} / \mathrm{SiO}_{2}$ and $30 \% \mathrm{Fe} / \mathrm{Al}_{2} \mathrm{O}_{3}$ had similar methane conversion and hence supports clearly affect the activity of catalysts (Figure 4-1 (b)).
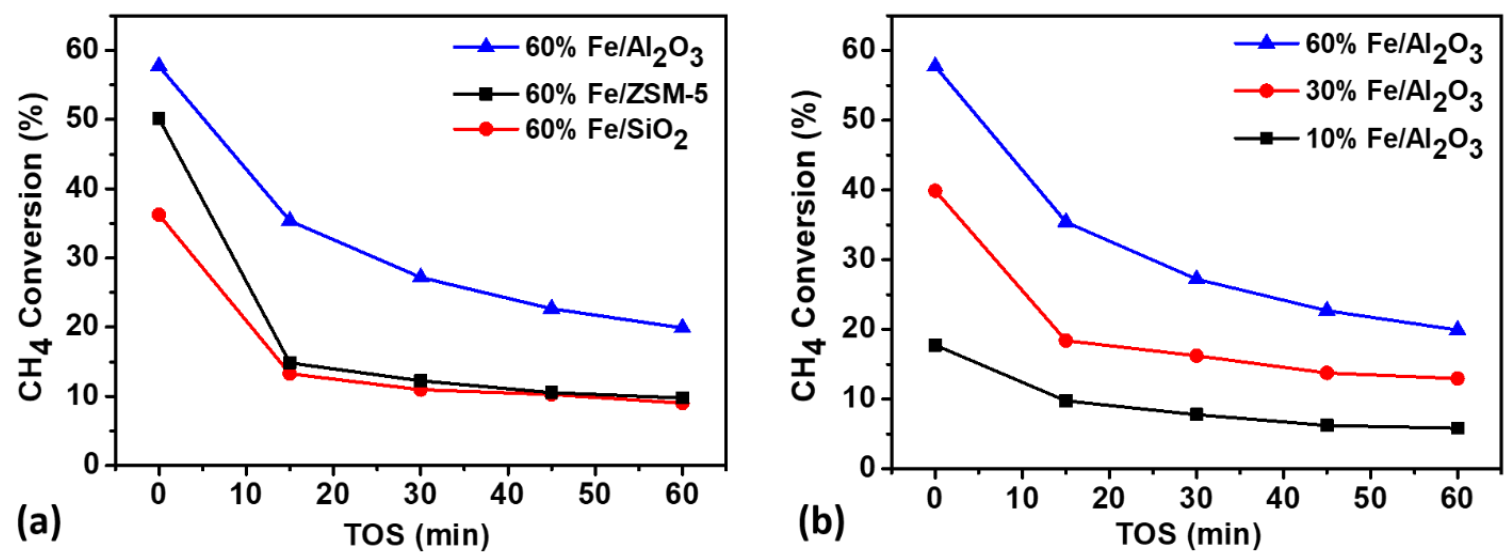

Figure 4-1. Methane decomposition over Fe-based catalysts at $700^{\circ} \mathrm{C}$ (a) different supports and (b) different loading of $\mathrm{Fe} / \mathrm{Al}_{2} \mathrm{O}_{3}$

\subsubsection{Yield of hydrogen and carbon}

During decomposition of methane, hydrogen and carbon were produced. The hydrogen yield for each catalyst was similar to the methane conversion which followed the similar trend. $60 \% \mathrm{Fe} / \mathrm{Al}_{2} \mathrm{O}_{3}$ indicate the highest initial yield of hydrogen at ca. $26 \% .60 \% \mathrm{Fe} / \mathrm{ZSM}-5$ and $60 \% \mathrm{Fe} / \mathrm{SiO}_{2}$ were $24 \%$ and $20 \%$, respectively, as presented in Figure 4-2(a). Moreover, different loading of $\mathrm{Fe}, 30 \% \mathrm{Fe} / \mathrm{Al}_{2} \mathrm{O}_{3}$ and $10 \% \mathrm{Fe} / \mathrm{Al}_{2} \mathrm{O}_{3}$ were $16 \%$ and $2 \%$, respectively, as shown in Figure 4-2 (b). All yield of carbon was an approximate measurement with per gram of catalyst after the reaction. Figure 4-2 (c) showed carbon formation of $60 \% \mathrm{Fe} / \mathrm{Al}_{2} \mathrm{O}_{3}$ was $0.785 \mathrm{~g} / \mathrm{g}$ of catalyst the highest carbon amount and 60\% Fe/ZSM-5 and $60 \% \mathrm{Fe} / \mathrm{SiO}_{2}$ were both at around $0.1 \mathrm{~g} / \mathrm{g}$ of catalyst. In addition, the yield of $30 \% \mathrm{Fe} / \mathrm{Al}_{2} \mathrm{O}_{3}$ and $10 \% \mathrm{Fe} / \mathrm{Al}_{2} \mathrm{O}_{3}$ were ca. 0.38 and $0.07 \mathrm{~g} / \mathrm{g}$ of cat., respectively, as shown in Figure 4-2(d). 

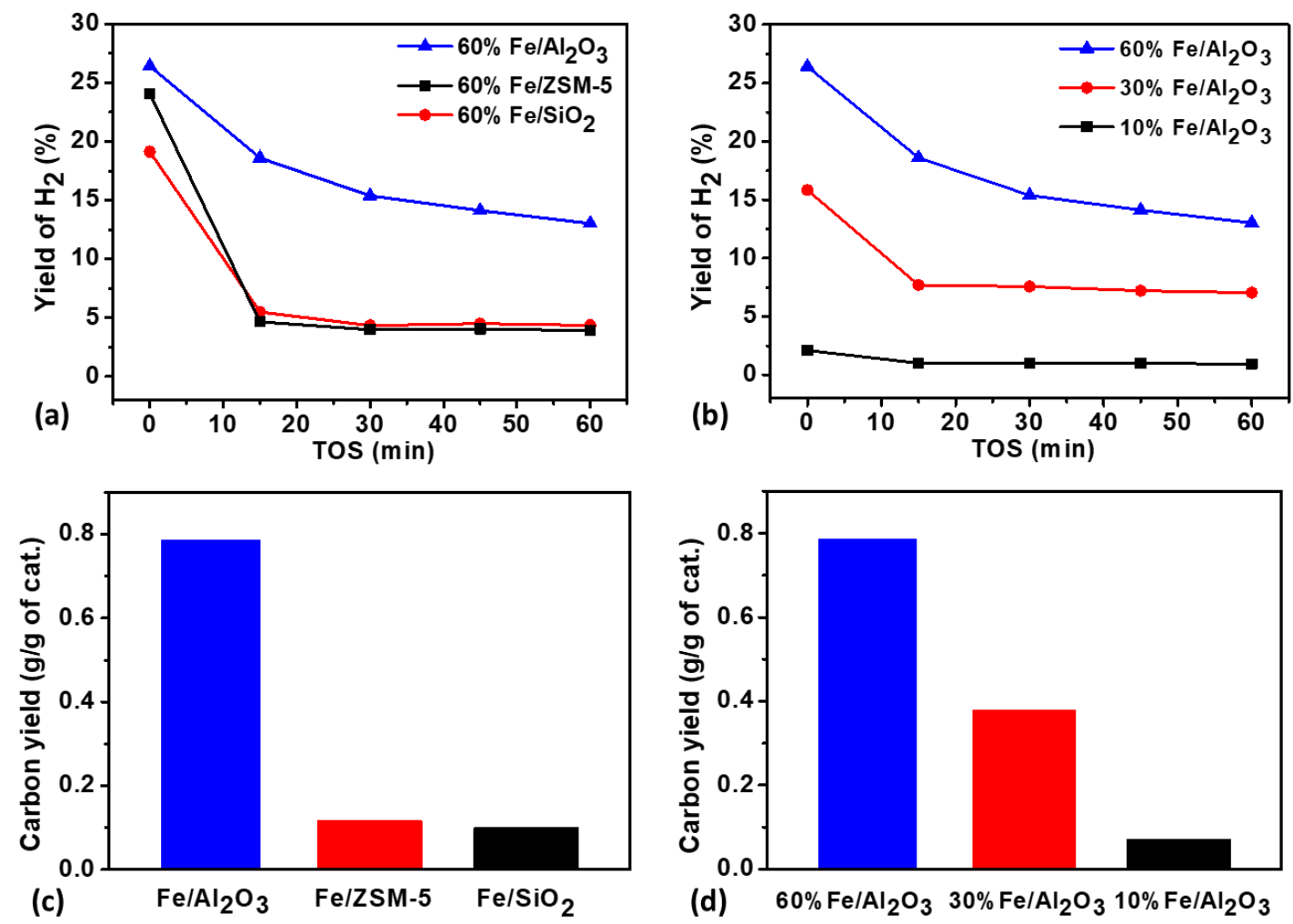

Figure 4-2. The yield of hydrogen and carbon deposited over Fe-based catalysts at $700^{\circ} \mathrm{C}$ (a) and (c) different support; (b) and (d) different loading of $\mathrm{Fe} / \mathrm{Al}_{2} \mathrm{O}_{3}$

\subsection{Properties of Catalysts and CNTs}

\subsubsection{XRD analysis}

Characteristic peaks observed in the XRD pattern confirmed the metallic state of Fe catalyst after reduction (Figure 4-3 (a)). The characteristic peaks of Fe were at $2 \theta=44.9^{\circ}$ as well as additional peaks were at $65.2^{\circ}$ and $82.5^{\circ}$. On the other hand, the characteristic peaks of $\mathrm{Al}_{2} \mathrm{O}_{3}$ and H-ZSM-5 supports were not visible in the XRD chromatogram due to the high loading of $\mathrm{Fe}\left(60 \mathrm{wt} \%\right.$ over the supports $(40 \mathrm{wt} \%)$. In addition, $\mathrm{SiO}_{2}$ support was an amorphous phase and showed the much broader peak adding up to the background. While $\mathrm{Al}_{2} \mathrm{O}_{3}$ support can be observed in the lower loading amount of $\mathrm{Fe}\left(10 \mathrm{wt} \% \mathrm{Fe}\right.$ loaded over $\left.90 \mathrm{wt} \% \mathrm{Al}_{2} \mathrm{O}_{3}\right)$ with characteristic peaks at $2 \theta=37.5^{\circ}, 45.8^{\circ}$, and $67.05^{\circ}$ corresponding to $\gamma-\mathrm{Al}_{2} \mathrm{O}_{3}$. After the methane decomposition, the used catalysts were investigated by XRD analysis. It was observed 
that for the spent catalysts XRD diffractogram showed peaks at $2 \theta=37.8^{\circ}, 42.9^{\circ}, 43.8^{\circ}, 44.6^{\circ}$, $44.9^{\circ}, 45.9^{\circ}, 48.6^{\circ}$, and $49.1^{\circ}$ which are the characteristic peaks for $\mathrm{Fe}_{3} \mathrm{C}$ species (JCPDS Card no. 65-2413), as shown in Figure 4-3 (b). But in our previous studies on methane decomposition over nickel-based catalyst, we did not observe any evidence from XRD for the formation of $\mathrm{Ni}_{\mathrm{x}} \mathrm{C}$ as intermediate species. Carbide cycle mechanism can be used to explain the observation $[81,82]$. During methane decomposition $\mathrm{Fe}_{3} \mathrm{C}$ is formed on the free surface fragment of the catalytic particle. Since $\mathrm{Fe}_{3} \mathrm{C}$ is metastable, it is decomposed to graphitized carbon and $\alpha$ species of $\mathrm{Fe}$. The $\alpha-\mathrm{Fe}$ along with $\mathrm{Fe}_{3} \mathrm{C}$ facilitates methane decomposition and carbon growth. These active Fe species are deactivated by the encapsulation of these species by the growing carbon filament resulting in the fragmentary dispersion of Fe particles. The carbon deposited on the spent catalyst as proven by the XRD peak at $2 \theta=26.3^{\circ}$ which was assigned to characteristic peak of graphitic carbon (002) and indicating the CNTs have a good degree of graphitization. The carbon peak of $10 \% \mathrm{Fe} / \mathrm{Al}_{2} \mathrm{O}_{3}$ was weak due to its low conversion.
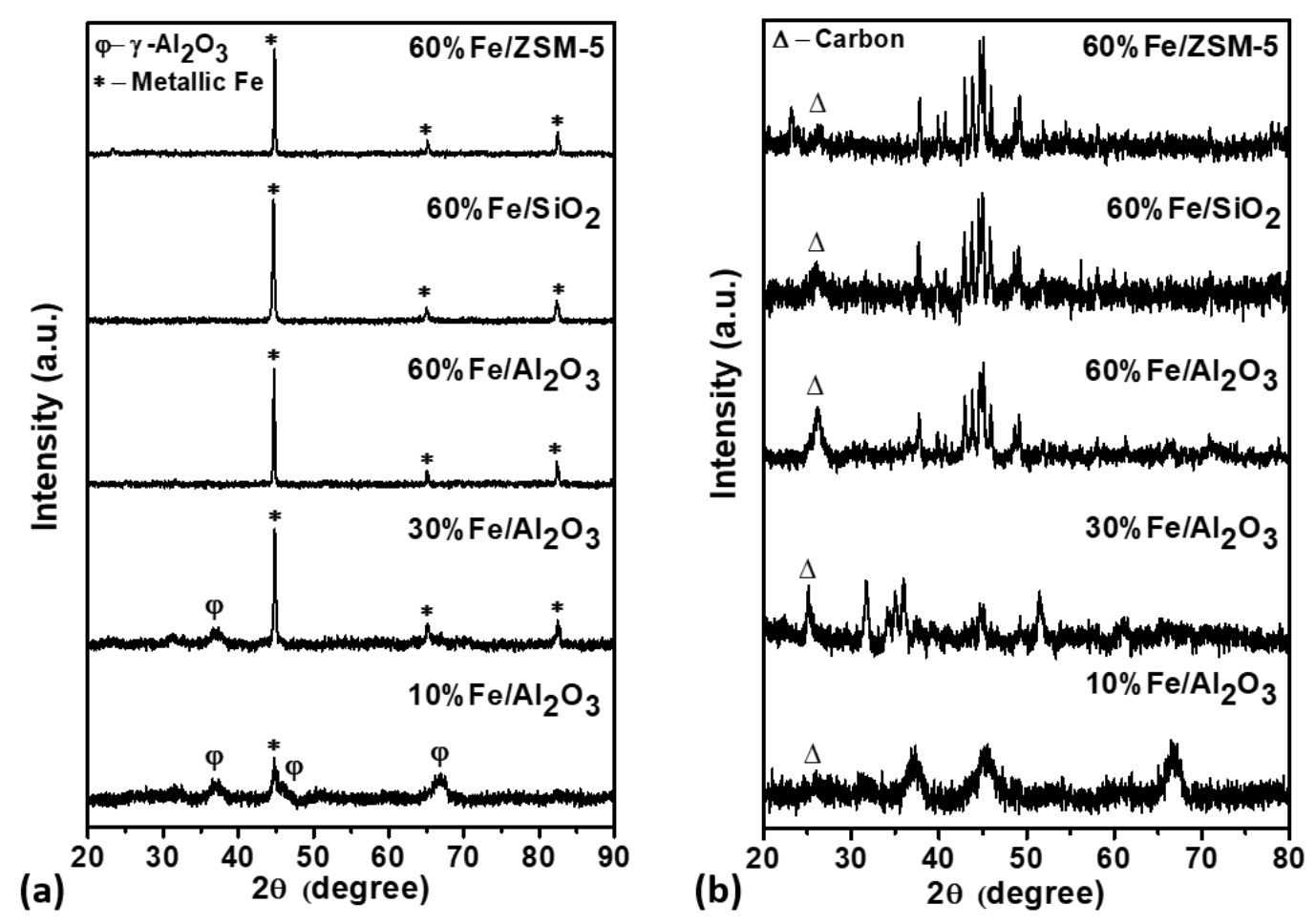

Figure 4-3. XRD patterns of (a) fresh Fe-based catalysts after $\mathrm{H}_{2}$ reduction and (b) spent catalysts Fe-based catalyst after methane decomposition at $700^{\circ} \mathrm{C}$ 


\subsubsection{TEM analysis}

The morphology of metal particles and CNT formation mechanism over the catalyst were analyzed by TEM. The Fe-based catalysts were presented on a higher portion of base grown carbon nanotube compared with $\mathrm{Ni} / \mathrm{SiO}_{2}$ and $\mathrm{Co} / \mathrm{SiO}_{2}$ catalyst. As depicted in Figure 4-4, due to SMSI, metal particles could be inhibited by support and CNT grew from the bottom. The morphology of spent catalysts $\mathrm{Fe} / \mathrm{Al}_{2} \mathrm{O}_{3}$ can form much longer $\mathrm{CNT}$ than $\mathrm{Fe} / \mathrm{SiO}_{2}$ and $\mathrm{Fe} / \mathrm{H}-$ ZSM-5 during $1 \mathrm{~h}$ reaction time and its length can be up to $100 \mathrm{~nm}$. In addition, the outer diameter of $\mathrm{CNT}$ over $\mathrm{Fe} / \mathrm{Al}_{2} \mathrm{O}_{3}$ was smaller than other two catalysts due to nano-dispersion of Fe particles, which demonstrated that the $\mathrm{Al}_{2} \mathrm{O}_{3}$ support can effectively prevent the metal agglomeration. Moreover, TEM images clearly observed that the carbons grew as multi-walled CNT with several graphene layers. The black spots corresponded to the size and location of Fe metal particles and were located at either tip or base of the carbon nanotube.

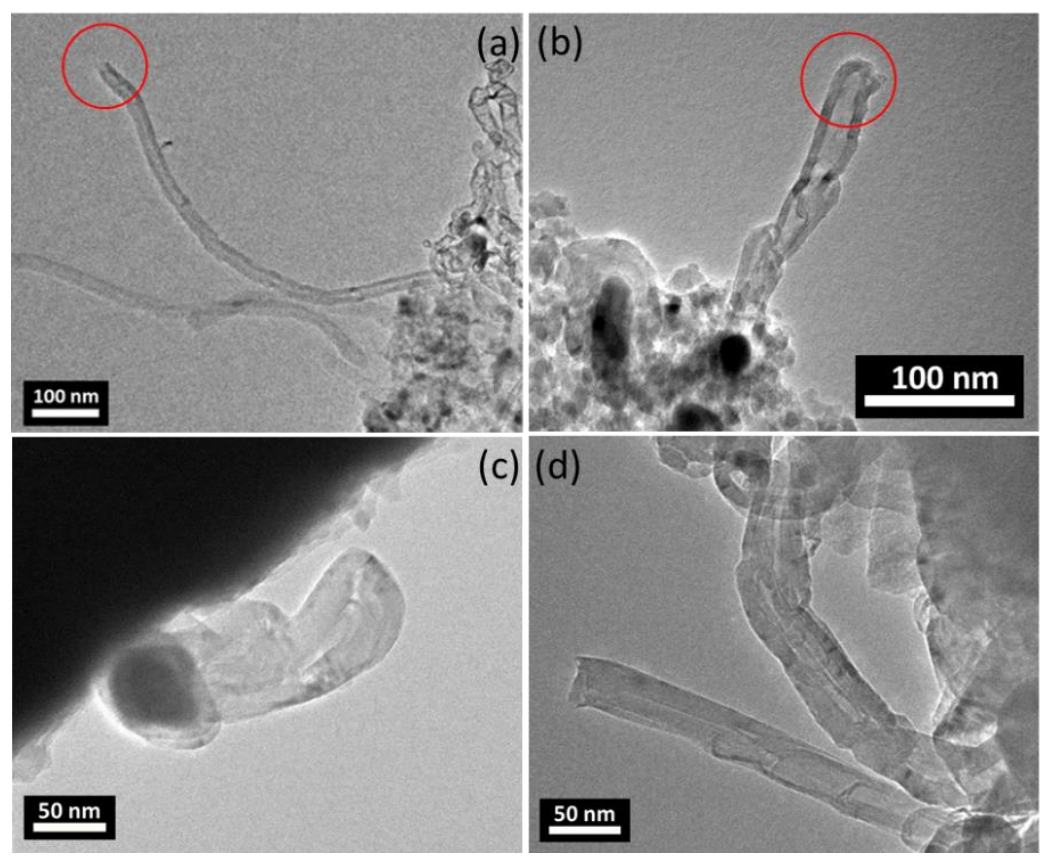

Figure 4-4. Growth of carbon filaments over (a) $\mathrm{Fe} / \mathrm{Al}_{2} \mathrm{O}_{3}$, (b) $\mathrm{Fe} / \mathrm{SiO}_{2}$, (c,d) Fe/H-ZSM-5 catalysts after methane decomposition 


\subsubsection{Raman analysis}

The crystallinity of carbon nanotube was evaluated by Raman spectra. Figure 4-5 depicted the Raman spectra of carbon deposited over Fe catalysts on various supports. Two individual bands were observed the D-band at $1335 \mathrm{~cm}^{-1}$ due to the presence of disorder structure and Gband at $1580 \mathrm{~cm}^{-1}$ due to the in-plane oscillation of $\mathrm{sp}^{2}$ carbon atoms and it indicated the wellordered structure $[80,81]$. The relative intensity of $\mathrm{I}_{\mathrm{D}} / \mathrm{I}_{\mathrm{G}}$ ratio can be used to characterize the graphitic degree of CNT as well. Lower value for $\mathrm{I}_{\mathrm{D}} / \mathrm{I}_{\mathrm{G}}$ indicates higher crystallinity for the carbon formed. Among the catalysts compared the $\mathrm{I}_{\mathrm{D}} / \mathrm{I}_{\mathrm{G}}$ value is in the order $\mathrm{Fe} / \mathrm{H}$ ZSM-5( $\left.\mathrm{I}_{\mathrm{D}} / \mathrm{I}_{\mathrm{G}}=0.784\right)>\mathrm{Fe} / \mathrm{A} 12 \mathrm{O} 3(0.755)>\mathrm{Fe} / \mathrm{SiO} 2(0.699)$ shown in Figure 4-5. Raman spectra for $\mathrm{Fe} / \mathrm{Al}_{2} \mathrm{O}_{3}$ catalysts with different loading (10wt $\%, 30 \mathrm{wt} \%$, and $\left.60 \mathrm{wt} \%\right)$ also showed affected the quality of carbon formed. It was observed that $60 \mathrm{wt} \% \mathrm{Fe} / \mathrm{Al}_{2} \mathrm{O}_{3}$ formed the most crystalline carbon compared to its lower Fe loadings.

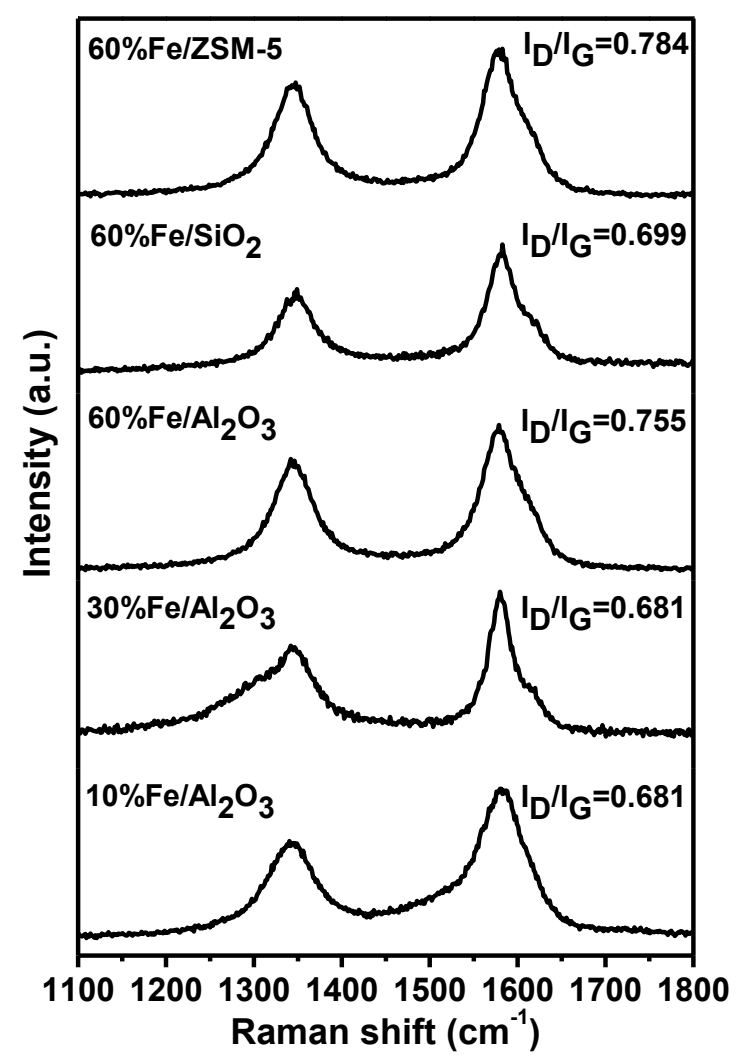

Figure 4-5. Raman spectra of carbon deposited over spent catalysts with different supports and Fe loading 


\subsection{Harvest of Carbon Nanotube}

Here, we selected the $60 \% 9 \mathrm{Ni}-1 \mathrm{Fe} / \mathrm{SiO}_{2}$ and $\mathrm{Fe} / \mathrm{Al}_{2} \mathrm{O}_{3}$ catalysts for purification because they have exhibited the best performance. About $0.3 \mathrm{~g}$ spent catalysts were suspended in a 3.0 $\mathrm{M} \mathrm{HNO}_{3}$ solution with a volume of $45 \mathrm{ml}$ under reflux condition with magnetic stirring at $120^{\circ} \mathrm{C}$ for $24 \mathrm{~h}$ and $48 \mathrm{~h}$. The purified CNT were filtered and washed with deionized water followed by drying overnight at $120^{\circ} \mathrm{C}$. Most metal particles and supports on the spent catalysts used for the synthesis of the CNT were removed by acid-treatment and the results were presented below.

\subsubsection{XRD and Raman analysis for purified CNT}

To perform XRD analysis, the spent catalysts were purified with $3.0 \mathrm{M} \mathrm{HNO}_{3}$ acid treatment for 24 and 48 h. Figure 4-6 (a) shows most metal particles and supports were removed from the spent catalysts which corresponded to the main peak position at the region $2 \theta=40$ $50^{\circ}$, while the weak peak of graphitic carbon (100) plane at $2 \theta=43^{\circ}$ appearing became stronger peak than before (JCPDS card no. 65-6212). In addition, Figure 4-6 (b) showed the Raman spectra of purified catalysts. The $\mathrm{I}_{\mathrm{D}} / \mathrm{I}_{\mathrm{G}}$ ratio of spent $\mathrm{Fe} / \mathrm{Al}_{2} \mathrm{O}_{3}$ was 0.755 and purified $\mathrm{Fe} / \mathrm{Al}_{2} \mathrm{O}_{3}$ were $0.758(24 \mathrm{~h})$ and $0.73(48 \mathrm{~h})$. The $\mathrm{I}_{\mathrm{D}} / \mathrm{I}_{\mathrm{G}}$ ratio of spent $9 \mathrm{NiFe} / \mathrm{SiO}_{2}$ was 0.822 and purified $9 \mathrm{NiFe} / \mathrm{SiO}_{2}$ were $0.834(24 \mathrm{~h})$ and $0.804(48 \mathrm{~h})$. Thus, the ratio of $\mathrm{I}_{\mathrm{D}} / \mathrm{I}_{\mathrm{G}}$ did not change, which indicate the $\mathrm{HNO}_{3}$ did not affect the crystalline structure of the formed CNT. CNT formed on different catalysts had different graphitization degree and $\mathrm{Fe} / \mathrm{Al}_{2} \mathrm{O}_{3}$ can produce higher crystalline carbon. Both results revealed that the acid treatment for $48 \mathrm{~h}$ effectively metal and support residue of the spent catalyst but keep the crystalline structure of produced CNT's. 

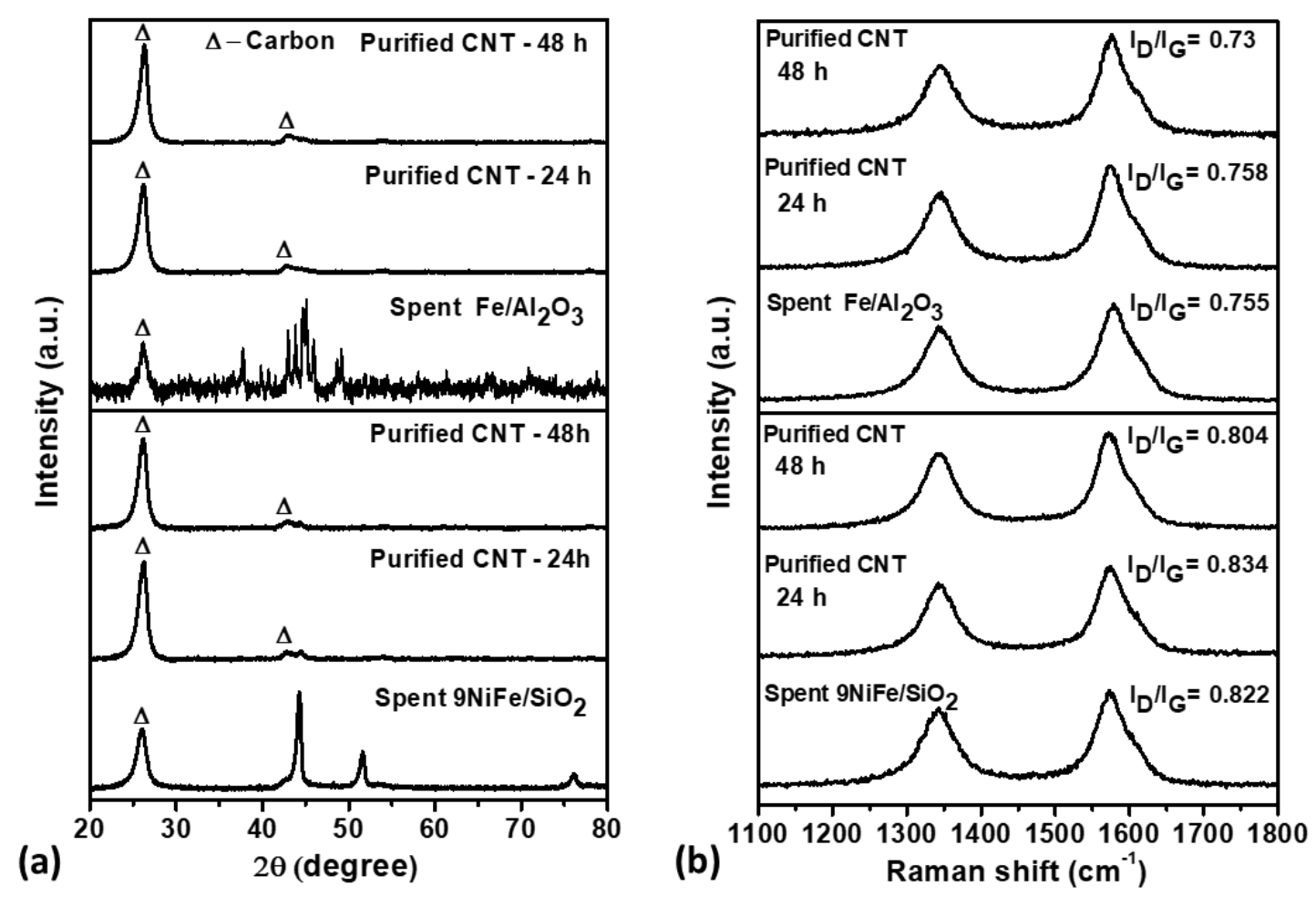

Figure 4-6. (a) XRD patterns of spent catalysts and purified CNT ( $24 \mathrm{~h}$ and $48 \mathrm{~h}$ );

(b) Raman spectra of spent catalysts and purified CNT (24 h and $48 \mathrm{~h}$ ) 


\subsubsection{TEM and SEM-EDS analysis for purified CNT}

TEM images indicated the corn-shaped metal particle at the tip of CNT from 9Ni$1 \mathrm{Fe} / \mathrm{SiO}_{2}$ after acidic purification (Figure 4-7). There are trace metal nanoparticles without open tip encapsulated in the interior of carbon nanotubes. (All measurements were performed on the same conditions and the Au pattern was from the sample sputter coating. On the other hand, SEM-EDX demonstrated that, after treated with an acid solution for $48 \mathrm{~h}$, there were almost no trace of metal and support detected on $60 \% \mathrm{Fe} / \mathrm{Al}_{2} \mathrm{O}_{3}$ and only with little oxygen signal, while $60 \% 9 \mathrm{Ni}-1 \mathrm{Fe} / \mathrm{SiO}_{2}$ still showed the signal of $\mathrm{SiO}_{2}$ support, as presented in Fig. 48. Overall, acidic purification is good to remove alumina which is amphoteric substance, while not as effective as to purified CNTs from $\mathrm{Fe} / \mathrm{SiO}_{2}$ catalyst.
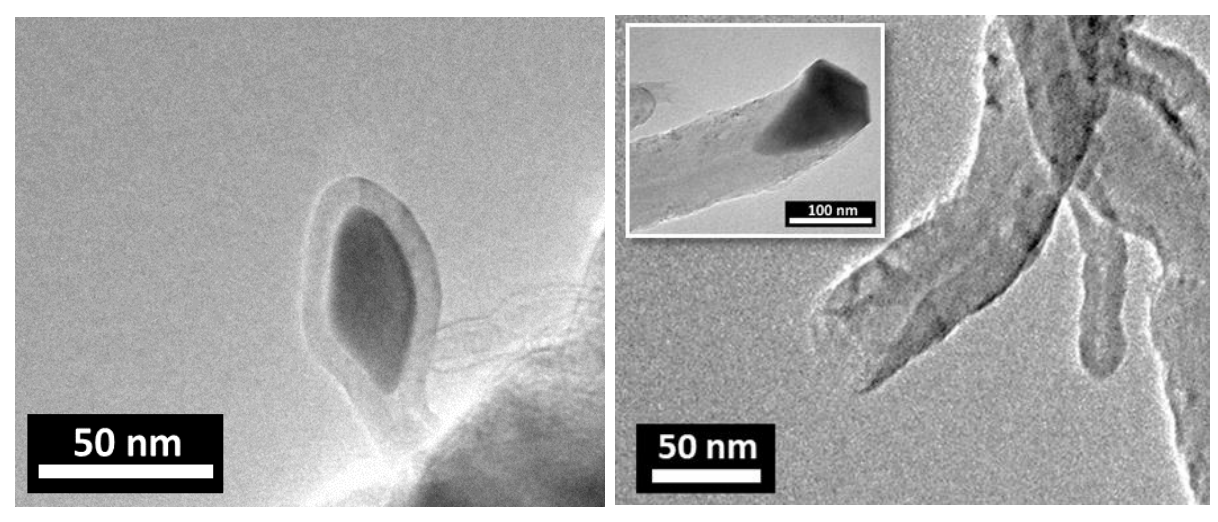

Figure 4-7. TEM images of purified CNT from $9 \mathrm{Ni}-1 \mathrm{Fe} / \mathrm{SiO}_{2}$ catalyst with $\mathrm{HNO}_{3}$ for $48 \mathrm{~h}$
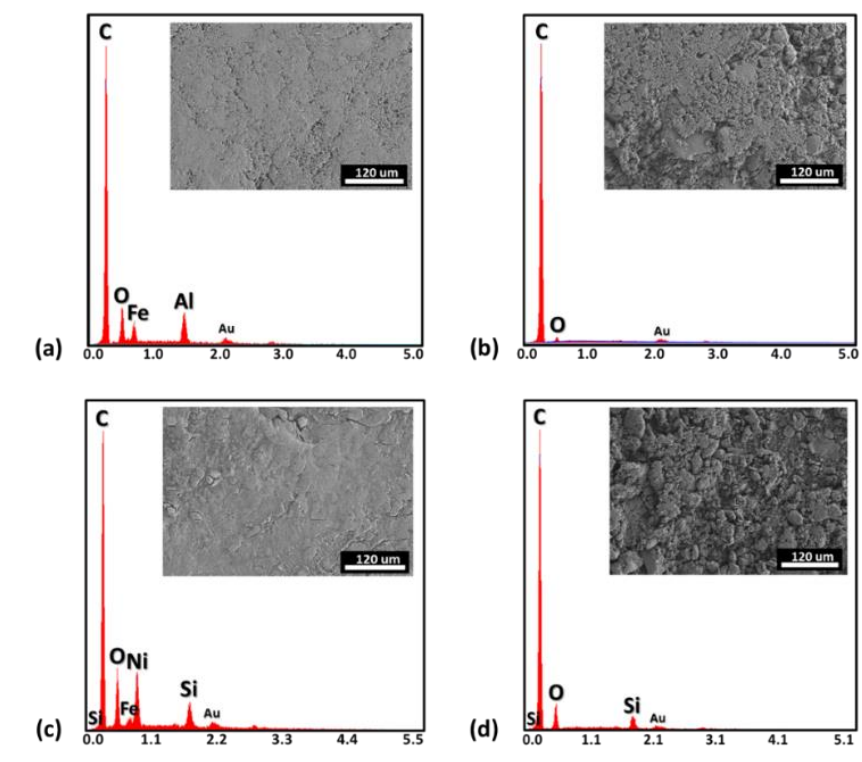

(b)

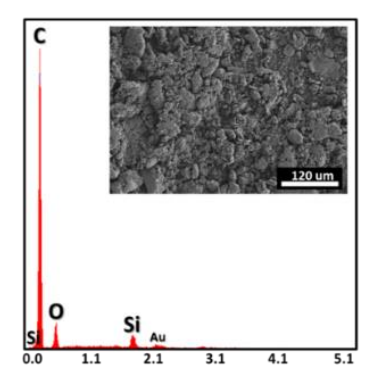

Figure 4-8. SEM-EDX analysis (a) spent $\mathrm{Fe} / \mathrm{Al}_{2} \mathrm{O}_{3}$, (b) purified CNT from $\mathrm{Fe} / \mathrm{Al}_{2} \mathrm{O}_{3}$, (c) spent $9 \mathrm{Ni}-1 \mathrm{Fe} / \mathrm{SiO}_{2}$, and (d) purified $\mathrm{CNT}$ from $9 \mathrm{Ni}-1 \mathrm{Fe} / \mathrm{SiO}_{2}$ 


\subsubsection{TGA analysis}

TGA measurement was carried out to determine the content of metal impurity in CNT and reveal the stability of CNT at a given temperature. Less crystalline CNT will react preferentially with the oxidant and lose weight at a lower temperature compared with more highly crystalline CNT. The slight weight gained between $350^{\circ} \mathrm{C}$ and $500^{\circ} \mathrm{C}$ might be attributed to metal oxidation in spent $60 \% \mathrm{Fe} / \mathrm{Al}_{2} \mathrm{O}_{3}$ (Figure 4-9 (a) and (c)). The maximum weight loss was at $582^{\circ} \mathrm{C}$ and the endpoint was at $700^{\circ} \mathrm{C}$ and the residual was ca. $57 \mathrm{wt} \%$. The maximal weight loss temperature shifted to $630^{\circ} \mathrm{C}$ and the end temperature at ca. $726^{\circ} \mathrm{C}$ for both 24 and $48 \mathrm{~h}$. The residual catalyst was ca. $4.7 \mathrm{wt} \%$ and $3.8 \mathrm{wt} \%$ for $24 \mathrm{~h}$ and $48 \mathrm{~h}$, respectively. Regarding $60 \% 9 \mathrm{NiFe} / \mathrm{SiO}_{2}$, the slight weight gain between $350^{\circ} \mathrm{C}$ and $500^{\circ} \mathrm{C}$ might be also attributed to metal oxidation (Figure 4-9 (b) and (d)). The maximum weight loss was at $612^{\circ} \mathrm{C}$ and the endpoint was at $730^{\circ} \mathrm{C}$. The residual catalyst was ca. $57.4 \mathrm{wt} \%$, which is slightly more than that of $60 \% \mathrm{Fe} / \mathrm{Al}_{2} \mathrm{O}_{3}$. After the purification, the maximal weight loss temperature shifted to $670^{\circ} \mathrm{C}(24 \mathrm{~h})$ and $654^{\circ} \mathrm{C}(48 \mathrm{~h})$ and the end temperature at $745^{\circ} \mathrm{C}(24 \mathrm{~h}$ and $48 \mathrm{~h})$. The residual weight remains $17.2 \mathrm{wt} \%$ and $11.8 \mathrm{wt} \%$ for $24 \mathrm{~h}$ and $48 \mathrm{~h}$, respectively. Therefore, TGA data confirmed that acidic purification was more effective for $\mathrm{Al}_{2} \mathrm{O}_{3}$ supported catalysts than that of $\mathrm{SiO}_{2}$, which is consistent with the above-mentioned SEM-EDS results. Therefore, the weight loss before $500^{\circ} \mathrm{C}$ may be assigned to the decomposition of functional groups, carboxyl and hydroxyl groups which were consumed about $1.5-2 \%$ weight loss on both purified catalysts [82-84]. The thermal stability of CNT was improved slightly, due to the remove of catalytic particles and amorphous carbon impurities [87]. 

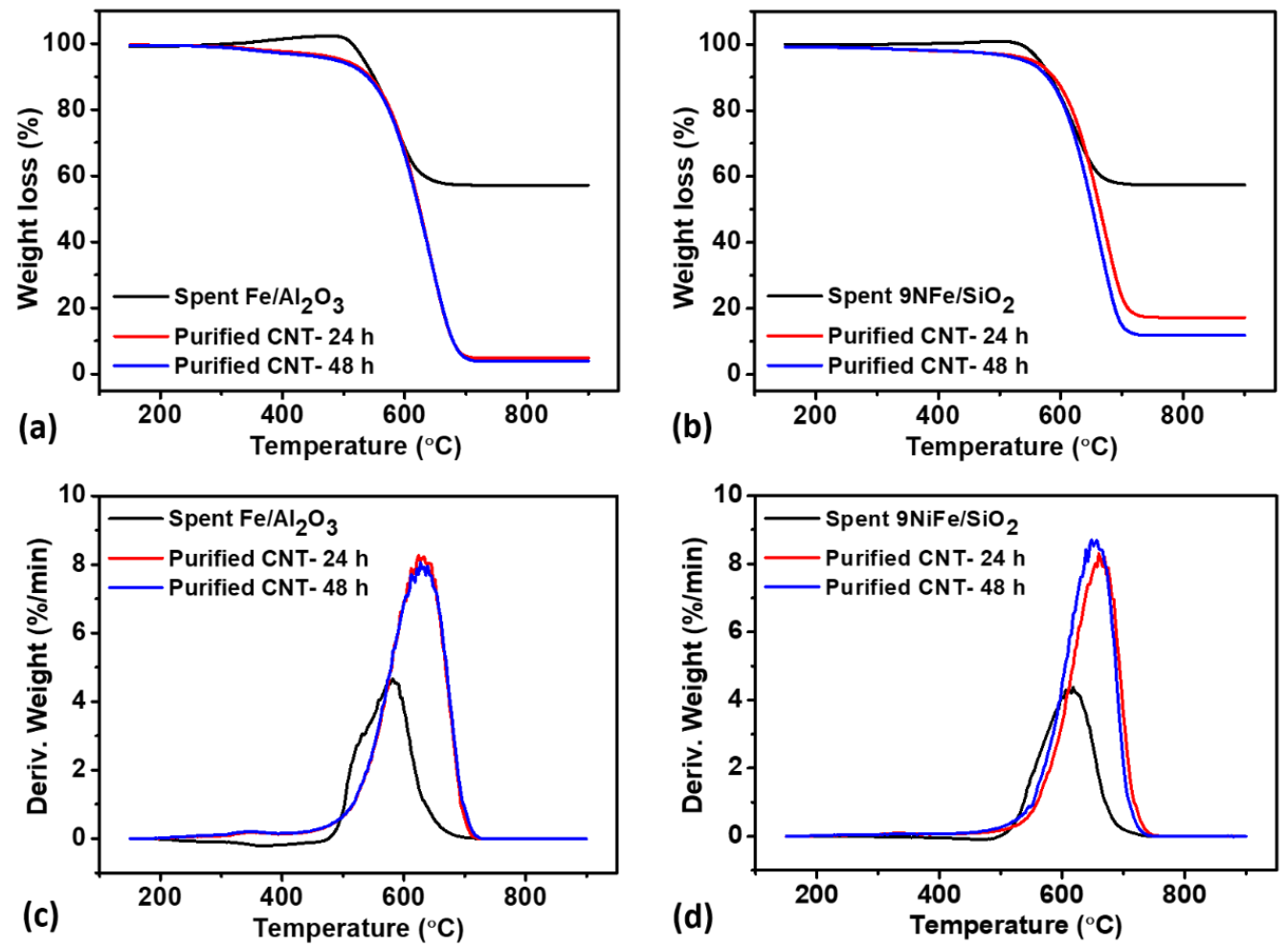

Figure 4-9. TGA profiles of spent catalysts and purified CNT: Weight loss (\%)

(a) $\mathrm{Fe} / \mathrm{Al}_{2} \mathrm{O}_{3}$, and (b) $9 \mathrm{Ni}-1 \mathrm{Fe} / \mathrm{SiO}_{2}$; Deriv. Weight (\%/min) (c) $\mathrm{Fe} / \mathrm{Al}_{2} \mathrm{O}_{3}$ and $9 \mathrm{Ni}-1 \mathrm{Fe} / \mathrm{SiO}_{2}$

\subsubsection{The dispersion of purified catalysts}

Due to their nanometer size and the weak attraction of van der Waals force between the CNT surface, they have a high tendency to become bundle together and agglomerated, which influenced its dispersion or miscibility in a solvent or polymer matrices [88]. Therefore, one way to prevent the agglomeration of CNT was to modify the CNT surface by chemical oxidation. After acid treatment, we speculate that the functional groups such as hydroxyl (C$\mathrm{OH})$, carbonyl $(\mathrm{C}=\mathrm{O})$, and carboxyl $(\mathrm{COOH})$ were introduced on the sidewalls or ends of $\mathrm{CNT}$ $[78,83,84]$. A comparison of dispersibility between before and after purification was performed as below. All samples were sonicated for 15 mins and suspended in a polar media, isopropanol. The good dispersion indicated the solution maintained a uniform black color without precipitation. Figure 4-10 presents the dispersion states of CNT after long-term deposition. The spent catalysts without acid treatment completely sediment after settled in a few hours, while samples with acid treatment still dispersed well in the solvent even after 60 
days. Also, we expected that the metal particles and support might affect the dispersion state of CNT. Thus, the results confirmed as the acid treatment applied improved the dispersion stability of CNT.
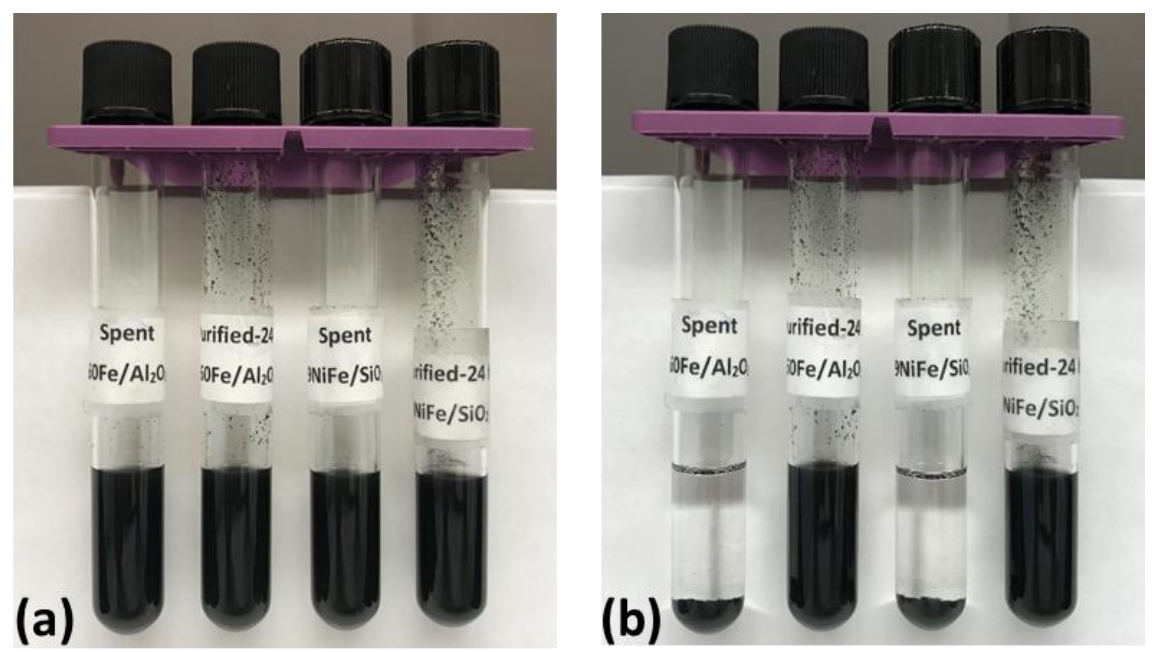

Figure 4-10. Photographs of the spent catalysts and purified CNT dispersed in isopropanol

(a) just after sonication for 15 mins (b) after dispersion for 60 days

\subsection{Conclusion}

We have discovered that the $\mathrm{Fe} / \mathrm{SiO}_{2}$ catalyst formed base grown CNT. We continued to study Fe-based catalysts and to improve its activity and stability. The support and the loading of $\mathrm{Fe}$ on $\mathrm{Al}_{2} \mathrm{O}_{3} .60 \mathrm{wt} \% \mathrm{Fe} / \mathrm{Al}_{2} \mathrm{O}_{3}$ catalyst demonstrated the best activity and stability. Catalysts were characterized using XRD, XPS, TEM, and Raman. After acid treatment, we also compared the properties of CNT by XRD, Raman, SEM-EDX, TEM, and TGA. XRD analysis showed almost all metal particles were removed from CNT. The results of Raman spectra did not change which means no detrimental damage. SEM-EDS measurement revealed the little support elements of $\mathrm{SiO}_{2}$ can be detected. The amount of residual catalysts was presented by TGA and purified $\mathrm{Fe} / \mathrm{Al}_{2} \mathrm{O}_{3}$ only remained $3.8 \mathrm{wt} \%$ of catalysts. Above results showed that the acid treatment was very effective in purifying $\mathrm{Fe} / \mathrm{Al}_{2} \mathrm{O}_{3}$ catalyst. As a consequent, the acid treatment can influence the dispersion of CNT in the isopropanol. 


\section{Chapter 5 Synthesis Aerogel Catalyst for Methane Decomposition}

\subsection{Catalyst Preparation of $\mathrm{Ni} / \mathrm{Al}_{2} \mathrm{O}_{3}$ and $\mathrm{Co} / \mathrm{Al}_{2} \mathrm{O}_{3}$ Aerogel Catalysts}

Analytical grade chemicals including $\mathrm{AlCl}_{3} \cdot 6 \mathrm{H}_{2} \mathrm{O}, \mathrm{Ni}\left(\mathrm{NO}_{3}\right)_{2} \cdot 6 \mathrm{H}_{2} \mathrm{O}, \mathrm{Co}\left(\mathrm{NO}_{3}\right)_{2} \cdot 6 \mathrm{H}_{2} \mathrm{O}$, ethanol (anhydrous) and propylene oxide (PO) were purchased from Acros Organics and used as received without further purification. Deionized water was used in making the metal solutions. This section describes the preparation of $2 \mathrm{~g} 50 \mathrm{wt} \% \mathrm{Ni} / \mathrm{Al}_{2} \mathrm{O}_{3}$ aerogel catalyst as an example. In the preparation, $4.74 \mathrm{~g}$ of $\mathrm{AlCl}_{3} \cdot 6 \mathrm{H}_{2} \mathrm{O}$ was mixed with $4.95 \mathrm{~g}$ of Ni($\left(\mathrm{NO}_{3}\right)_{2} \cdot 6 \mathrm{H}_{2} \mathrm{O}$, followed by adding $10 \mathrm{~mL}$ of deionized water and $15.5 \mathrm{~mL}$ anhydrous ethanol under rigorous agitation for $30 \mathrm{~min}$. The beaker containing the solution was sealed and then heated in an oil bath at $80^{\circ} \mathrm{C}$ for $1 \mathrm{~h}$. The solution was cooled to room temperature when $16 \mathrm{ml}$ of propylene oxide (PO) was added. Keep the solution in an ice bath for 35 min and allow aerogel to form. After formation, the wet gel was washed with deionized water and soaked in anhydrous ethanol overnight to allow ethanol filling into the pores. The wet gel was vacuum dried for $9 \mathrm{~h}$ followed by calcination at $600^{\circ} \mathrm{C}$ for $8 \mathrm{~h}$. Before the test, the $\mathrm{Ni} / \mathrm{Al}_{2} \mathrm{O}_{3}$ aerogel catalyst was reduced at $450^{\circ} \mathrm{C}$ for $2.5 \mathrm{~h} . \mathrm{Co} / \mathrm{Al}_{2} \mathrm{O}_{3}$ aerogel catalysts were calcined at $500^{\circ} \mathrm{C}$ for $3 \mathrm{~h}$ and reduced at $600^{\circ} \mathrm{C}$ for $2.5 \mathrm{~h}$. The details on the composition for the preparation of $\mathrm{Ni} / \mathrm{Al}_{2} \mathrm{O}_{3}$ and $\mathrm{Co} / \mathrm{Al}_{2} \mathrm{O}_{3}$ aerogel catalysts are summarized in Table 5-1. Figure 5-1 (1) and (2) illustrate the major steps involved in the synthesis of aerogel catalysts. $\mathrm{AlCl}_{3} \cdot 6 \mathrm{H}_{2} \mathrm{O}$ was chosen as a precursor for alumina oxide whereas ethanol and deionized water were used as solvents. PO was used as a gelation chemical that consumed protons from the hydrated metal species to facilitate sol-gel polymerization reaction $[85,86,87]$. 
Table 5-1. Details on $\mathrm{Ni} / \mathrm{Al}_{2} \mathrm{O}_{3}$ and $\mathrm{Co} / \mathrm{Al}_{2} \mathrm{O}_{3}$ aerogel catalysts compositions

\begin{tabular}{cccccccc}
\hline & \multicolumn{2}{c}{$\mathrm{Ni} / \mathrm{Al}_{2} \mathrm{O}_{3}$ aerogel catalyst $(2 \mathrm{~g})$} & & \multicolumn{2}{c}{$\mathrm{Co} / \mathrm{Al}_{2} \mathrm{O}_{3}$ aerogel catalyst $(2 \mathrm{~g})$} \\
\cline { 2 - 3 } & $50 \mathrm{wt} \%$ & $60 \mathrm{wt} \%$ & $70 \mathrm{wt} \%$ & & $50 \mathrm{wt} \%$ & $60 \mathrm{wt} \%$ & $70 \mathrm{wt} \%$ \\
\hline $\mathrm{AlCl}_{3} \cdot 6 \mathrm{H}_{2} \mathrm{O} / \mathrm{g}$ & 4.74 & 3.8 & 2.85 & & 4.74 & 3.8 & 2.85 \\
$\mathrm{Ni}\left(\mathrm{NO}_{3}\right)_{2} \cdot 6 \mathrm{H}_{2} \mathrm{O} / \mathrm{g}$ & 4.95 & 5.95 & 6.94 & ---- & ---- & ---- \\
$\mathrm{Co}\left(\mathrm{NO}_{3}\right)_{2} \cdot 6 \mathrm{H}_{2} \mathrm{O} / \mathrm{g}$ & ---- & ---- & ---- & & 4.93 & 5.92 & 6.91 \\
$\mathrm{EtOH} / \mathrm{mL}$ & 15.5 & 15.5 & 15.5 & & 15.5 & 15.5 & 15.5 \\
$\mathrm{PO} / \mathrm{mL}$ & 16 & 16 & 16 & & 16 & 16 & 16 \\
$\mathrm{H}$ & 10 & 10 & 10 & & 10 & 10 & 10 \\
\hline
\end{tabular}

\section{(1)

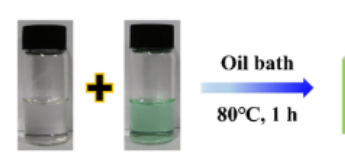

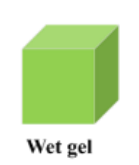
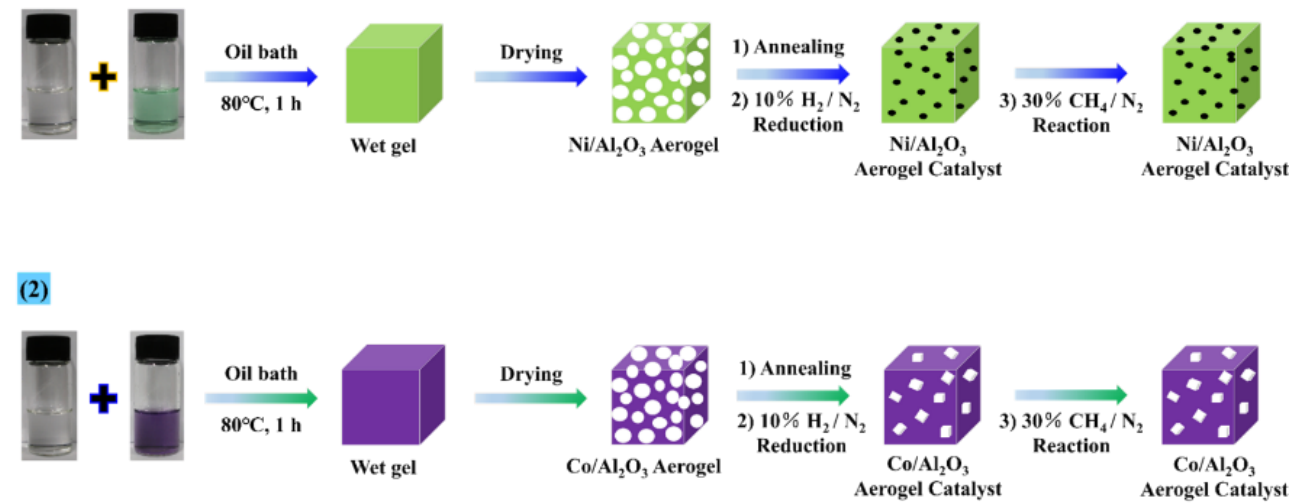

Figure 5-1. The formation mechanism of (1) $\mathrm{Ni} / \mathrm{Al}_{2} \mathrm{O}_{3}$ and (2) $\mathrm{Co} / \mathrm{Al}_{2} \mathrm{O}_{3}$ aerogel catalysts

\subsection{Methane Conversion over Aerogel Catalysts}

As shown in Figure 5-2(a), in the initial $20 \mathrm{~min}$, the $60 \mathrm{wt} \% \mathrm{Ni} / \mathrm{Al}_{2} \mathrm{O}_{3}$ aerogel catalyst exhibits the highest $\mathrm{CH}_{4}$ conversion of $79.2 \%$, but as the reaction proceeds, its conversion declines faster than $50 \mathrm{wt} \%$ and $70 \mathrm{wt} \% \mathrm{Ni} / \mathrm{Al}_{2} \mathrm{O}_{3}$ aerogel catalysts. It appeared that three $\mathrm{Ni} / \mathrm{Al}_{2} \mathrm{O}_{3}$ aerogel catalysts had induction periods during the early stage of the reaction. After the induction period, the $50 \% \mathrm{Ni} / \mathrm{Al}_{2} \mathrm{O}_{3}$ catalyst exhibited the highest methane conversion. In Table 2, the amount of carbon formed per gram of aerogel catalyst was calculated, which was found to be approximately $0.63-0.83 \mathrm{~g}$ over $50 \mathrm{wt} \% \mathrm{Ni} / \mathrm{Al}_{2} \mathrm{O}_{3}$ aerogel catalyst, 3.31-3.39 $\mathrm{g}$ for $60 \mathrm{wt} \% \mathrm{Ni} / \mathrm{Al}_{2} \mathrm{O}_{3}$ aerogel catalyst and $0.53-0.65 \mathrm{~g}$ for $70 \mathrm{wt} \% \mathrm{Ni} / \mathrm{Al}_{2} \mathrm{O}_{3}$ aerogel catalyst, respectively. Figure 5-2(b) shows hydrogen yields for $\mathrm{Ni} / \mathrm{Al}_{2} \mathrm{O}_{3}$ catalysts. 
Methane decomposition over three different metal loading $\mathrm{Co} / \mathrm{Al}_{2} \mathrm{O}_{3}$ aerogel catalysts was carried out. As shown in Figure 5-2 (c), different from $\mathrm{Ni} / \mathrm{Al}_{2} \mathrm{O}_{3}$ aerogel catalysts, the induction period is not observed over $\mathrm{Co} / \mathrm{Al}_{2} \mathrm{O}_{3}$ aerogel catalysts. The methane conversion of $\mathrm{Co} / \mathrm{Al}_{2} \mathrm{O}_{3}$ catalysts drops significantly to ca. $10 \%$ after 20 min which is explained by the enhanced pore size distribution and tortuosity of $\mathrm{Ni} / \mathrm{Al}_{2} \mathrm{O}_{3}$ aerogel in the following sections. As shown in Figure 5-2 (d), for $\mathrm{Co} / \mathrm{Al}_{2} \mathrm{O}_{3}$ catalyst, the $\mathrm{H}_{2}$ yield is higher when the metal loading was 60 $\mathrm{wt} \%$.

Table 5-2. Carbon Productivity (gram carbon/gram catalyst per hour)

\begin{tabular}{cccc}
\hline Catalyst & \multicolumn{3}{c}{ Metal Loading } \\
\cline { 2 - 4 } & $50 \mathrm{wt} \%$ & $60 \mathrm{wt} \%$ & $70 \mathrm{wt} \%$ \\
\hline $\mathrm{Ni} / \mathrm{Al}_{2} \mathrm{O}_{3}$ & $0.63-0.83$ & $3.31-3.39$ & $0.53-0.65$ \\
\hline $\mathrm{Co} / \mathrm{Al}_{2} \mathrm{O}_{3}$ & $0.45-0.68$ & $2.05-2.51$ & $0.58-0.86$ \\
\hline
\end{tabular}
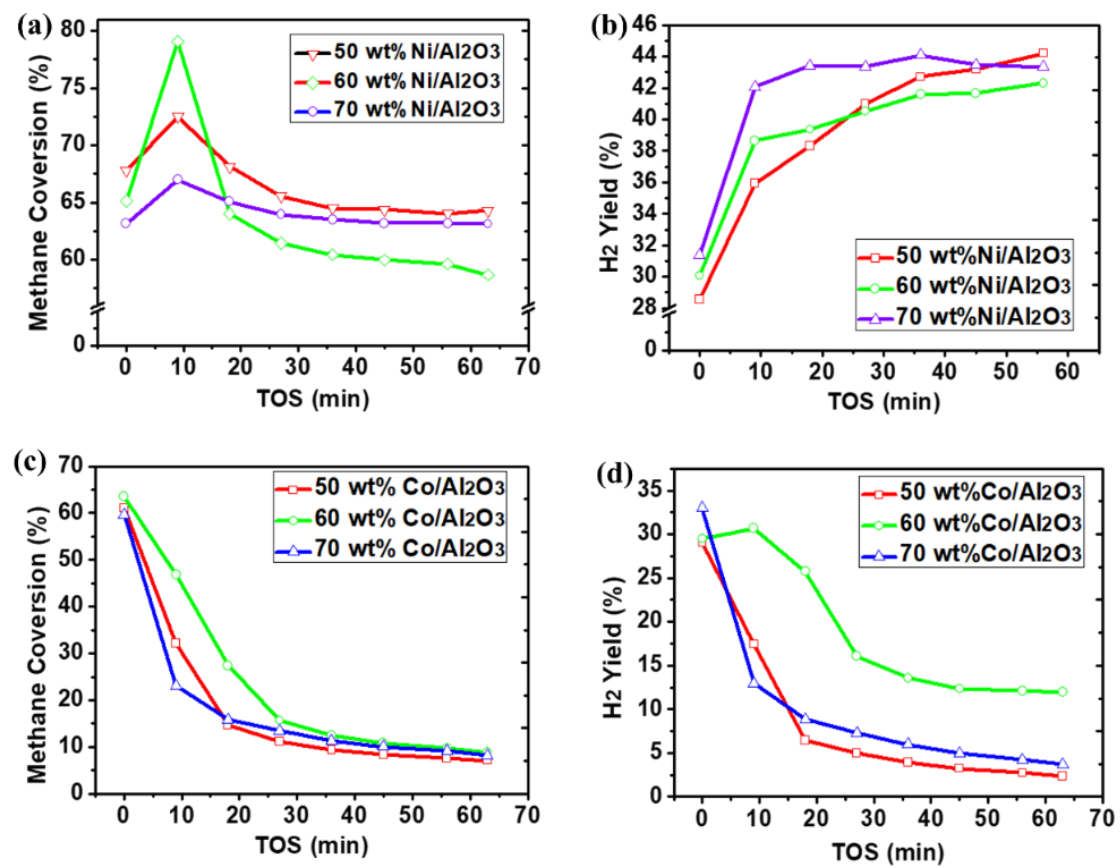

Figure 5-2. Methane decomposition over aerogel catalysts (a) Methane conversion over $\mathrm{Ni} / \mathrm{Al}_{2} \mathrm{O}_{3}$ (b) $\mathrm{H}_{2}$ yield over $\mathrm{Ni} / \mathrm{Al}_{2} \mathrm{O}_{3}$ (c) Methane conversion over $\mathrm{Co} / \mathrm{Al}_{2} \mathrm{O}_{3}$ (d) $\mathrm{H}_{2}$ yield over $\mathrm{Co} / \mathrm{Al}_{2} \mathrm{O}_{3}$ 


\subsection{Characterization of $\mathrm{Ni} / \mathrm{Al}_{2} \mathrm{O}_{3}$ and $\mathrm{Co} / \mathrm{Al}_{2} \mathrm{O}_{3}$ Aerogel Catalysts}

The properties of fresh and spent $\mathrm{Ni} / \mathrm{Al}_{2} \mathrm{O}_{3}$ and $\mathrm{Co} / \mathrm{Al}_{2} \mathrm{O}_{3}$ aerogel catalysts were characterized using a number of analytical instrumentations including XRD, TGA, Raman, BET, SEM, and TEM measurements. The XRD patterns of fresh and spent $\mathrm{Ni} / \mathrm{Al}_{2} \mathrm{O}_{3}$ and $\mathrm{Co} / \mathrm{Al}_{2} \mathrm{O}_{3}$ aerogel catalysts are presented in Figure 5-3 (a) and (b). The characteristic peaks associated with $\mathrm{Ni}$, Co and $\mathrm{Al}_{2} \mathrm{O}_{3}$ support are shown in XRD spectra. Some peaks related to $\mathrm{Al}_{2} \mathrm{O}_{3}$ support are not visible in the XRD spectra because of the presence of high intensity metal peaks. The sharp peaks for metals indicate the formation of the the crystalline phase of the active element $(\mathrm{Ni}$ and $\mathrm{Co})$. The $\mathrm{Ni}$ oxide characteristic peaks are identified at $2 \theta=37.3^{\circ}, 46.7^{\circ}$, $52.8^{\circ}, 66.6^{\circ}$, and $76.6^{\circ}$ (JCPDS No. 04-850) whereas Co characteristic peaks are observed at $2 \theta=44.8^{\circ}, 48.2^{\circ}$, and $77.6^{\circ}$ (JCPDS No.15-0806). After the reaction, spent catalysts were once again characterized by XRD analysis. As shown in Figure 5-3 (a) and (b), compared to the fresh catalysts, XRD patterns of the spent $\mathrm{Ni} / \mathrm{Al}_{2} \mathrm{O}_{3}$ and $\mathrm{Co} / \mathrm{Al}_{2} \mathrm{O}_{3}$ aerogel catalysts show the presence of graphitic carbon by a very intense peak $(002)$ at $2 \theta=26.2^{\circ}$. Due to the limitation of XRD analysis, the microstructural features between $\mathrm{CNT}$ and similar graphitic structures are difficult to differentiate because their characteristic peaks are overlapping. The intensity of the (002) diffraction peak is related to the degree of graphitization. Lower intensity indicates the presence of the less graphitized material. The overall intensity of the CNT peaks over $\mathrm{Co} / \mathrm{Al}_{2} \mathrm{O}_{3}$ catalysts appears to be much less compared to $\mathrm{Ni} / \mathrm{Al}_{2} \mathrm{O}_{3}$ aerogel catalysts. 

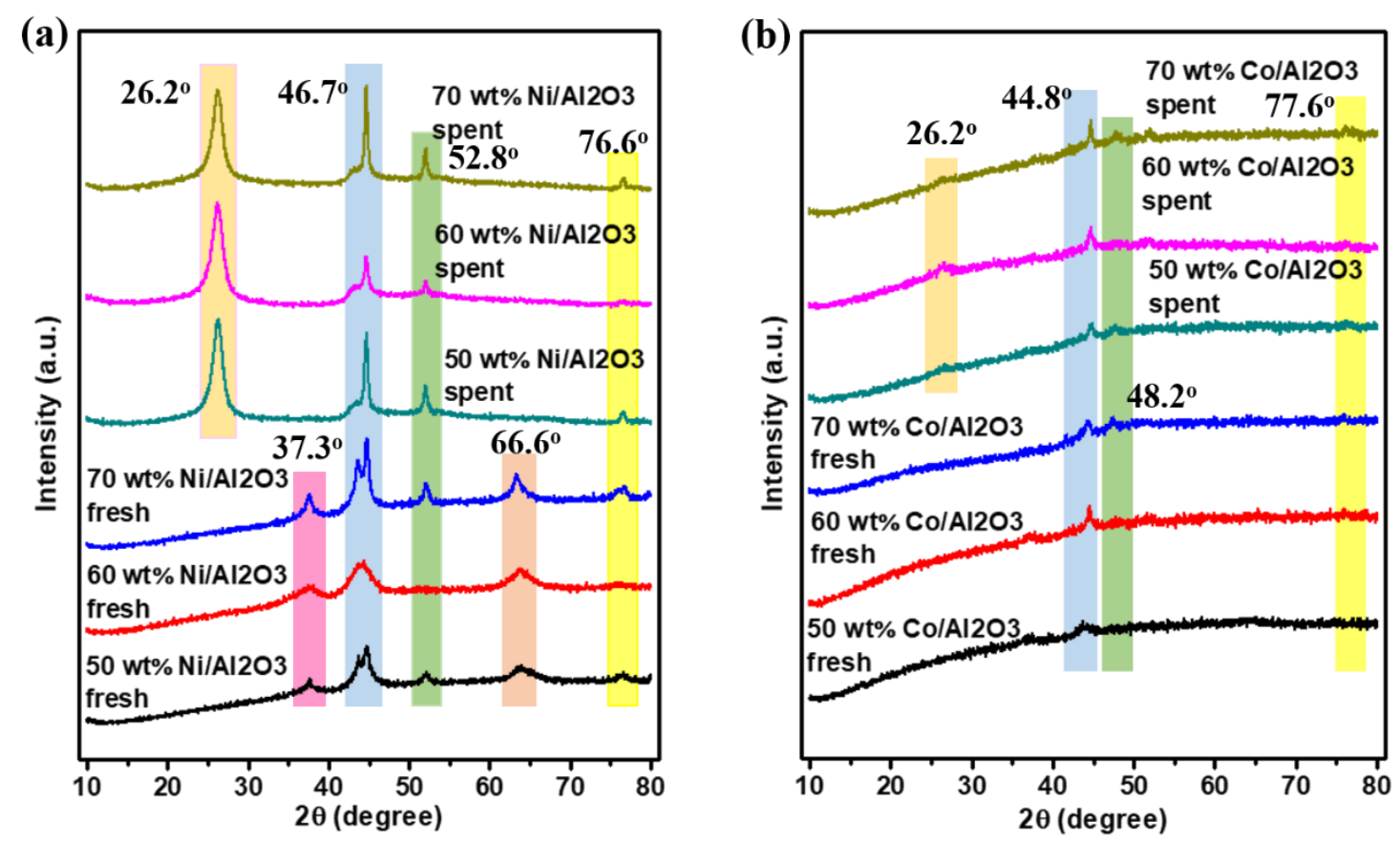

Figure 5-3. XRD analysis of fresh and spent catalysts (a) $\mathrm{Ni} / \mathrm{Al}_{2} \mathrm{O}_{3}$ and (b) $\mathrm{Co} / \mathrm{Al}_{2} \mathrm{O}_{3}$

Raman spectroscopic measurement was carried out to further investigate the quality and crystallinity of the carbon products. As presented in Figure 5-4 (a) and (b), two distinct bands are observed, the D-band at $1342 \mathrm{~cm}^{-1}$ represents either defect or amorphous carbon whereas G-band at $1575 \mathrm{~cm}^{-1}$ represents the crystalline carbon. The graphitization degree and the crystallinity of the CNTs can be simply measured through the intensity ratio of $\mathrm{I}_{\mathrm{D}} / \mathrm{I}_{\mathrm{G}}$. The aerogel catalyst with the lowest $\mathrm{I}_{\mathrm{D}} / \mathrm{I}_{\mathrm{G}}$ carbon represents the highest crystallinity. The $\mathrm{I}_{\mathrm{D}} / \mathrm{I}_{\mathrm{G}}$ ratio for $60 \mathrm{wt} \% \mathrm{Ni} / \mathrm{Al}_{2} \mathrm{O}_{3}$ aerogel catalyst is slightly higher than $50 \mathrm{wt} \%$ and $70 \mathrm{wt} \% \mathrm{Ni} / \mathrm{Al}_{2} \mathrm{O}_{3}$ aerogel catalysts. The $\mathrm{I}_{\mathrm{D}} / \mathrm{I}_{\mathrm{G}}$ values for $70 \mathrm{wt} \% \mathrm{Co} / \mathrm{Al}_{2} \mathrm{O}_{3}$ and $60 \mathrm{wt} \% \mathrm{Co} / \mathrm{Al}_{2} \mathrm{O}_{3}$ aerogel catalysts are similar. Raman spectra showed that both $70 \mathrm{wt} \% \mathrm{Ni} / \mathrm{Al}_{2} \mathrm{O}_{3}$ and $70 \mathrm{wt} \% \mathrm{Co} / \mathrm{Al}_{2} \mathrm{O}_{3}$ aerogel catalysts form most crystalline CNTs with the lowest $\mathrm{I}_{\mathrm{D}} / \mathrm{I}_{\mathrm{G}}(0.835$ and 0.725$)$. Although the $60 \% \mathrm{Ni} / \mathrm{Al}_{2} \mathrm{O}_{3}$ aerogel showed higher productivity than any of $\mathrm{Co} / \mathrm{Al}_{2} \mathrm{O}_{3}$, the $\mathrm{I}_{\mathrm{D}} / \mathrm{I}_{\mathrm{G}}$ was not lower implying the formation of defect CNTs (D band in Raman). We speculate that the length of CNTs on $\mathrm{Ni} / \mathrm{Al}_{2} \mathrm{O}_{3}$ aerogel is much longer than those on $\mathrm{Co} / \mathrm{Al}_{2} \mathrm{O}_{3}$ aerogel. Therefore, poor electron transfer that might affect crystallization causing the defect of CNTs. This result is 
consistent with the TEM analysis which will be discussed in later section [95].

The spent $\mathrm{Ni} / \mathrm{Al}_{2} \mathrm{O}_{3}$ and $\mathrm{Co} / \mathrm{Al}_{2} \mathrm{O}_{3}$ aerogel catalysts were characterized by TGA to study the thermal stability of CNTs. The TGA measurements were carried out in an atmosphere of $2 \%$ $\mathrm{O}_{2} / \mathrm{He}$. As shown in Figure 5-4 (c), there is no thermal degradation taking place in the temperature range of $150-350^{\circ} \mathrm{C}$ for $\mathrm{Co} / \mathrm{Al}_{2} \mathrm{O}_{3}$ and $\mathrm{Ni} / \mathrm{Al}_{2} \mathrm{O}_{3}$ aerogel catalysts. These ranges are corresponding to amorphous carbon decomposition. As shown in Figure 5-4 (c), for the 50 $\mathrm{wt} \% \mathrm{Ni} / \mathrm{Al}_{2} \mathrm{O}_{3}$ aerogel catalyst, the thermal degradation starts at around $500^{\circ} \mathrm{C}$ with a weight loss of $84 \%$. For the $60 \mathrm{wt} \% \mathrm{Ni} / \mathrm{Al}_{2} \mathrm{O}_{3}$ aerogel catalyst, the degradation starts at $500^{\circ} \mathrm{C}$ with a weight loss of $87 \%$. Similar to the $60 \mathrm{wt} \% \mathrm{Ni} / \mathrm{Al}_{2} \mathrm{O}_{3}$ aerogel catalyst, the $70 \mathrm{wt} \% \mathrm{Ni} / \mathrm{Al}_{2} \mathrm{O}_{3}$ aerogel catalyst shows a weight loss of $78 \%$. Thermal degradation temperature for $\mathrm{Co} / \mathrm{Al}_{2} \mathrm{O}_{3}$ is much lower than over $\mathrm{Ni} / \mathrm{Al}_{2} \mathrm{O}_{3}$. In addition, the amount of carbon formed over $\mathrm{Co} / \mathrm{Al}_{2} \mathrm{O}_{3}$ aerogel catalysts was found much less than that on $\mathrm{Ni} / \mathrm{Al}_{2} \mathrm{O}_{3}$ aerogel catalysts, which was consistent with the results of catalytic activity tests.

(a)
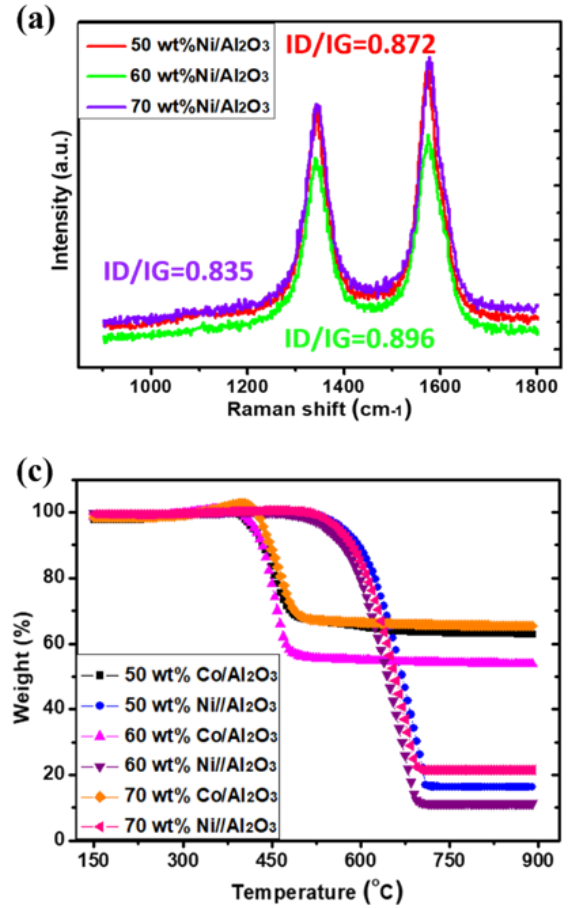

(b)

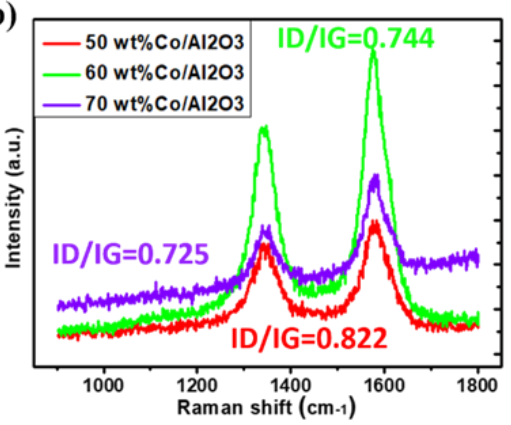

Figure 5-4. (a) Raman spectra of spent $\mathrm{Ni} / \mathrm{Al}_{2} \mathrm{O}_{3}$ catalyst and (b) Raman spectra of spent $\mathrm{Co} / \mathrm{Al}_{2} \mathrm{O}_{3}$ catalyst; (c)TGA analysis of spent $\mathrm{Ni} / \mathrm{Al}_{2} \mathrm{O}_{3}$ and $\mathrm{Co} / \mathrm{Al}_{2} \mathrm{O}_{3}$ catalyst 
SEM and BET measurements were carried out to investigate the microstructure, pore size distribution and adsorption-desorption properties of the spent $\mathrm{Ni} / \mathrm{Al}_{2} \mathrm{O}_{3}$ and $\mathrm{Co} / \mathrm{Al}_{2} \mathrm{O}_{3}$ aerogel catalysts. The measurements were limited to the $60 \mathrm{wt} \% \mathrm{Ni} / \mathrm{Al}_{2} \mathrm{O}_{3}$ and $\mathrm{Co} / \mathrm{Al}_{2} \mathrm{O}_{3}$ aerogel catalysts which showed the best performance in the reactions. As shown in Figure 5-5 (a), the isotherms of the $60 \mathrm{wt} \% \mathrm{Ni} / \mathrm{Al}_{2} \mathrm{O}_{3}$ and $60 \mathrm{wt} \% \mathrm{Co} / \mathrm{Al}_{2} \mathrm{O}_{3}$ aerogel catalysts are quite similar, and the BET surface area of these aerogel catalysts are measured to be $324,271 \mathrm{~m}^{2} / \mathrm{g}$, respectively. As shown in Figure 5-5 (b), the Barrett-Joyner-Halenda (BJH) pore sizes for 60 $\mathrm{wt} \% \mathrm{Ni} / \mathrm{Al}_{2} \mathrm{O}_{3}$ aerogel catalyst is in the region of $10-25 \mathrm{~nm}$ whereas for the $60 \mathrm{wt} \% \mathrm{Co} / \mathrm{Al}_{2} \mathrm{O}_{3}$ aerogel catalyst, the pore size is mainly distributed at ca. 5-15 nm. The annealing can reduce the surface area, but the aerogel catalysts still exhibited a high surface area after heat treatment at $650^{\circ} \mathrm{C}$ and a broad pore size distribution at the mesoporous range. Nanocomposite $\mathrm{Ni} / \mathrm{Al}_{2} \mathrm{O}_{3}$ and $\mathrm{Co} / \mathrm{Al}_{2} \mathrm{O}_{3}$ aerogel catalysts have high surface area and good adsorption properties, which helps to improve the catalytic activity and oxidative regeneration. High specific surface area facilitates the reactants adsorption step and provides more active species which are responsible for enhancing the catalytic performance. SEM images show that channels with the gap distance from a few tens to a few hundred nanometers are formed among colloidal particles. Crosslinking CNT's are formed among CNT's and catalyst particles. As presented in Figure 5-5 (c) and (d), SEM images show that the CNT's are interlaced and combined with support particles to form a reticular structure. CNT's are growing in random direction due to space competition and the length of CNT's depends on the reaction time. As shown in Figure 5-6, for $60 \mathrm{wt} \%$ and $70 \mathrm{wt} \% \mathrm{Ni} / \mathrm{Al}_{2} \mathrm{O}_{3}$ aerogel catalysts, the CNT's formed are found to be multiwall carbon nanotubes and the CNT's formed over $\mathrm{Ni} / \mathrm{Al}_{2} \mathrm{O}_{3}$ and $\mathrm{Co} / \mathrm{Al}_{2} \mathrm{O}_{3}$ aerogel catalysts have a large portion of base-growth and crowded dense population with entangled fibers. Figure 5-6 (a-f) shows that the length of most of the CNT's formed is in the range of 50-250 nm. From the TEM analysis shown in Figure 5-6, it is observed that the walls of CNT's formed are of a linear 
or curved structure in which the graphene layers are stacked obliquely. In this type of CNT's, the graphite planes are not aligned with the axis of CNT. When graphene layers stack up, the defects may form between the edge planes. This has explained the observation of $\mathrm{D}$ band in Raman spectra, but no amorphous phase was identified in TGA analysis. For $60 \mathrm{wt} \%$ and 70 $\mathrm{wt} \% \mathrm{Co} / \mathrm{Al}_{2} \mathrm{O}_{3}$ aerogel catalysts, as displayed in Figure 5-7 (a-f), MWCNT's with 50-150 nm diameters are formed together with transition metal nanoparticles located at the bottom. Compared to CNT's formed over $\mathrm{Ni} / \mathrm{Al}_{2} \mathrm{O}_{3}$ aerogel catalysts, the CNT's formed on $\mathrm{Co} / \mathrm{Al}_{2} \mathrm{O}_{3}$ aerogel catalysts are relatively thin and smaller in diameter.
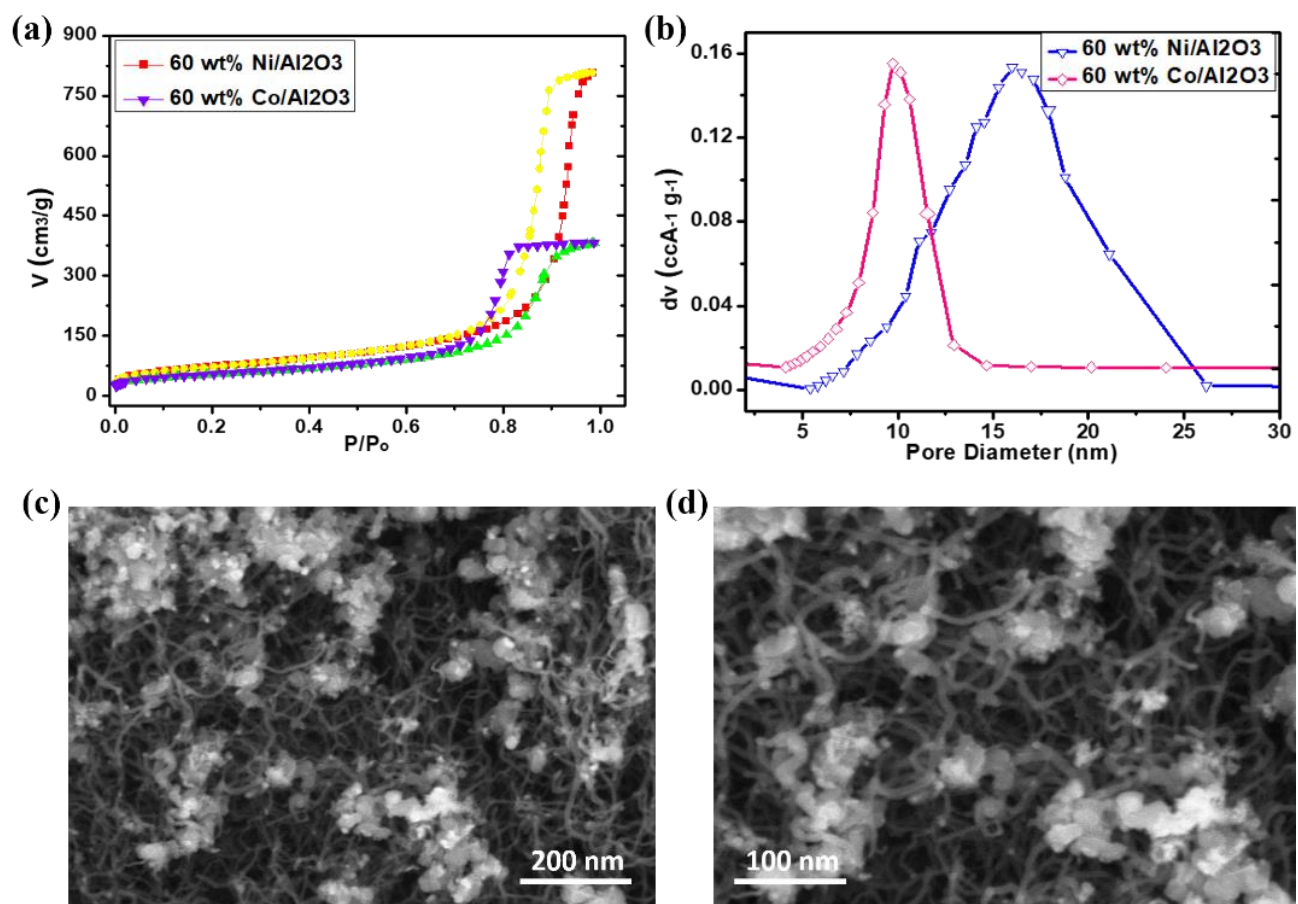

Figure 5-5. Characterization of the spent $60 \mathrm{wt} \% \mathrm{Ni} / \mathrm{Al}_{2} \mathrm{O}_{3}$ and $\mathrm{Co} / \mathrm{Al}_{2} \mathrm{O}_{3}$ aerogel catalysts BET analysis of (a) $\mathrm{N}_{2}$ adsorption-desorption isotherms (b) pore sizes distribution (c and d) SEM images of $60 \mathrm{wt} \% \mathrm{Ni} / \mathrm{Al}_{2} \mathrm{O}_{3}$ aerogel catalyst 

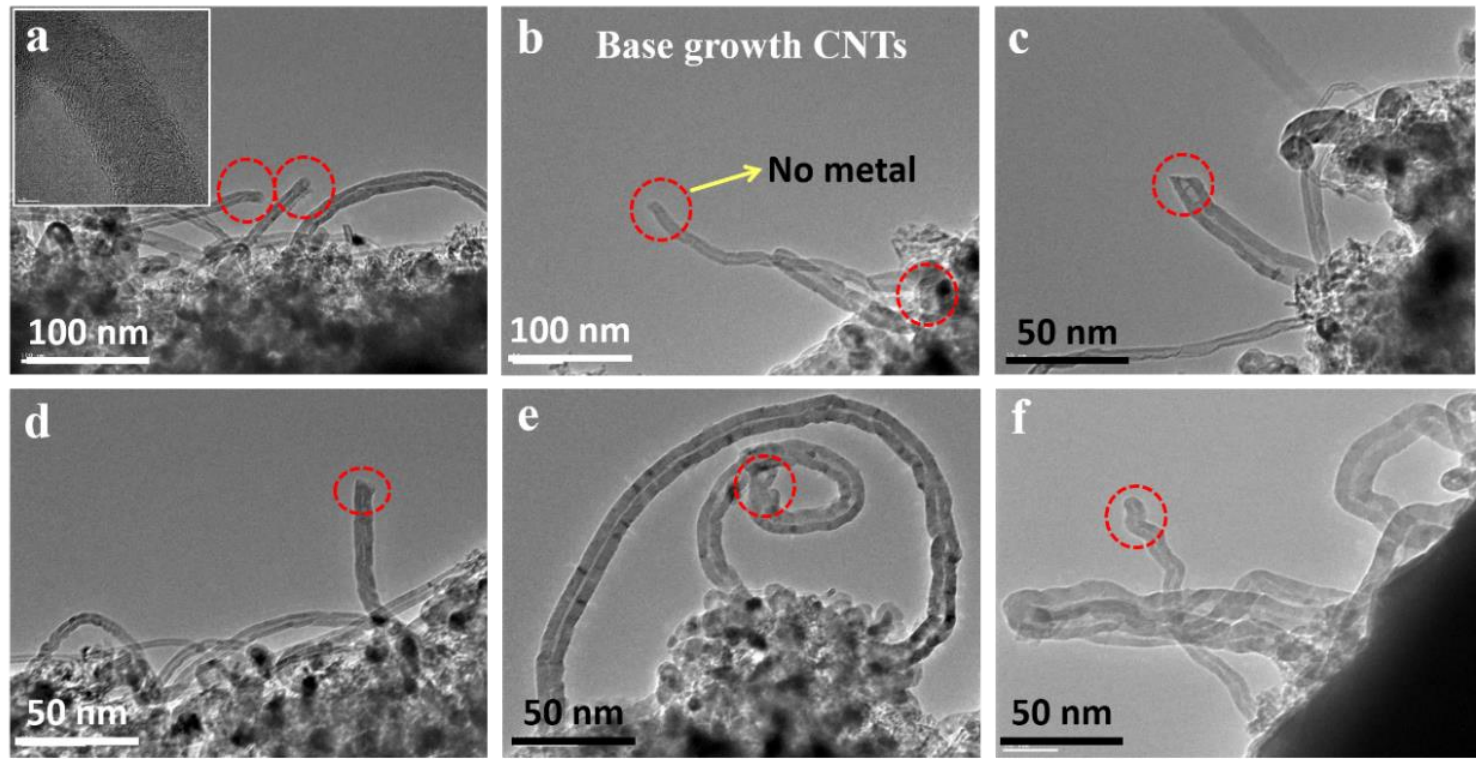

Figure 5-6. TEM images of the spent $\mathrm{Ni} / \mathrm{Al}_{2} \mathrm{O}_{3}$ catalysts (a-c) $60 \mathrm{wt} \%$ and (d-f) $70 \mathrm{wt} \%$
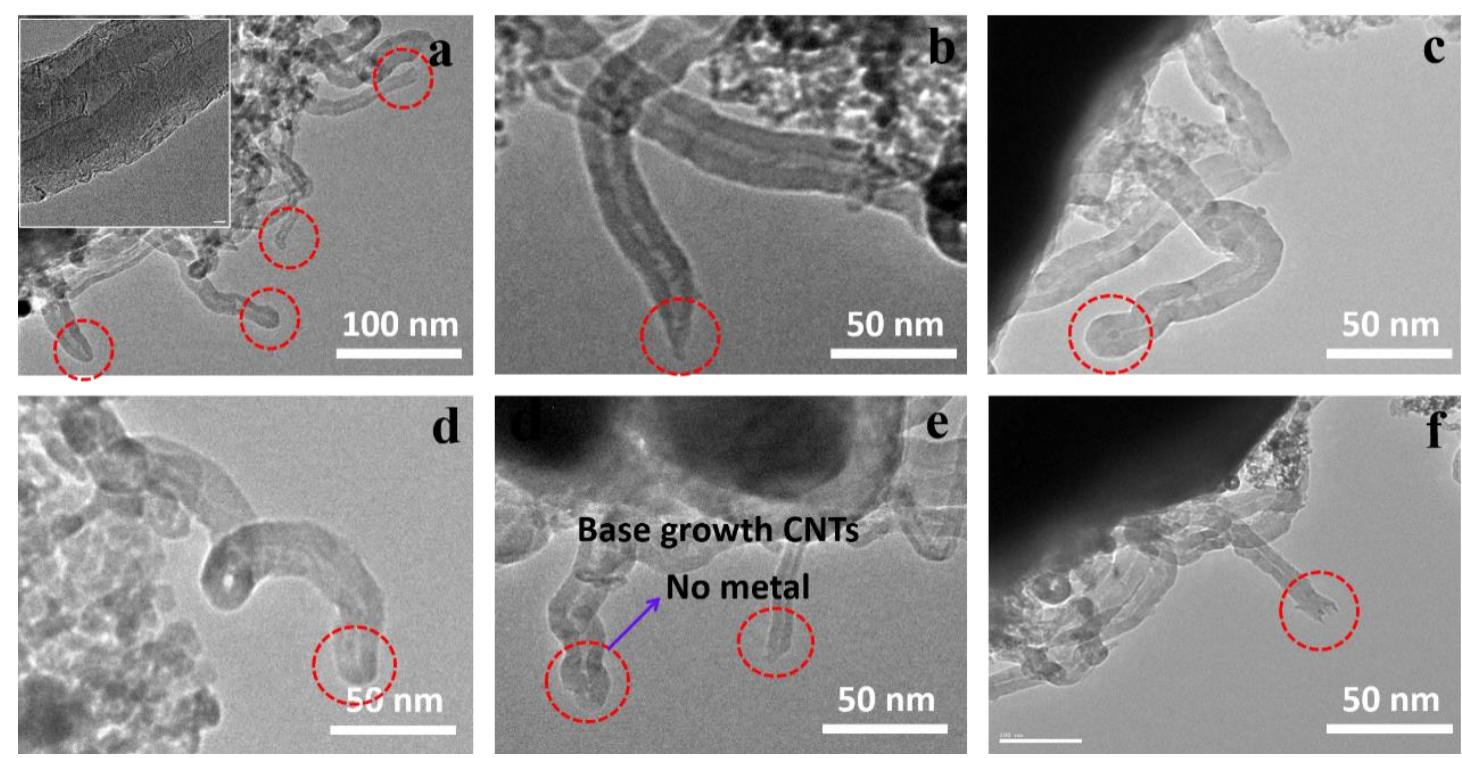

Figure 5-7. TEM images of he spent (a-c) $60 \mathrm{wt} \%$ and (d-f) $70 \mathrm{wt} \% \mathrm{Co} / \mathrm{Al}_{2} \mathrm{O}_{3}$ catalysts

\subsection{Growth CNT over $\mathrm{Ni} / \mathrm{Al}_{2} \mathrm{O}_{3}$ and $\mathrm{Co} / \mathrm{Al}_{2} \mathrm{O}_{3}$ Aerogel Catalysts}

The aim of this study was to elucidate the growth mechanisms in order to control the catalytic property that favors the formation of base-growth CNTs. TEM images have shown that CNTs formed over $\mathrm{Ni} / \mathrm{Al}_{2} \mathrm{O}_{3}$ or $\mathrm{Co} / \mathrm{Al}_{2} \mathrm{O}_{3}$ aerogel catalysts are base growth. This is attributed to the strong interaction between metal nanoparticles and aerogel support. During the decomposition reaction, in the initial stage, carbon diffusion occurred on $\mathrm{Ni}$ or Co that were 
strongly anchored in the aerogel structure, therefore it is difficult for carbon to penetrate between the support and metal. It is also known from the literature that the graphene planes formed are strongly chemisorbed on a metal surface, reducing the surface energy of the metal nanoparticles and enhancing metal-support interaction. Furthermore, TEM measurement showed that graphitic caps were formed on the metal nanoparticles which were lifted upwards during the subsequent deposition of carbon fragments. TEM images reveal that CNTs grow away from the metal nanoparticles, forming a base-growth of carbon nanotubes [76].

\subsection{Conclusions}

The activity, selectivity, stability of the $\mathrm{Ni} / \mathrm{Al}_{2} \mathrm{O}_{3}$ and $\mathrm{Co} / \mathrm{Al}_{2} \mathrm{O}_{3}$ aerogel catalysts were demonstrated in methane decomposition reaction. Characterization results indicated that metal oxide aerogel was a porous material with abundant pores and high specific surface area. In addition, during the synthesis of the aerogel catalysts, $\mathrm{Ni}$ and Co were incorporated into the structure of $\mathrm{Al}_{2} \mathrm{O}_{3}$ aerogel. As a result, the $\mathrm{Ni} / \mathrm{Al}_{2} \mathrm{O}_{3}$ and $\mathrm{Co} / \mathrm{Al}_{2} \mathrm{O}_{3}$ aerogel catalysts developed in this study contained an increased number of active sites exhibiting strong metal-support interaction which led to the formation of base-growth CNTs. The $\mathrm{Ni} / \mathrm{Al}_{2} \mathrm{O}_{3}$ and $\mathrm{Co} / \mathrm{Al}_{2} \mathrm{O}_{3}$ aerogel catalysts showed enhanced performance in terms of methane conversion. SEM images confirmed the formation of the small nanoparticles in the $\mathrm{Ni} / \mathrm{Al}_{2} \mathrm{O}_{3}$ and $\mathrm{Co} / \mathrm{Al}_{2} \mathrm{O}_{3}$ aerogel catalysts. Among $\mathrm{Co} / \mathrm{Al}_{2} \mathrm{O}_{3}$ aerogel catalysts the catalytic activity towards methane conversion was comparatively lower than the $\mathrm{Ni} / \mathrm{Al}_{2} \mathrm{O}_{3}$ aerogel catalysts. The XRD analysis indicated that metal contents in the $\mathrm{Ni} / \mathrm{Al}_{2} \mathrm{O}_{3}$ and $\mathrm{Co} / \mathrm{Al}_{2} \mathrm{O}_{3}$ aerogel catalysts control the degrees of graphitization of the carbon formed. TGA analysis elucidated unlikely formation of amorphous carbon over $\mathrm{Ni}$ or $\mathrm{Co}$ aerogel catalysts. It was discovered that both $\mathrm{Ni} / \mathrm{Al}_{2} \mathrm{O}_{3}$ and $\mathrm{Co} / \mathrm{Al}_{2} \mathrm{O}_{3}$ aerogel catalysts selectively produced base growth CNTs which are considered to be easy for harvesting without sacrificing the catalyst sites. 


\section{References}

[1] J. D.Holladay, J.Hu, D. L.King, andY.Wang, “An overview of hydrogen production technologies," Catal. Today, vol. 139, no. 4, pp. 244-260, 2009.

[2] R. W.Howarth, "A bridge to nowhere: methane emissions and the greenhouse gas footprint of natural gas," Energy Sci. Eng., vol. 2, no. 2, pp. 47-60, 2014.

[3] J. N.Armor, "The multiple roles for catalysis in the production of H2," Appl. Catal. A Gen., vol. 176, no. 2, pp. 159-176, 1999.

[4] Q.Weizhong et al., "Production of hydrogen and carbon nanotubes from methane decomposition in a two-stage fluidized bed reactor," Appl. Catal. A Gen., vol. 260, pp. 223-228, 2004.

[5] R. T. K.Baker, "Catalytic growth of carbon filaments," Carbon N. Y., vol. 27, pp. 315323, 1989.

[6] G. E.Gadd et al., "The world's smallest gas cylinders?," Science (80-. )., vol. 277, no. 5328, pp. 933-936, 1997.

[7] N. M.Rodriguez, M. S.Kim, and. T. K.Baker, "Carbon nanofibers: A unique catalyst support medium,” J. Phys. Chem., vol. 98, no. 50, pp. 13108-13111, 1994.

[8] K. P.DEJONG and J. W.GEUS, “Carbon Nanofibers: Catalytic Synthesis and Applications," Catal. Rev., vol. 42, no. 4, pp. 481-510, 2000.

[9] H. F.Abbas and W. M. A.Wan Daud, "Hydrogen production by methane decomposition: A review," Int. J. Hydrogen Energy, vol. 35, no. 3, pp. 1160-1190, 2010.

[10] T.V.Choudhary and D. W.Goodman, "Methane Decomposition : Production of Hydrogen and Carbon Filaments," Analysis, vol. 19, pp. 164-183, 2006.

[11] T.Zhang and M. D.Amiridis, "Hydrogen Production via the Direct Cracking of Methane over Silica-Supported Nickel Catalysts,” Appl. Catal. A Gen., vol. 167, no. 2, pp. 161-172, 1998.

[12] A. M.Amin, E.Croiset, C.Constantinou, and W.Epling, "Methane cracking using Ni supported on porous and non-porous alumina catalysts," Int. J. Hydrogen Energy, vol. 37, no. 11, pp. 9038-9048, 2012.

[13] S. T.Hussain, S.Gul, M.Mazhar, D. H.Anjum, and F.Larachi, "Effect of surface structure on the catalytic behavior of $\mathrm{Ni}: \mathrm{Cu} / \mathrm{Al}$ and $\mathrm{Ni}: \mathrm{Cu}: \mathrm{K} / \mathrm{Al}$ catalysts for methane decomposition,” J. Nat. Gas Chem., vol. 17, no. 4, pp. 374-382, 2008.

[14] Y.Wang et al., "Effect of Pr addition on the properties of Ni/A12O3catalysts with an 
application in the autothermal reforming of methane," Int. J. Hydrogen Energy, vol. 39, no. 2, pp. 778-787, 2014.

[15] A.Monzón et al., "Improvement of activity and stability of $\mathrm{Ni}-\mathrm{Mg}$ - $\mathrm{Al}$ catalysts by $\mathrm{Cu}$ addition during hydrogen production by catalytic decomposition of methane," Catal. Today, vol. 116, no. 3, pp. 264-270, 2006.

[16] J.Ashok, P. S.Reddy, G.Raju, M.Subrahmanyam, and A.Venugopal, "Catalytic Decomposition of Methane to Hydrogen and Carbon Nanofibers over $\mathrm{Ni}-\mathrm{Cu}-\mathrm{SiO}_{2}$ Catalysts," Energy \& Fuels, vol. 23, no. 1, pp. 5-13, 2009.

[17] I.Suelves, M. J.Lázaro, R.Moliner, Y.Echegoyen, andJ. M.Palacios, "Characterization of $\mathrm{NiAl}$ and $\mathrm{NiCuAl}$ catalysts prepared by different methods for hydrogen production by thermo catalytic decomposition of methane," Catal. Today, vol. 116, no. 3, pp. 271-280, 2006.

[18] J.Chen, Y.Li, Z.Li, and X.Zhang, "Production of COx-free hydrogen and nanocarbon by direct decomposition of undiluted methane on Ni-Cu-alumina catalysts," Appl. Catal. A Gen., vol. 269, no. 1-2, pp. 179-186, 2004.

[19] Y.Li, J.Chen, Y.Ma, J.Zhao, Y.Qin, and L.Chang, "Formation of bamboo-like nanocarbon and evidence for the quasi-liquid state of nanosized metal particles at moderate temperatures," Chem. Commun., vol. 3, no. 12, pp. 1141-1142, 1999.

[20] G.Wang, Y.Jin, G.Liu, andY.Li, "Production of hydrogen and nanocarbon from catalytic decomposition of methane over a Ni-Fe/A12O3 catalyst," Energy and Fuels, vol. 27, no. 8, pp. 4448-4456, 2013.

[21] M. A.Ermakova, D. Y.Ermakov, andG. G.Kuvshinov, "Effective catalysts for direct cracking of methane to produce hydrogen and filamentous carbon. Part I. Nickel catalysts," Appl. Catal. A Gen., vol. 201, no. 1, pp. 61-70, 2000.

[22] A. H.Fakeeha, A. A.Ibrahim, W. U.Khan, A. E.Abasaeed, andA. S.Al-Fatesh, "Hydrogen production by catalytic methane decomposition over $\mathrm{Ni}, \mathrm{Co}$, and $\mathrm{Ni}-\mathrm{Co} / \mathrm{Al}$ ${ }_{2} \mathrm{O}_{3}$ catalyst," Pet. Sci. Technol., vol. 34, no. 19, pp. 1617-1623, 2016.

[23] L. B.Avdeeva, T.V.Reshetenko, Z. R.Ismagilov, andV. A.Likholobov, "Ironcontaining catalysts of methane decomposition: Accumulation of filamentous carbon," Appl. Catal. A Gen., vol. 228, no. 1-2, pp. 53-63, 2002.

[24] A. E.Awadallah, M. S.Abdel-Mottaleb, A. A.Aboul-Enein, M. M.Yonis, andA. K.Aboul-Gheit, "Catalytic Decomposition of Natural Gas to CO/CO2-Free Hydrogen Production and Carbon Nanomaterials Using MgO-Supported Monometallic Iron 
Family Catalysts," Chem. Eng. Commun., vol. 202, no. 2, pp. 163-174, 2015.

[25] W.-H.Chiang andR. M.Sankaran, "Synergistic Effects in Bimetallic Nanoparticles for Low Temperature Carbon Nanotube Growth,” Adv. Mater., vol. 20, no. 24, pp. 48574861, 2008.

[26] W. Q.Deng, X.Xu, andW. A.Goddard, “A two-stage mechanism of bimetallic catalyzed growth of single-walled carbon nanotubes," Nano Lett., vol. 4, no. 12, pp. 2331-2335, 2004.

[27] W.Shen et al., "Catalytic Nonoxidative Dehydrogenation of Ethane over Fe - Ni and Ni Catalysts Supported on $\mathrm{Mg}$ ( $\mathrm{Al}$ ) O to Produce Hydrogen and Easily Purified Carbon Nanotubes," Energy, pp. 3520-3529, 2007.

[28] M.Pudukudy, Z.Yaakob, andZ. S.Akmal, "Direct decomposition of methane over SBA-15 supported Ni, Co and Fe based bimetallic catalysts,” Appl. Surf. Sci., vol. 330, pp. 418-430, 2015.

[29] S. A.Shokry, A. K.ElMorsi, M. S.Sabaa, R. R.Mohamed, andH. E.ElSorogy, "Study of the productivity of MWCNT over Fe and Fe-Co catalysts supported on $\mathrm{SiO} 2, \mathrm{Al} 2 \mathrm{O} 3$ and MgO," Egypt. J. Pet., vol. 23, no. 2, pp. 183-189, 2014.

[30] S.Takenaka, H.Ogihara, I.Yamanaka, andK.Otsuka, "Decomposition of methane over supported-Ni catalysts: Effects of the supports on the catalytic lifetime," Appl. Catal. A Gen., vol. 217, no. 1-2, pp. 101-110, 2001.

[31] A. A.Ibrahim, A. H.Fakeeha, A. S.Al-Fatesh, A. E.Abasaeed, andW. U.Khan, "Methane decomposition over iron catalyst for hydrogen production," Int. J. Hydrogen Energy, vol. 40, no. 24, pp. 7593-7600, 2015.

[32] S.Takenaka, H.Ogihara, I.Yamanaka, andK.Otsuka, "Decomposition of methane over supported-Ni catalysts: Effects of the supports on the catalytic lifetime," Appl. Catal. A Gen., vol. 217, no. 1-2, pp. 101-110, 2001.

[33] M. A.Ermakova, D. Y.Ermakov, A. L.Chuvilin, andG. G.Kuvshinov, "Decomposition of Methane over Iron Catalysts at the Range of Moderate Temperatures : The Influence of Structure of the Catalytic Systems and the Reaction Conditions on the Yield of Carbon and Morphology of Carbon Filaments,” vol. 197, pp. 183-197, 2001.

[34] A. M.Cassell, J. A.Raymakers, J.Kong, andH.Dai, "Large Scale CVD Synthesis of Single-Walled Carbon Nanotubes," J. Phys. Chem. B, vol. 103, no. 31, pp. 6484-6492, 1999.

[35] W. Z.Li, J. G.Wen, M.Sennett, andZ. F.Ren, “Clean double-walled carbon nanotubes 
synthesized by CVD," Chem. Phys. Lett., vol. 368, no. 3-4, pp. 299-306, 2003.

[36] Y. J.Jung et al., "High-Density, Large-Area Single-Walled Carbon Nanotube Networks on Nanoscale Patterned Substrates," J. Phys. Chem. B, vol. 107, no. 28, pp. 6859-6864, 2003.

[37] J. W.Ward, B. Q.Wei, andP. M.Ajayan, "Substrate effects on the growth of carbon nanotubes by thermal decomposition of methane," Chem. Phys. Lett., vol. 376, no. 56, pp. 717-725, 2003.

[38] H.Hongo, M.Yudasaka, T.Ichihashi, F.Nihey, andS.Iijima, "Chemical vapor deposition of single-wall carbon nanotubes on iron-film-coated sapphire substrates," Chem. Phys. Lett., vol. 361, no. 3-4, pp. 349-354, 2002.

[39] R. L.VanderWal, T. M.Ticich, andV. E.Curtis, "Substrate-support interactions in metal-catalyzed carbon nanofiber growth," Carbon N. Y., vol. 39, no. 15, pp. 2277$2289,2001$.

[40] H.Kanzow andA.Ding, "Formation mechanism of single-wall carbon nanotubes on liquid-metal particles," Phys. Rev. B, vol. 60, pp. 11180-11186, 1999.

[41] G. G.Tibbetts, "Why are carbon filaments tubular?," J. Cryst. Growth, vol. 66, pp. 632-638, 1984.

[42] H.Yoshida, S.Takeda, T.Uchiyama, H.Kohno, andY.Homma, "Atomic-scale in-situ observation of carbon nanotube growth from solid state iron carbide nanoparticles," Nano Lett., vol. 8, no. 7, pp. 2082-2086, 2008.

[43] J.Li, C.Papadopoulos, J. M.Xu, andM.Moskovits, "Highly-ordered carbon nanotube arrays for electronics applications," Appl. Phys. Lett., vol. 75, no. 3, pp. 367-369, 1999.

[44] H.Yoshida, S.Takeda, T.Uchiyama, H.Kohno, andY.Homma, "Atomic-scale in-situ observation of carbon nanotube growth from solid state iron carbide nanoparticles.," Nano Lett., vol. 8, no. 7, pp. 2082-2086, 2008.

[45] S.Hofmann et al., "In situ observations of catalyst dynamics during surface-bound carbon nanotube nucleation," Nano Lett., vol. 7, no. 3, pp. 602-608, 2007.

[46] S.Fan, "Self-Oriented Regular Arrays of Carbon Nanotubes and Their Field Emission Properties," Science (80-. )., vol. 283, no. 5401, pp. 512-514, 1999.

[47] C. E.Banks, A.Crossley, C.Salter, S. J.Wilkins, andR. G.Compton, "Carbon nanotubes contain metal impurities which are responsible for the 'electrocatalysis' seen at some nanotube-modified electrodes," Angew. Chemie - Int. Ed., vol. 45, no. 16, pp. $2533-$ 
2537, 2006.

[48] S. K.Smart, A. I.Cassady, G. Q.Lu, andD. J.Martin, "The biocompatibility of carbon nanotubes," Carbon N. Y., vol. 44, no. 6, pp. 1034-1047, 2006.

[49] I. D.Rosca, F.Watari, M.Uo, andT.Akasaka, "Oxidation of multiwalled carbon nanotubes by nitric acid," Carbon N. Y., vol. 43, no. 15, pp. 3124-3131, 2005.

[50] V.Datsyuk et al., "Chemical oxidation of multiwalled carbon nanotubes," Carbon N. Y., vol. 46, no. 6, pp. 833-840, 2008.

[51] J.Zhang et al., "Effect of chemical oxidation on the structure of single-walled carbon nanotubes," J. Phys. Chem. B, vol. 107, no. 16, pp. 3712-3718, 2003.

[52] N.Hüsing andU.Schubert, “Aerogels-Airy Materials: Chemistry, Structure, and Properties," Angew. Chemie Int. Ed., vol. 37, no. 1/2, pp. 22-45, 1998.

[53] Y.Sun, S.Gao, F.Lei, andY.Xie, "Atomically-thin two-dimensional sheets for understanding active sites in catalysis," Chem. Soc. Rev., vol. 44, no. 3, pp. 623-636, 2015.

[54] F.Bonaccorso et al., "Graphene, related two-dimensional crystals, and hybrid systems for energy conversion and storage," Science (80-. )., vol. 347, no. 6217, 2015.

[55] J. N.Coleman et al., "Supporting Online Material for Two-Dimensional Nanosheets Produced by Liquid Exfoliation of Layered Materials Two-dimensional nano-sheets produced by liquid exfoliation of layered materials," Science (80-. )., vol. 331, no. 568, pp. 568-571, 2011.

[56] B.Gao, Y.Ma, J.Mei, S.Lu, andL.Ren, "Functional nanocomposite wet gels and aerogels induced by transition/lanthanide metal ions coordination," Chem. Eng. J., vol. 331, no. May 2017, pp. 597-605, 2018.

[57] D. R.Rolison andB.Dunn, "Electrically conductive oxide aerogels: New materials in electrochemistry," J. Mater. Chem., vol. 11, no. 4, pp. 963-980, 2001.

[58] D. R.Rolison, "Catalytic nanoarchitectures - The importance of nothing and the unimportance of periodicity," Science (80-. )., vol. 299, no. 5613, pp. 1698-1701, 2003.

[59] A. C.Pierre andG. M.Pajonk, "Chemistry of aerogels and their applications," Chem. Rev., vol. 102, no. 11, pp. 4243-4265, 2002.

[60] J.Li, L.Zhou, Q.Zhu, andH.Li, "Enhanced methanation over aerogel $\mathrm{NiCo} / \mathrm{A} 12 \mathrm{O} 3$ catalyst in a magnetic fluidized bed," Ind. Eng. Chem. Res., vol. 52, no. 20, pp. 6647-6654, 2013. 
[61] S. R.Kirumakki, B. G.Shpeizer, G. V.Sagar, K. V. R.Chary, andA.Clearfield, "Hydrogenation of Naphthalene over $\mathrm{NiO} / \mathrm{SiO} 2-\mathrm{Al} 2 \mathrm{O} 3$ catalysts: Structure-activity correlation," J. Catal., vol. 242, no. 2, pp. 319-331, 2006.

[62] J. T.Feng, Y. J.Lin, D. G.Evans, X.Duan, andD. Q.Li, "Enhanced metal dispersion and hydrodechlorination properties of a $\mathrm{Ni} / \mathrm{Al} 2 \mathrm{O} 3$ catalyst derived from layered double hydroxides," J. Catal., vol. 266, no. 2, pp. 351-358, 2009.

[63] S. B.Ren, J. H.Qiu, C. Y.Wang, B. L.Xu, Y. N.Fan, andY.Chen, "Influence of nickel salt precursors on the hydrogenation activity of Ni/gamma-Al2O3 catalyst," Chinese J. Catal., vol. 28, no. 7, pp. 651-656, 2007.

[64] L. H.Zhu, X. M.Ma, andL.Zhao, "Study on phase transformation of Fe-Ni powders during mechanical alloying,” J. Mater. Sci., vol. 36, no. 23, pp. 5571-5574, 2001.

[65] J. F.Valderruten, G. A.Pérez Alczar, andJ. M.Grenèche, "Mössbauer and x-ray study of mechanically alloyed $\mathrm{Fe}-\mathrm{Ni}$ alloys around the Invar composition," J. Phys. Condens. Matter, vol. 20, no. 48, 2008.

[66] P.Ubilla, R.García, J. L. G.Fierro, andN.Escalona, "Hydrocarbons synthesis from a simulated biosyngas feed over FE/SIO2catalysts," J. Chil. Chem. Soc., vol. 55, no. 1, pp. 35-38, 2010.

[67] J.Yang et al., "Effect of magnesium promoter on iron-based catalyst for FischerTropsch synthesis," J. Mol. Catal. A Chem., vol. 245, no. 1-2, pp. 26-36, 2006.

[68] P.Jana, V. A.DeLa Peña O’Shea, J. M.Coronado, andD. P.Serrano, “Mild temperature hydrogen production by methane decomposition over cobalt catalysts prepared with different precipitating agents," Int. J. Hydrogen Energy, vol. 37, no. 8, pp. 7034-7041, 2012.

[69] D. J.Duvenhage andN. J.Coville, "Fe:Co/TiO2bimetallic catalysts for the FischerTropsch reaction I. Characterization and reactor studies," Appl. Catal. A Gen., vol. 153, no. 1-2, pp. 43-67, 1997.

[70] R. J.Kale??czuk, "The effect of cobalt on the reactants adsorption and activity of fused iron catalyst for ammonia synthesis," Catal. Letters, vol. 33, no. 3-4, pp. 255-268, 1995.

[71] W.Qian, T.Liu, F.Wei, Z.Wang, andY.Li, "Enhanced production of carbon nanotubes: Combination of catalyst reduction and methane decomposition," Appl. Catal. A Gen., vol. 258, no. 1, pp. 121-124, 2004.

[72] C.-M.Chen, Y.-M.Dai, J. G.Huang, andJ.-M.Jehng, "Intermetallic catalyst for carbon 
nanotubes (CNTs) growth by thermal chemical vapor deposition method," Carbon $N$. Y., vol. 44, pp. 1808-1820, 2006.

[73] A. E.Awadallah, A. A.Aboul-Enein, D. S.El-Desouki, andA. K.Aboul-Gheit, "Catalytic thermal decomposition of methane to COx-free hydrogen and carbon nanotubes over MgO supported bimetallic group VIII catalysts," Appl. Surf. Sci., vol. 296, pp. 100-107, 2014.

[74] W. Z.Zhu, D. E.Miser, W. G.Chan, andM. R.Hajaligol, "Characterization of multiwalled carbon nanotubes prepared by carbon arc cathode deposit," Mater. Chem. Phys., vol. 82, no. 3, pp. 638-647, 2003.

[75] C. E.Banks andR. G.Compton, "New electrodes for old: From carbon nanotubes to edge plane pyrolytic graphite,” Analyst, vol. 131, no. 1, pp. 15-21, 2006.

[76] H.Dai, A. G.Rinzler, P.Nikolaev, A.Thess, D. T.Colbert, andR. E.Smalley, "Singlewall nanotubes produced by metal-catalyzed disproportionation of carbon monoxide," Chem. Phys. Lett., vol. 260, no. 3-4, pp. 471-475, 1996.

[77] C. T.Campbell, "Catalyst-support interactions: Electronic perturbations," Nat. Chem., vol. 4, no. 8, pp. 597-598, 2012.

[78] S. J.Tauster, S. C.Fung, andR. L.Garten, "Strong Metal-Support Interactions. Group 8 Noble Metals Supported on TiO2," J. Am. Chem. Soc., vol. 100, no. 1, pp. 170-175, 1978.

[79] C.Mattevi et al., "In-situ X-ray Photoelectron Spectroscopy Study of Catalyst- Support Interactions and Growth of Carbon Nanotube Forests," J. Phys. Chem. C, vol. 112, no. 32, pp. 12207-12213, 2008.

[80] D.Torres, J. L.Pinilla, M. J.Lázaro, R.Moliner, andI.Suelves, "Hydrogen and multiwall carbon nanotubes production by catalytic decomposition of methane:

Thermogravimetric analysis and scaling-up of Fe-Mo catalysts," Int. J. Hydrogen Energy, vol. 39, no. 8, pp. 3698-3709, 2014.

[81] M. A.Ermakova, D. Y.Ermakov, A. L.Chuvilin, andG. G.Kuvshinov, "Decomposition of methane over iron catalysts at the range of moderate temperatures: The influence of structure of the catalytic systems and the reaction conditions on the yield of carbon and morphology of carbon filaments," J. Catal., vol. 201, no. 2, pp. 183-197, 2001.

[82] A.Jorio, M. A.Pimenta, A. G. S.Filho, R.Saito, G.Dresselhaus, andM. S.Dresselhaus, "Characterizing carbon nanotube samples with resonance Raman scattering Characterizing carbon nanotube samples with resonance Raman scattering," New J. 
Phys., vol. 5, no. 1, p. 139.1-139.17, 2003.

[83] M. S.Dresselhaus, G.Dresselhaus, R.Saito, andA.Jorio, "Raman spectroscopy of carbon nanotubes," Phys. Rep., vol. 409, no. 2, pp. 47-99, 2005.

[84] F.Avilés, J.V.Cauich-Rodríguez, L.Moo-Tah, A.May-Pat, andR.Vargas-Coronado, "Evaluation of mild acid oxidation treatments for MWCNT functionalization," Carbon N. Y., vol. 47, no. 13, pp. 2970-2975, 2009.

[85] S.Chen et al., "Preparation of Poly ( acrylic acid ) Grafted Multiwalled Carbon Nanotubes by a Two-Step Irradiation Technique Preparation of Poly ( acrylic acid ) Grafted Multiwalled Carbon Nanotubes by a Two-Step Irradiation Technique,” pp. 330-334, 2006.

[86] C.Peniche, W.Argüelles-Monal, N.Davidenko, R.Sastre, A.Gallardo, andJ.San Román, "Self-curing membranes of chitosan/PAA IPNs obtained by radical polymerization: Preparation, characterization and interpolymer complexation," Biomaterials, vol. 20, no. 20, pp. 1869-1878, 1999.

[87] R.Yudianti, "Analysis of Functional Group Sited on Multi-Wall Carbon Nanotube Surface,” Open Mater. Sci. J., vol. 5, no. 1, pp. 242-247, 2011.

[88] X. L.Xie, Y. W.Mai, andX. P.Zhou, "Dispersion and alignment of carbon nanotubes in polymer matrix: A review," Mater. Sci. Eng. R Reports, vol. 49, no. 4, pp. 89-112, 2005.

[89] F.Avile, "Evaluation of mild acid oxidation treatments for MWCNT functionalization," vol. 7, pp. 5-10, 2009.

[90] S. W.Kim et al., "Surface modifications for the effective dispersion of carbon nanotubes in solvents and polymers," Carbon N. Y., vol. 50, no. 1, pp. 3-33, 2012.

[91] A. G.Osorio, I. C. L.Silveira, V. L.Bueno, andC. P.Bergmann, "H2SO4/HNO3/HClFunctionalization and its effect on dispersion of carbon nanotubes in aqueous media," Appl. Surf. Sci., vol. 255, no. 5 PART 1, pp. 2485-2489, 2008.

[92] A. E.Gash, T. M.Tillotson, J. H.Satcher, J. F.Poco, L. W.Hrubesh, andR. L.Simpson, "Use of epoxides in the sol-gel synthesis of porous iron(III) oxide monoliths from Fe(III) salts," Chem. Mater., vol. 13, no. 3, pp. 999-1007, 2001.

[93] T. F.Baumann, A. E.Gash, S. C.Chinn, A. M.Sawvel, R. S.Maxwell, andJ. H.Satcher, "Synthesis of high-surface-area alumina aerogels without the use of alkoxide precursors," Chem. Mater., vol. 17, no. 2, pp. 395-401, 2005.

[94] N. Z.Muradov andT. N.Veziroğlu, "From hydrocarbon to hydrogen-carbon to 
hydrogen economy," Int. J. Hydrogen Energy, vol. 30, no. 3, pp. 225-237, 2005.

[95] N.Muradov, F.Smith, andA.T-Raissi, "Catalytic activity of carbons for methane decomposition reaction,” Catal. Today, vol. 102-103, pp. 225-233, 2005. 